UNIVERSIDADE DE SÃO PAULO

FACULDADE DE ECONOMIA, CONTABILIDADE E CONTABILIDADE DEPARTAMENTO DE ECONOMIA PROGRAMA DE PÓS-GRADUAÇÃO EM CIÊNCIAS ECONÔMICAS

AVALIAÇÃO DOS GANHOS DE EFICIÊNCIA E PRODUTIVIDADE NA INDÚSTRIA FARMACÊUTICA BRASILEIRA: 1996-2003.

Igor Viveiros Souza

Orientadora: Prof. ${ }^{a}$ Dr. ${ }^{\text {a }}$ Fabiana Fontes Rocha

SÃO PAULO

2006 
Profa. Dra. Suely Vilela

Reitora da Universidade de São Paulo

Profa. Dr. Carlos Roberto Azzoni

Diretor da Faculdade de Economia, Administração e Contabilidade

Profa. Dr. Joaquim José Martins Guilhoto

Chefe do Departamento de Economia

Prof. Dr. Dante Mendes Aldrighi

Coordenador do Programa de Pós-Graduação em Economia 


\title{
AVALIAÇÃO dOS GANHOS DE EFICIÊNCIA E PRODUTIVIDADE NA INDÚSTRIA FARMACÊUTICA BRASILEIRA: 1996-2003.
}

\author{
Dissertação apresentada ao \\ Departamento de Economia da \\ Faculdade de Economia, Administração \\ e Contabilidade da Universidade de São \\ Paulo como requisito para a obtenção do \\ título de Mestre em Ciências \\ Econômicas.
}

Orientadora: Prof. ${ }^{\text {a }}$ Dr. ${ }^{\text {a }}$ Fabiana Fontes Rocha 


\section{Souza, Igor Viveiros}

Avaliação dos ganhos de eficiência e produtividade na indústria farmacêutica brasileira : 1996-2003 / Igor Viveiros Souza. - São Paulo, 2006.

$108 \mathrm{p}$.

Dissertação (Mestrado) - Universidade de São Paulo, 2006 Bibliografia

1. Indústria farmacêutica - Brasil 2. Produtividade industrial I. Universidade de São Paulo. Faculdade de Economia, Administração e Contabilidade. II. Título.

CDD - 338.476151 
Aos meus pais cuja dedicação me permitiu ver mais longe. 


\section{AGRADECIMENTOS}

Agradeço à Fapesp pelo fundamental apoio prestado a este estudo e, sem o qual, certamente ele não seria realizado.

Aos funcionários da Faculdade de Economia, Administração e Contabilidade que de maneira indireta contribuíram para realização deste estudo.

Aos funcionários do IBGE pelo apoio prestando durante minha estada no Rio de Janeiro, em especial ao pesquisador Alexandre Brandão que, desde o início de meu projeto, sempre esteve à disposição para me ajudar.

Aos professores do Curso de Mestrado em Economia que através da transfusão de seus conhecimentos para minha confusa cabeça me ajudaram a conhecer melhor o universo das Ciências Econômicas. Em especial a minha orientadora, a Professora Fabiana Rocha que com seu conhecimento, amizade e apoio às minhas idéias me agüentou por dois anos, sempre com bom humor e dedicação.

Como diz aquela dupla de gênios de Liverpool: "I get high with little help from my friends". Sendo assim, tenho de agradecer aos amigos que fiz em São Paulo e aos que deixei em Belo Horizonte. Em especial ao amigo Bruno Rocha, sempre me recebendo com prazer em sua casa (apesar de seu péssimo gosto para times de futebol), e minha amiga Fernanda Cabral pelas imprescindíveis estadias a mim cedidas no Rio de Janeiro.

Aos meus sogros Marlene e Alfredo sempre muito amigos e me suportando em sua casa.

As minhas irmãs Janaína e Sabrina e ao meu irmão Juliano sempre ao meu lado nos momentos de dor (Rebaixamento em 2005) e alegria (Ascensão em 2006) - Dá-lhe Galo Juju! Aos meus pais sempre presentes, carinhosos e atentos. Sempre digo que nunca tive muitas dificuldades pois meus pais as tiveram por mim.

E por fim, a minha doce Giselle. Minha Pequena, mas grande meu amor. A pessoa que tenho dividido nesses últimos cinco anos os mais diversos sentimentos, alegrias, complicações e tristezas, enfim, minha vida. Apesar de nossas divergências iniciais na forma como enxergamos o mundo, no final sempre convergimos para o mesmo ponto.

A todos vocês e aqueles que, por falta de memória sempre presente, eu tenha esquecido muito obrigado. 


\section{RESUMO}

O presente estudo buscou avaliar, a partir de informações da Pesquisa Anual Industrial do IBGE, a evolução da Produtividade Total dos Fatores (PTF) para a indústria farmacêutica nacional, objetivando contribuir com o debate acerca dos reajustes de preços do setor no âmbito da resolução $N^{\circ}$ 1, de 27 de Fevereiro de 2004 da CMED. Para tanto, foram estimadas as fronteiras de produção estocásticas segundo o modelo implementado em Battese e Coelli (1995) com o emprego da Forma Flexível de Fourrier. A partir da metodologia citada acima, calculou-se os índices PTF de Malmquist para o período compreendido entre 1996 e 2003.

Foram construídos seis índices distintos de produtividade para avaliar o setor. Tal construção se deveu à necessidade de se atribuir exogenamente as taxas de depreciação para o cálculo do estoque de capital. Desta forma, três hipóteses distintas $(8 \%, 9 \%$ e $10 \%$, seguindo valores dentro do intervalo utilizado pela literatura de ciclos reais no Brasil) foram atribuídas com o objetivo de checar a robustez dos índices. A partir deste conjunto de três séries, foram calculados índices de média geométrica (seguindo a metodologia mais popular entre os autores da literatura de índices de Malmquist) e de média ponderada (cujo peso atribuído foi a participação do Valor da Transformação Industrial de cada empresa em relação ao total do mercado).

Dentre os resultados obtidos, vale destacar que, no período investigado, o setor não apresentou variações tecnológicas significativas. Os coeficientes são, numericamente próximos a zero e os índices de variação técnica variam positivamente até 1999 e, posteriormente, apresentam variações negativas que compensam o efeito positivo do período anterior. O mesmo não pode ser dito ineficiência técnica. De acordo com as equações estimadas, a ineficiência não apenas está presente, como predomina a variância do erro idiossincrático. Sua variação não apresenta um padrão decrescente nítido como a tecnologia. Entretanto, quando avaliada de maneira acumulada, os resultados mostram que, em todos os índices elaborados, houve uma perda de eficiência.

Os resultados finais dos índices, obtidos a partir da variação da eficiência técnica e da variação técnica, apontam para uma perda de produtividade acumulada nos dois grupos de índices, isto é, tomando como base o ano de 1996. Desta forma, o ano de 2003 apresentou uma perda média de $8 \%$ para a média ponderada e de aproximadamente $7 \%$ na média geométrica. 


\begin{abstract}
The aim of this study is develop a contribution about the prices readjustments in Brazilian Pharmaceutical Industrial Sector, which is regulated by Resolution $\mathrm{N}^{\mathrm{o}} 1$ from 27 February of Brazilian's Medicines Chamber (CMED). The present work uses information from IBGE's Industrial Annual Research between 1996-2003. This contribution comes from measuring the Malmquist Total Factor Productivity Index of this sector. In order to do so, Battese and Coelli's (1995) stochastic productions frontiers were estimated whit employment of Fourrier Flexible Form.
\end{abstract}

Six different indexes were constructed by the necessity to attribute an exogenous depreciation factor to calculus of capital stock. Therefore, three distinct hypotheses $(8 \%, 9 \%$ and $10 \%)$ were established to this factor, following the values used by Brazilian Real Business Cycles Literature. Apart from these values, two sets of indexes were constructed: a geometric mean index (following the most popular methodology in the Malmquist Index Literature) and a weighted mean index (the weight used is the relatively participation of each firm at the total Industrial Transformation Value).

The results shows that the sector doesn't have a significant technological variation in the investigated period. The technological coefficients are numerically near to zero and the derivative technological indexes present positive variation until 1999. After this period, the technological indexes present negative variation, so the final effect is quite null. Looking to the technical efficiency, we can't assume the same result. According to the estimated equation, inefficiency is not only present but it's effects seem dominate the idiosyncratic error. Moreover, the inefficiency doesn't show a clear decreasing pattern like technological variation. However, when someone evaluate this variable accumulated, the results show an efficiency lost.

The final results of these indexes were got by the technical indexes and technical efficiencies indexes and present an accumulated efficiency lost in two sets of indexes with 1996 as basis. Therefore, 2003 shows an average lost about $8 \%$ in weighted mean and about $7 \%$ in geometric mean. 


\section{SUMÁRIO}

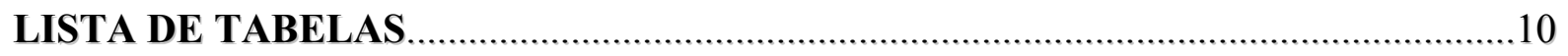

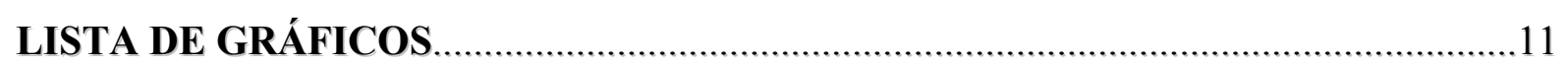

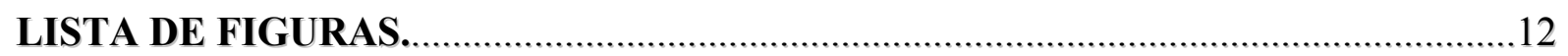

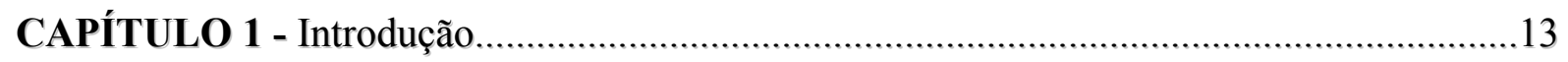

CAPÍTULO 2 - Revisão da Literatura: Características do Setor Farmacêutico Brasileiro.....16

CAPÍTULO 3 - Microeconomia da Produção........................................................................25

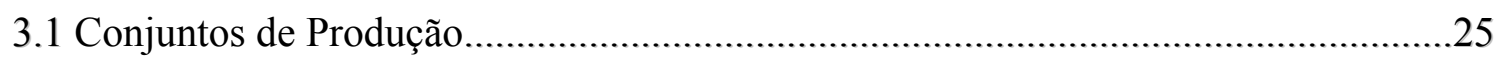

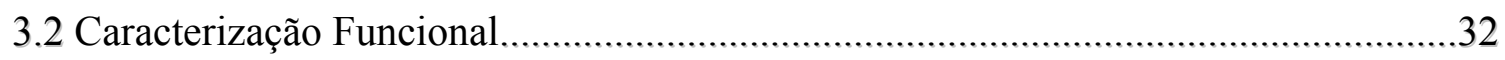

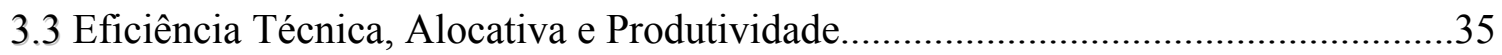

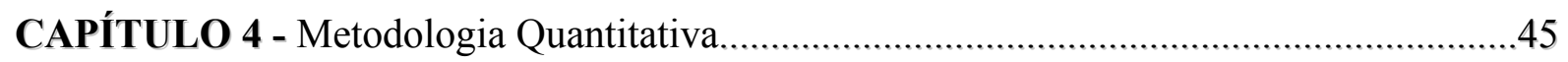

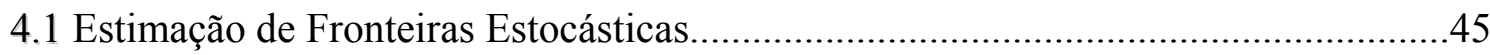

4.2 Vantagens, Deficiências e Críticas à Metodologia de Fronteiras Estocásticas e

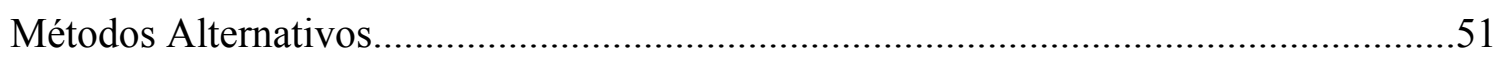

CAPÍTULO 5 - Base de Dados, Variáveis e Principais Resultados .......................................61

5.1 Fonte de dados e construção de variáveis................................................................. 61

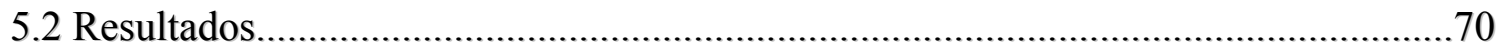

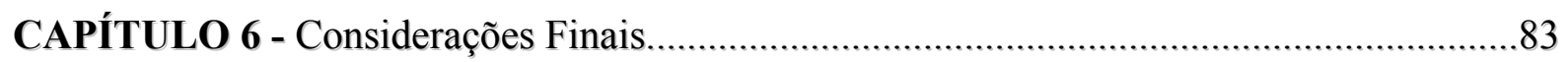

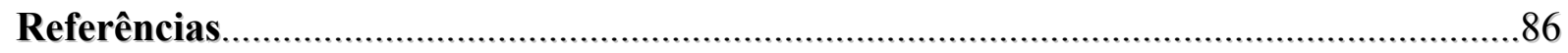

\section{APÊNDICES:}

I. Estimações em Mínimos Quadrados..............................................................................95

II. Densidade Kernel da ineficiência e do choque aleatório......................................................98

III. Fronteiras estocásticas sob hipóteses de retornos variáveis..........................................100

IV. Índices de Produtividade Desagregados por Estado da Federação e Grande Região

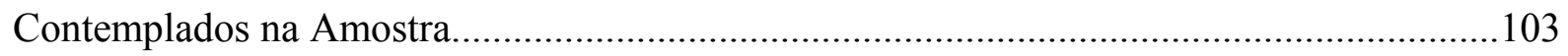




\section{LISTA DE TABELAS}

Tabela 2.1 - Produtos Farmacêuticos: Evolução das Exportações e Importações -1997 a 2005

- US\$ FOB.

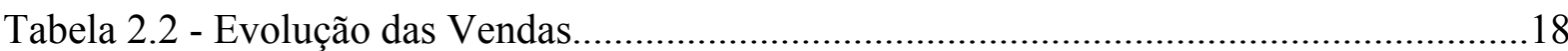

Tabela 2.3 - Principais Mudanças Estruturais Realizadas nos Últimos Anos.........................22

Tabela 2.4 - Faixas de Concentração e Poder de Monopólio dos Mercados Relevantes

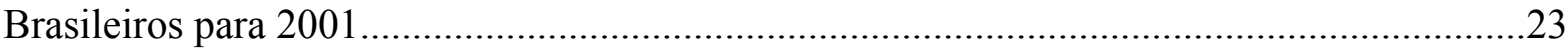

Tabela 5.1 - Investimento Real - Em R\$ 1.000,00 de 2003 …............................................66

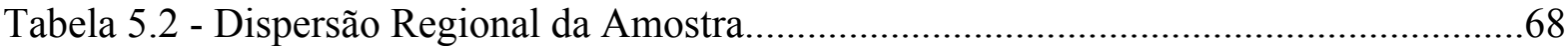

Tabela 5.3 - Percentual de Empresas Exportadoras - Participação das Exportações por

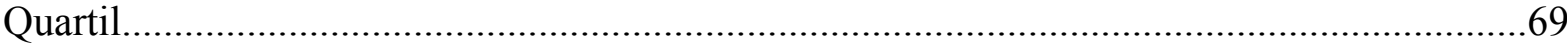

Tabela 5.4 - Testes de Assimetria nos Resíduos do MQO........................................................71

Tabela 5.5 - Funções de Produção Estocásticas - Modelo B\&C 1995.....................................72

Tabela 5.6 - Testes de Hipótese.................................................................................................74

Tabela 5.7 - Índices de Variação Tecnica, Variação da Eficiência e Produtividade.................76

Tabela 5.8 - Variação na Escala e na Eficiência Técnica Pura...............................................76 


\section{LISTA DE GRÁFICOS}

Gráfico 2.1a - Evolução das Vendas - Em Milhões de Reais.................................................19

Gráfico 2.1b - Evolução das Vendas - Em Milhões de Unidades..........................................19

Gráfico 5.1 - Valor da Transformação Industrial - Em R\$ 1.000,00 de 2003 ..........................64

Gráfico 5.2 - Trabalho: Administração e Sócios - Em R\$ 1.000,00 de 2003 ..........................65

Gráfico 5.3 - Trabalho: Produção e Sócios - Em R\$ 1.000,00 de 2003 .................................65

Gráfico 5.4 - Estoques de Capital - Em R\$ 1.000,00 de 2003 ...............................................67

Gráfico 5.5 - Percentual de Compra de Insumos Importados Ano a Ano................................69

Gráfico 5.6 - Evolução da Produtividade - Índice em Média Geométrica................................76

Gráfico 5.7 - Evolução da Produtividade - Índice em Média Ponderada..................................77

Gráfico 5.8 - Evolução da Produtividade - Índice em Média Geométrica e Ponderada...........77

Gráfico 5.9 - Variação Técnica - Índices de Média Geométrica e Ponderada..........................78

Gráfico 5.10 - Evolução da Efíciência Técnica - Índices de Média Geométrica e

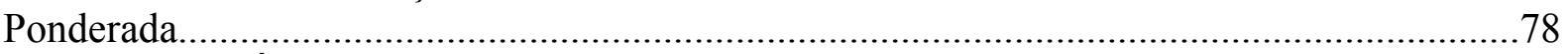

Gráfico 5.11 - Índices de Produtividade Acumulada - Base 1996.........................................82 


\section{LISTA DE FIGURAS}

Figura 3.1 - Conjunto de Tecnologia de Produção..............................................................25

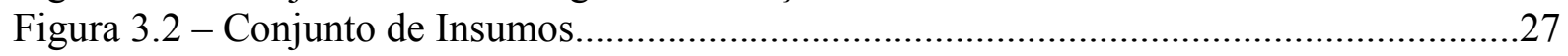

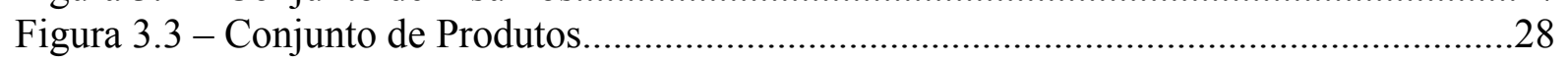

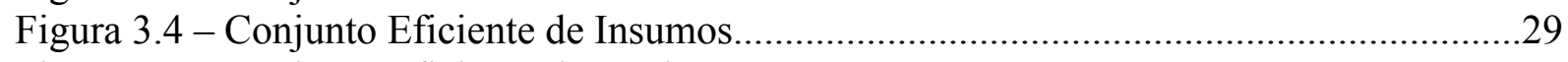

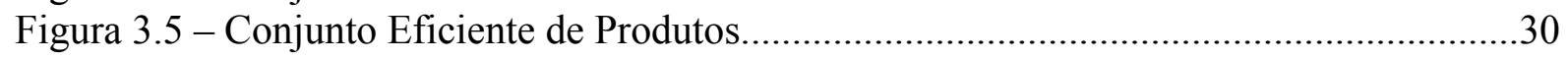

Figura 3.6 - Representação Gráfica das Funções Distância.......................................................33

Figura 3.7 - Medida de Eficiência Segundo Farrell.............................................................. 37

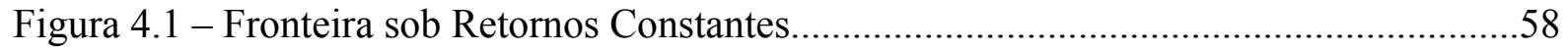

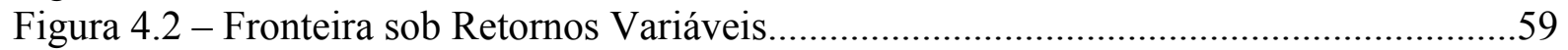

Figura 4.3 - Fronteira sob Hipótese de Livre Descarte...........................................................60 


\section{1) Introdução}

O marco regulatório brasileiro tem sido, nos últimos anos, alvo de constantes discussões com o objetivo de estabelecer regras que facilitem a retomada dos investimentos e atender as exigências do mercado consumidor dos bens e serviços regulados pelo Governo. A regulação do setor farmacêutico, não tem sido diferente. O Ministério da Saúde, a Agência Nacional de Vigilância Sanitária (ANVISA) e a Câmara de Regulação do Mercado de Medicamentos (CMED) são os órgãos responsáveis pelo estabelecimento dos preços no setor e têm como objetivo a manutenção de preços compatíveis com o nível de renda da população.

Apesar da reconhecida demanda da população pelos serviços de saúde, um marco regulatório eficaz deve-se preocupar também com a eficiência, produtividade e capacidade da indústria farmacêutica de investir na pesquisa e desenvolvimento de novos medicamentos e novas apresentações, permitindo a esta praticar preços que garantam as condições acima citadas. Desta forma, este trabalho objetiva verificar quais foram os ganhos de produtividade do setor para o período compreendido entre 1996-2003.

A relevância desta questão se encontra na forma como o controle de preços é instituído. A Lei $\mathrm{N}^{\mathrm{o}}$ 10.742, de 06 de Outubro de 2003 através de seu Art. $4^{\circ}, \S 1^{\circ}$ estabelece que: "O ajuste de preços de medicamentos será baseado em modelo de teto de preços calculado com base em um índice ${ }^{1}$ de preços, em um fator de produtividade e em um fator de ajuste de preços relativos intra-setor e entre setores." Além disto, o $\S 3^{\circ}$ do Art. $4^{\circ}$ estabelece que: "O fator de produtividade, expresso em percentual, é o mecanismo que permite repassar aos consumidores, por meio dos preços dos medicamentos, projeções de ganhos de produtividade das empresas produtoras de medicamentos".

Assim, a CMED, conforme anexo da resolução No 1, de 27 de Fevereiro de 2004, estabelece a seguinte fórmula para o reajuste de preços:

- $\quad \mathrm{VPP}=\mathrm{IPCA}-\mathrm{X}+\mathrm{Y}+\mathrm{Z}$, onde:

\footnotetext{
${ }^{1} \mathrm{O}$ índice escolhido, conforme o $\S 2^{\circ}$ do Art. 4, é o IPCA.
} 
$\mathrm{VPP}=$ representa a variação percentual permitida no preço do medicamento,

IPCA = representa a taxa de inflação medida pela variação percentual do Índice de Preços ao Consumidor Amplo (IPCA),

$\mathrm{X}=$ fator de produtividade,

$\mathrm{Y}=$ fator de ajuste de preços relativos entre setores,

$\mathrm{Z}=$ fator de ajuste de preços relativos intra-setores.

Os valores estabelecidos para o fator de produtividade, conforme tal resolução foram $0,00 \%$ para $2004,1,50 \%$ para 2005 e $1,87 \%$ para o ano de 2006 .

Na definição de quais medicamentos devem seguir esta regra de precificação, o Brasil adota o sistema de Listas Negativas, isto é, a princípio, todos os medicamentos comercializados no mercado brasileiro estão sujeitos a esta regra exceto aqueles incluídos nas listas divulgadas pela CMED. Além dos medicamentos inclusos nas Listas Negativas, estão também livres de regulação os medicamentos fitoterápicos assim reconhecidos pela ANVISA.

Dentro deste prospecto, o fator de produtividade passa a ser um índice não apenas de interesse do setor, mas também de interesse público. Sendo assim, para seu cálculo, utiliza-se, neste trabalho, o índice de Produtividade Total dos Fatores (PTF) de Malmquist proposto por Caves, Christensen e Diwert (1982). Para a obtenção do índice, é aplicada a metodologia de Fronteiras Estocásticas desenvolvida em Battese e Coelli (1995). Esta metodologia permite a separação da PTF em variação na eficiência técnica (uso da melhor tecnologia disponível) e variação tecnológica. Assim, espera-se encontrar valores que estejam refletindo os verdadeiros ganhos (ou perdas) de produtividade do setor para o período 1996-2003. A inclusão de períodos anteriores à retomada do controle de preços em $2000^{2}$ tem por objetivo verificar se as mudanças ocorridas no ambiente, fruto da alteração do marco regulatório, ocasionaram algum impacto na PTF e na eficiência das firmas.

As informações referentes ao setor são extraídas da Pesquisa Industrial Anual (PIA) do Instituto Brasileiro de Geografia e Estatística (IBGE). Tal base fornece informações

\footnotetext{
${ }^{2}$ Em 2000, foi criada a Câmara de Medicamentos (Camed) que, posteriormente, foi substituída pela CMED, possuía a incumbência de exercer tal controle através de uma Fórmula Paramétrica de Reajustes de Preços de Medicamentos. A diferença entre a Evolução Média de Preços de cada empresa um Índice Paramétrico de Preços era o critério utilizado para decidir se uma empresa poderia reajustar seus preços, tendo estes sido congelados durante o ano de 2001.
} 
detalhadas sobre as firmas que compõe os diversos setores industriais da economia brasileira. Colocados os pontos iniciais, este estudo está organizado da seguinte maneira: o capítulo 2 faz uma breve exposição de alguns estudos que abordam temas relacionados à indústria farmacêutica e literatura sobre produtividade que se utiliza dos métodos aqui aplicados. No capítulo seguinte, o modelo teórico subjacente é apresentado. Desta forma, as hipóteses microeconômicas sobre as quais este estudo repousa são explicitadas. No capítulo 4, atenção especial é deslocada à metodologia quantitativa, apresentando, portanto, o modelo de fronteiras estocásticas. O quinto capítulo disserta sobre a base de dados selecionada, as variáveis construídas para a análise e os resultados empíricos. Por fim, o capítulo 6 se encarrega de fornecer as principais conclusões. 


\section{2) Revisão da Literatura: Características do Setor Farmacêutico Brasileiro.}

Apesar de o setor farmacêutico brasileiro possuir uma série de estudos que abordam diferentes questões relevantes, o setor carece de estudos contemplando a produtividade e eficiência das firmas. Dentre os assuntos levantados, destacam-se estudos que consideram o comportamento da oferta, o comportamento da demanda por medicamentos, estrutura do mercado nacional e sobre o impacto da política de genéricos.

No tocante à oferta de medicamentos, Hasenclever (2002) mostra que o mercado brasileiro encontra-se entre os dez maiores do mundo para o período compreendido entre 1997 e 2000. O estudo verifica que grande parte da indústria localizada no país é de origem estrangeira. Romano e Bernardo (2001) argumentam que esta forte internacionalização da indústria farmacêutica nacional faz com que as firmas instaladas no Brasil estejam voltadas basicamente para o processamento físico dos princípios ativos importados. Desta maneira, o Brasil possui, dentro da cadeia produtiva de medicamentos, uma indústria especializada na elaboração dos produtos finais enquanto atividades de Pesquisa e Desenvolvimento (P\&D) e a produção de fármacos (princípios ativos) são concentradas nos EUA, Europa e, em menor escala, na Índia e China. Conforme Queiroz e Gonzáles (2001) diversos fatores contribuíram para o não desenvolvimento das etapas de $\mathrm{P} \& \mathrm{D}$ e produção de fármacos. São eles:

- A escassez relativa de mão de obra especializada em relação aos países de origem das empresas;

- As economias de escala inerentes à atividade de P\&D (oriundas, por exemplo, de externalidades do conhecimento, dos altos custos da pesquisa e capacidade que grandes empresas possuem de captar os recursos necessários) fazem com que estas sejam concentradas em um mesmo centro de pesquisa;

- A inexistência até 1996 de uma legislação que protegia a propriedade industrial estimulava a cópia de moléculas já existentes, mas não as atividades de descoberta de novos compostos.

Apesar desta situação, Queiroz e Gonzáles (2001), argumentam que nos últimos três anos se iniciou no país um movimento de transferência, por parte de alguns laboratórios, de atividade 
de P\&D. Entretanto, esse movimento ainda é bem modesto e consiste apenas em uma das etapas do amplo processo de P\&D que é a fase clínica ${ }^{3}$.

A internacionalização do setor teve reflexos não apenas na estrutura produtiva mas, também, no saldo comercial do setor uma vez que a maior parte dos insumos utilizados na produção dos medicamentos é importada. Durante a década de oitenta, devido a ausência de proteção patentária, o processo de substituição de importações foi estimulado, conforme exposto, através da cópia de moléculas existentes. Ainda assim, a presença das importações na quantidade de fármacos consumidos pela indústria local era considerável.

Bermudez et al (2000) argumentam que as importações de fármacos se intensificaram durante o processo de abertura da economia brasileira na década passada. Magalhães et al. (2003a), utilizando dados da Secretaria de Comércio Exterior (Secex), corroboram o fato de o Brasil apresentar déficit comercial no setor. De acordo com este estudo, o país passou a importar não apenas os fármacos mas também medicamentos prontos tendo estes apenas suas embalagem manipuladas internamente. Palmeira Filho e Pam (2003) colocam ainda que, além da abertura, o câmbio valorizado até 1999 contribuiu para este incentivo as importações.

Mesmo após a desvalorização, o setor continuou a apresentar saldo comercial negativo. Entretanto a participação das exportações vem crescendo a cada ano segundo dados da Febrafarma $^{4}$, apresentados na Tabela 2.1.

Considerando o faturamento do setor para o mesmo período contemplado na Tabela 2.1, mesmo com um volume de vendas de unidades decrescente, há uma elevação do mesmo entre meados da década de noventa e 2005 . Houve uma elevação de $37,66 \%$ no faturamento real entre 1997 e 2005. Entretanto, considerando as variações a cada ano, tal variável apresentou decréscimo em relação ao período anterior de 3,16\% em 2000 e de 0,97\% em 2003 ao passo que em 1999, de maneira distinta da economia que sofria uma recessão, a indústria apresentou a maior elevação registrada nos anos considerados. O resultado negativo em 2000 também surpreende dado que a economia brasileira apresentou uma variação positiva no Produto Interno Bruto (PIB) de 4,36\%, além de uma retomada do setor industrial cuja elevação do PIB

\footnotetext{
${ }^{3}$ Fase na qual um novo fármaco é testado em um pequeno grupo de voluntários e busca-se verificar sua eficácia e efeitos colaterais.

${ }^{4}$ Disponível em www.febrafarma.com.br. Acesso realizado em 23/10/06.
} 
foi 4,87\%, segundo informações do IBGE. Tais informações podem ser consultadas a seguir na tabela 2.2. O gráfico 2.1 ilustra a evolução das vendas nominais, vendas reais e vendas em unidades.

\begin{tabular}{|c|c|c|c|c|c|c|c|}
\hline \multicolumn{8}{|c|}{ Tabela 2.1- Produtos Farmacêuticos: Evolução das Exportações e Importações -1997 a 2005 - US\$ FOB } \\
\hline Ano & $\begin{array}{c}\text { Exportações } \\
\text { (US\$ FOB) }\end{array}$ & $\begin{array}{c}\text { Variação } \\
\text { percentual }\end{array}$ & $\begin{array}{c}\text { Índice Base: } \\
\text { 1997=100 }\end{array}$ & $\begin{array}{l}\text { Importações } \\
\text { (US\$ FOB) }\end{array}$ & $\begin{array}{c}\text { Variação } \\
\text { percentual }\end{array}$ & $\begin{array}{c}\text { Índice Base: } \\
\text { 1997=100 }\end{array}$ & Saldo Comercial \\
\hline 1997 & $154.306 .311,00$ & - & 100,00 & $1.013 .759 .105,00$ & - & 100,00 & $-859.452 .794,00$ \\
\hline 1998 & $195.127 .915,00$ & $26,45 \%$ & 126,45 & $1.213 .273 .638,00$ & $19,68 \%$ & 119,68 & $-1.018 .145 .723,00$ \\
\hline 1999 & $231.557 .980,00$ & $18,67 \%$ & 150,06 & $1.512 .084 .532,00$ & $24,63 \%$ & 149,16 & $-1.280 .526 .552,00$ \\
\hline 2000 & $218.691 .166,00$ & $-5,56 \%$ & 141,73 & $1.421 .181 .317,00$ & $-6,01 \%$ & 140,19 & $-1.202 .490 .151,00$ \\
\hline 2001 & $241.703 .196,00$ & $10,52 \%$ & 156,64 & $1.522 .062 .679,00$ & $7,10 \%$ & 150,14 & $-1.280 .359 .483,00$ \\
\hline 2002 & $253.534 .538,00$ & $4,89 \%$ & 164,31 & $1.527 .816 .650,00$ & $0,38 \%$ & 150,71 & $-1.274 .282 .112,00$ \\
\hline 2003 & $279.916 .767,00$ & $10,41 \%$ & 181,40 & $1.512 .222 .003,00$ & $-1,02 \%$ & 149,17 & $-1.232 .305 .236,00$ \\
\hline 2004 & $351.243 .691,00$ & $25,48 \%$ & 227,63 & $1.784 .804 .231,00$ & $18,02 \%$ & 176,06 & $-1.433 .560 .540,00$ \\
\hline 2005 & $473.289 .888,00$ & $25,79 \%$ & 306,72 & $2.037 .043 .307,00$ & $14,13 \%$ & 200,94 & $-1.563 .753 .419,00$ \\
\hline
\end{tabular}

Fonte: Febrafarma/Dep. de Economia a partir de dados da Secretaria de Comércio Exterior (SECEX).

\begin{tabular}{lccccc}
\hline \multicolumn{5}{c}{ Tabela 2.2 - Evolução das Vendas } \\
\hline \multirow{2}{*}{ Ano } & Vendas & Vendas reais* & Variação \% do & Vendas em & \\
& Rominais em & em R\$ & Faturamento & $\mathbf{1 . 0 0 0 . 0 0 0}$ & Variação \% \\
\hline $\mathbf{1 9 9 7}$ & $9.210,34$ & $16.154,21$ & real & Unidades & \\
$\mathbf{1 9 9 8}$ & $10.064,78$ & $17.106,30$ & $5,89 \%$ & $1.854,09$ & - \\
$\mathbf{1 9 9 9}$ & $11.847,53$ & $19.203,30$ & $12,26 \%$ & $1.814,34$ & $-2,14 \%$ \\
$\mathbf{2 0 0 0}$ & $12.281,75$ & $18.597,10$ & $-3,16 \%$ & $1.778,80$ & $-1,96 \%$ \\
$\mathbf{2 0 0 1}$ & $13.427,73$ & $19.030,60$ & $2,33 \%$ & $1.697,82$ & $-4,55 \%$ \\
$\mathbf{2 0 0 2}$ & $14.944,28$ & $19.529,65$ & $2,62 \%$ & $1.640,25$ & $-3,39 \%$ \\
$\mathbf{2 0 0 3}$ & $16.977,88$ & $19.341,18$ & $-0,97 \%$ & $1.497,88$ & $-1,55 \%$ \\
$\mathbf{2 0 0 4}$ & $20.012,95$ & $21.387,75$ & $10,58 \%$ & $1.652,13$ & $-7,24 \%$ \\
$\mathbf{2 0 0 5}$ & $22.238,48$ & $22.238,48$ & $3,98 \%$ & $1.613,83$ & $-2,32 \%$ \\
\hline
\end{tabular}

Fonte: Febrafarma

* Em Reais de 2005 - Deflacionado pelo IPCA. 

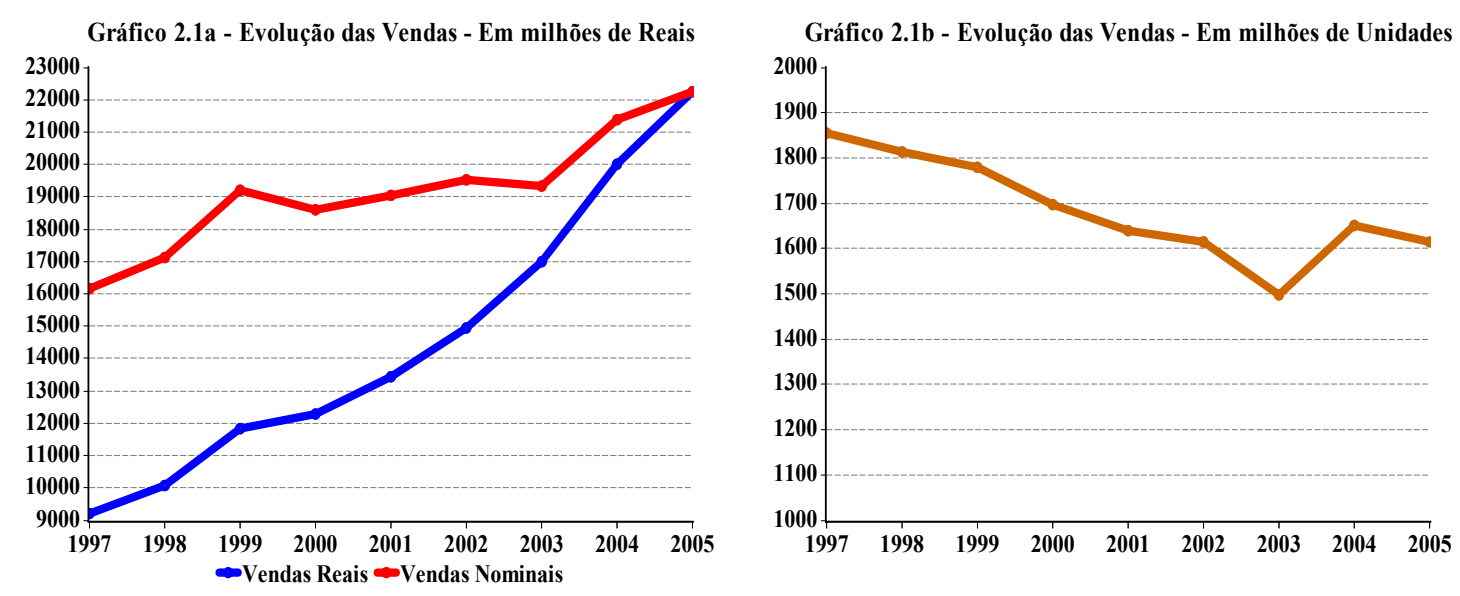

Outro acontecimento importante segundo Palmeira Filho e Pam (2003) é liberalização dos preços ocorridos no período entre 1992 e 1993 que resultaram na capitalização das empresas e realização de investimentos para a ampliação da capacidade de produção de medicamentos. Conforme mostram Fiuza e Lisboa (2001) os preços dos medicamentos elevaram-se de 1991 (período imediatamente após a liberalização) até o ano de 1999, acima do IPCA. Concomitantemente, o peso relativo dos medicamentos no orçamento das famílias de 1 a 40 salários mínimos elevou-se de 2,55\%, em outubro de 1987, para 3,55\% em setembro de $1996^{5}$.

Pelo lado da demanda, conforme observa Hasenclever (2002), cerca de $20 \%$ a $30 \%$ da demanda é realizada pelo Estado sendo o restante englobado pelo desembolso direto. Segundo a autora, o consumo de medicamentos está concentrado nas classes de mais alta renda sendo que apenas $15 \%$ da população brasileira que ultrapassam o limite de 10 salários mínimos mensais são responsáveis por cerca de $48 \%$ do consumo de medicamentos em termos monetários. Entretanto, Fiuza e Lisboa (2001), mostram que em termos relativos os mais pobres gastam parcela maior de sua renda com medicamentos. Conforme o estudo os $10 \%$ mais pobres gastam uma fração até oito vezes maior de sua renda que os $10 \%$ mais ricos. Assim, esta regressividade dos gastos reflete a inelasticidade da demanda em relação à renda.

Em estudo econométrico da demanda por medicamentos, contemplando de indivíduos que demandaram algum tipo de medicamento (ou seja, foram até o balcão da farmácia) Fridman e

\footnotetext{
${ }^{5}$ Os autores constroem estas estatísticas com dados da Pesquisa de Orçamento Familiar (POF) do IBGE.
} 
Rocha (2004) reportam resultados de inelasticidade-preço desta demanda para as diferentes classes terapêuticas abordadas no estudo (analgésicos, antibióticos, antiinflamatórios e antihipertensivos). Além disto, seus resultados mostram, também, que a função de gastos com medicamentos reage pouco à renda e à riqueza. A conclusão é que o barateamento relativo dos medicamentos após a retomada do controle de preços em 2000 não elevou de maneira significativa os gastos com medicamentos sacrificando, desta forma, o excedente do produtor.

Romano e Bernardo (2001) argumentam que o grau desinformação dos consumidores sobre o grau de substituição dos medicamentos e estrutura atomizada da são fatores agravantes para a inelasticidade da demanda. A estrutura atomizada leva à inexistência de poder de barganha pelos consumidores. Já a assimetria de informações atua reduzindo a concorrência mesmo quando existe a possibilidade de substituição entre produtos. Dado que os medicamentos são bens credenciais (bens em que somente um profissional especializado, no caso o médico, pode atestar a qualidade do produto), os consumidores são induzidos a obter apenas produtos de marca desconsiderando, assim, os genéricos. Este problema é mais grave nos mercados dos chamados medicamentos éticos, aqueles cuja receita médica é indispensável para a compra. Assim, os autores argumentam que mesmo na presença de um produto similar perfeito, este não é prescrito pelo médico (que desconhece o preço dos medicamentos) aos consumidores (que desconhecem sua existência). Por fim, argumenta-se que, no caso dos similares terapêuticos, a situação ainda é mais grave por abrir a discussão sobre a responsabilidade médica com o tratamento ${ }^{6}$. O argumento da assimetria informacional decorrente do fato dos medicamentos serem bens credenciais também é abordado em Fiuza e Lisboa (2001).

Outro relevante ponto abordado na literatura é o comportamento do mercado após a entrada dos genéricos a partir da Lei 9.787 de 10 de fevereiro de 1999. No Brasil, apesar dos incentivos adotados pelo Estado para a substituição dos medicamentos de marca pelos genéricos, estes ainda ocupam parcela pequena do mercado (Hasenclever, 2002). Segundo Romano e Bernardo (2001) o fato do Brasil até recentemente desrespeitar as patentes sobre medicamentos $^{7}$ fez com o país não desenvolvesse um mercado de genéricos e sim um mercado de similares de marca.

\footnotetext{
${ }^{6}$ Esta situação decorre do fato dos medicamentos similares, mesmo possuindo a mesma fórmula, não serem obrigados a apresentarem os testes de Bioequivalência que avaliam se o efeito do medicamento similar sobre o organismo humano é idêntico ao do medicamento de referência.

7 Somente em 1996 o Brasil passou a reconhecer os direitos e obrigações relativas à propriedade industrial através da Lei $n^{\circ} 9.279$.
} 
Entretanto, Nishijima e Biasoto Júnior (2003), argumentam que o preço dos medicamentos de marca, que se tornaram referência para os genéricos no mercado nacional, reagiu negativamente à entrada dos genéricos em seus respectivos mercados específicos. O estudo aponta que os preços são sensíveis ao número de genéricos existentes em seus mercados. No período anterior à entrada dos medicamentos genéricos (isto é, no período pré 1999) Fiuza e Lisboa (2001) estimaram modelos de efeitos fixos e aleatórios para medicamentos de marca, medicamentos líderes de mercado e medicamentos similares. Seus resultados apontam que o sistema de concorrência até então vigente possuía baixa eficácia no tocante à redução dos preços dos medicamentos de referência. Um resultado, até certo ponto, surpreendente é o fato da entrada dos similares ter elevado o preço dos medicamentos de marca.

Com relação à estrutura do mercado brasileiro, conforme já colocado, as plantas instaladas no país são, em grande parte, de capital estrangeiro. Segundo Magalhães et al (2003b) a política de estímulo aos genéricos tem ajudado a intensificar esta internacionalização ao atrair um número cada vez maior de laboratórios especializados na fabricação de medicamentos genéricos, embora boa parte dos investimentos neste setor, segundo este mesmo estudo, é realizada por laboratórios nacionais, em parceria com laboratórios estrangeiros, ou por laboratórios nacionais isoladamente.

É importante destacar, ainda, que o setor tem apresentado, a partir da década de noventa, um movimento cada vez maior de Fusões e Aquisições (F\&A) em âmbito internacional. Isto, sem dúvida, impacta a estrutura do mercado brasileiro dada presença marcante de empresas estrangeiras no país. Tais processos de F\&A têm sido orientados, segundo McKelvey e Orsenigo (2001), pelo aumento dos custos de P\&D, pelo aproveitamento das economias de escopo e a conseqüente ampliação do portifólio de medicamentos oferecidos ao mercado. Além disto, com o fim de diversas patentes, ocorridos neste período, grandes empresas têm buscado, cada vez mais, empresas produtoras de genéricos objetivando, assim, a concorrência em dois segmentos: o de preços mais elevados, onde se encontram os medicamentos de marca, e o de preços menores, onde se encontram os genéricos. A conseqüência dos processos de F\&A é uma maior concentração do mercado. A seguir, a tabela 2.3 apresenta alguns exemplos do processo descrito acima.

Avaliando o mercado nacional, Palmeira Filho e Pam (2003) argumentam que o setor é pouco concentrado uma vez que as dez maiores empresas detêm cerca de 38\%. Romano e Bernardo 
(2001), por sua vez, mostram que os quarenta maiores laboratórios detêm $86 \%$ do mercado farmacêutico total em faturamento.

\begin{tabular}{llc}
\hline \multicolumn{2}{c}{ Tabela 2.3 - Principais Mudanças Estruturais Realizadas nos Últimos Anos } \\
\hline $\mathbf{A n o}$ & \multicolumn{1}{c}{ Evento } & Valor do Negócio \\
\hline $\mathbf{1 9 9 6}$ & As suíças Sandoz e Ciba-Geigy se uniram para criar a Novartis & US\$ 27 bilhões \\
$\mathbf{1 9 9 9}$ & A britânica Zeneca e a sueca Astra se fundem criando a AstraZeneca & US\$ 36 bilhões \\
$\mathbf{1 9 9 9}$ & A francesa Rhône-Poulenc e a alemã Hoescht criaram a Aventis & US\$ 26 bilhões \\
$\mathbf{2 0 0 0}$ & $\begin{array}{l}\text { Fusão entre as britânicas Glaxo Wellcome e SmithKline Beecham criando o grupo } \\
\text { GlaxoSmithKline }\end{array}$ & US\$ 74 bilhões \\
$\mathbf{2 0 0 0}$ & Pfizer compra a Warner-Lambert & US\$ 114 bilhões \\
$\mathbf{2 0 0 2}$ & $\begin{array}{l}\text { A americana Amgen's assumiu o controle da empresa de biotecnologia Immunex } \\
\text { Corp }\end{array}$ & US\$ 10 bilhões \\
$\mathbf{2 0 0 3}$ & A americana Pfizer adquiriu a Pharmacia Corp & US\$ 60 bilhões \\
\hline $\mathbf{2 0 0 4}$ & Fusão entre a francesa Sanofi e a franco alemã Aventis criando o grupo Deborah & US\$ 59,4 bilhões \\
\hline
\end{tabular}

Fonte: O Globo, matéria publicada em 03/05/2004.

Hasenclever (2002) também apresenta a conclusão de que o mercado é pouco concentrado quando a participação total no mercado é usada como critério de avaliação. Porém, argumenta que esta não é a forma adequada de se verificar o grau de concentração desta indústria por desconsiderar a existência de insubstituibilidade dos medicamentos fabricados. Segundo a autora o grau de concentração deve ser avaliado seguindo uma estratificação por princípio ativo semelhante. Agindo desta forma, encontra um grau considerável de concentração no setor. Foram identificados 148 mercados relevantes e calculado o índice Herfindhal Hirschmann (HHI). Os resultados reportados no estudo são apresentados na tabela 2.4 a seguir: 


\begin{tabular}{|c|c|c|c|c|c|c|c|c|}
\hline $\begin{array}{c}\text { Faixas de } \\
\text { Concentração } \\
(\text { HHI })^{*}\end{array}$ & $\begin{array}{l}\text { Números de } \\
\text { Mercados }\end{array}$ & Percentual & $\begin{array}{c}\text { Soma das } \\
\text { vendas (US\$ } \\
1.000)\end{array}$ & Percentual & $\begin{array}{l}\text { Número de } \\
\text { Mercados } \\
\text { com } \\
\text { genéricos }\end{array}$ & Percentual & $\begin{array}{l}\text { Número de } \\
\text { Produtos } \\
\text { Genéricos }\end{array}$ & Percentual \\
\hline 0,0 a 0,1799 & 30 & 20,3 & 2.127 .701 & 44,8 & 24 & 36,9 & 220 & 56,6 \\
\hline 0,180 a 0,5599 & 70 & 47,3 & 2.454 .984 & 51,7 & 31 & 47,7 & 146 & 37,5 \\
\hline 0,560 a 0,9999 & 37 & 25,0 & 156.886 & 3,3 & 10 & 15,4 & 23 & 5,9 \\
\hline Igual a 1 & 11 & 7,4 & 9.853 & 0,2 & 0 & 0,0 & 0 & 0,0 \\
\hline Total & 148 & 100,0 & 4.749 .424 & 100 & 65 & 100,0 & 389 & 100,0 \\
\hline
\end{tabular}

Fonte: Hasenclever (2002) a partir de dados do IMS-Health. *O índice HHI conforme definido pela autora é: $\sum_{i=1}^{n} s_{i}^{2}$, onde é a razão das

vendas da empresa $i$ pelo total de vendas do mercado, ou seja, a parcela de mercado da empresa $i$.

Estes resultados mostram que 20,3\% do mercado podem ser considerados competitivos (HHI $<0,1800), 47,3 \%$ oligopolizado $(0,1800 \leq \mathrm{HHI}<0,5599)$ e $32,4 \%$ passíveis de ação de monopólio $(\mathrm{HHI} \geq 0,5600)$.

Nishijima (2003) também corrobora a concentração do mercado mesmo quando analisado por classe terapêutica. Segundo a autora, os quatro maiores laboratórios detêm de $90 \%$ a $100 \%$ do mercado para cerca de $50 \%$ das classes terapêuticas investigadas no estudo. Nas demais classes, os mesmos quatro laboratórios possuem ao menos 30\% do mercado. Seus resultados mostram, ainda, que cerca de $20 \%$ das classes investigadas possuem um índice HHI com valores entre 0,9 e 1,0 .

Outro importante ponto na estrutura organizacional desta indústria é a presença de economias de escopo. Hasenclever (2002) lembra da relevância das economias de escopo uma vez que a indústria farmacêutica apresenta firmas multiprodutoras. Barbosa (2004) argumenta que o desenvolvimento de novas drogas está associado ao conhecimento prévio adquirido. Assim, a produção de medicamentos torna-se mais fácil se os laboratórios podem usufruir deste conhecimento.

O grau de concentração por princípio ativo e por classe terapêutica, encontrado nos estudos anteriores, pode ser uma conseqüência destas economias de escopo pois uma vez que determinada firma se especializa em um princípio ativo, muito pouco de sua estrutura deve 
ser alterada para que os diversos medicamentos, a partir do princípio ativo em questão, sejam produzidos.

A presença de economias de escopo no setor farmacêutico é também abordada na literatura internacional. Entretanto, tais estudos mostram que as economias de escopo, muito presentes na elaboração de novas drogas, transbordam para a fase de produção de medicamentos, através do sistema de patentes. Desta forma, os laboratórios se especializam também, em produzir medicamentos dentro de uma mesma classe terapêutica. Os resultados encontrados em Henderson e Cockburn (1996) (em estudo realizado com dez grandes laboratórios, durante vinte anos) sugerem que os laboratórios mais produtivos são aqueles que produzem mais de um medicamento dentro da mesma classe terapêutica. Okada e Kawara (2004) realizam estudo semelhante para os dez maiores laboratórios japoneses e também verificam a presença de economias de escopo.

Já no tocante à escala, a literatura se ocupa em verificar a presença de economias de escala apenas nos estágios iniciais da cadeia produtiva de medicamentos, isto é, na fase de P\&D e produção dos fármacos. Um importante estudo nesta área é o realizado por Henderson e Cockburn (1996). De acordo com este trabalho, grandes firmas possuem maior capacidade de repartir os custos de $\mathrm{P} \& \mathrm{D}$ entre um número maior de consumidores. Possuem, também, vantagens sobre as firmas pequenas firmas no mercado de crédito além de explorar as externalidades de conhecimento geradas na pesquisa. São estimadas funções de produção de conhecimento usando como proxy para tal o número de patentes obtidas por firma. Dentre as variáveis explicativas incluídas, encontram-se os gastos anuais totais com pesquisa e o número de programas de pesquisa com gasto anual acima de U\$ 500.000,00. Estas variáveis buscam captar os efeitos das economias de escala e de escopo, respectivamente. Os resultados apontam que, ceteris paribus, os programas de $\mathrm{P} \& \mathrm{D}$ pertencentes a grandes firmas tendem a ser mais produtivos do que aqueles localizados em firmas pequenas embora, segundo os autores, boa parte desta maior produtividade seja devido às economias de escopo.

Antes de prosseguir à próxima seção, cabe ressaltar que a literatura sobre o setor não se ocupa em explicar os ganhos de escala na fase de produção de medicamentos que é predominante no Brasil. Feita esta ressalva, a seqüência deste trabalho busca explicitar o modelo teórico e as principais hipóteses sobre as quais este trabalho se apóia. 


\section{3) Microeconomia da Produção}

O objetivo deste capítulo é apresentar as bases teóricas sobre as quais repousa a análise da produção dentro da teoria Microeconômica. Inicialmente, define-se o conjunto de tecnologia de produção e os conjuntos que o formam: os conjuntos referentes aos vetores de insumos e aos vetores de produtos. Posteriormente, apresentam-se as funções que caracterizam estes conjuntos: as fronteiras de produção e as funções distância e, por fim, as medidas de ineficiência e produtividade ${ }^{8}$.

\section{1) Conjuntos de Produção}

Na teoria microeconômica da produção, assume-se que a firma utiliza vetores de insumos não negativos, definidos como $x=\left(x_{1}, \ldots, x_{n}\right) \in R_{+}^{N}$, para produzir quantidades não negativas de produtos, definidos como $y=\left(y_{1}, \ldots, y_{m}\right) \in R_{+}^{M}$. Assim, a partir desses vetores considera-se o Conjunto de Tecnologia de Produção, $Z$, como o conjunto de atividades produtoras factíveis, conforme a definição 3.1 e ilustrado na Figura 3.1.

Definição 3.1: O Conjunto de Tecnologia de Produção, $Z=\{(x, y): x$ pode produzir $y\}$, descreve todos os vetores de insumos e produtos factíveis.

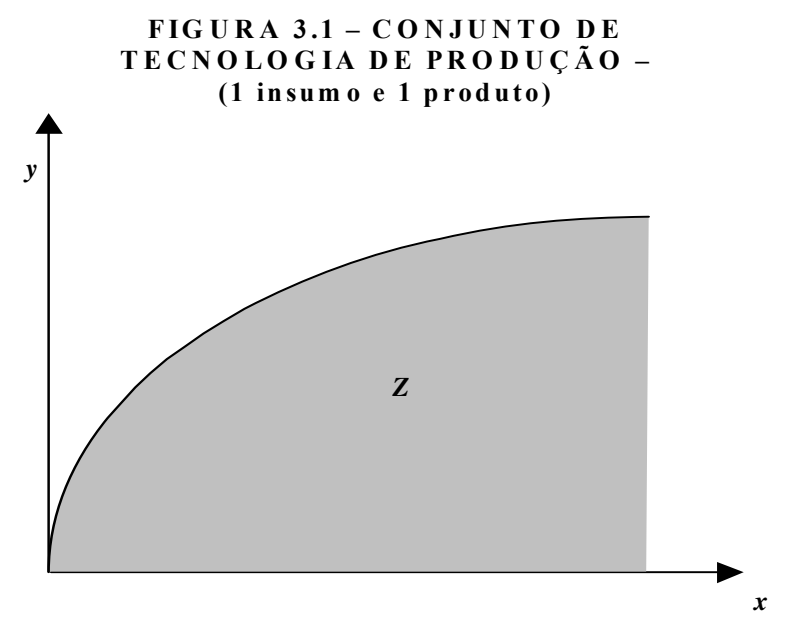

\footnotetext{
${ }^{8}$ Maiores detalhes das propriedades aqui apresentas podem ser encontradas em Mas-Collell, Whinston e Green (1995) ou Kumbhakar e Lovell (2000).
} 
Este conjunto, que comporta tanto tecnologias multiprodutoras como monoprodutoras deve satisfazer as seguintes propriedades, segundo Kumbhakar e Lovell (2000):

$Z_{1}:(x, 0) \in Z e(0, y) \in Z \rightarrow y=0$.

$Z_{2}: Z$ é um conjunto fechado.

$Z_{3}: Z$ é um conjunto limitado $\forall x \in R_{+}^{N}$.

$Z_{4}:(x, y) \in Z \rightarrow(\phi x, y) \in Z \forall \phi \geq 1$.

$Z_{5}:(x, y) \in Z \rightarrow(x, \phi y) \in Z \forall 0 \leq \phi \leq 1$

$Z_{6}: Z$ é um conjunto convexo.

A propriedade $Z_{1}$ garante que um vetor não negativo pode produzir ao menos zero de produto e que um vetor nulo de insumos pode produzir somente um vetor nulo de produto. Esta última é também conhecida como propriedade de no free lunch.

A segunda propriedade, $Z_{2}$, é necessária para que os elementos pertencentes à fronteira do conjunto $\mathrm{Z}$ estejam contidos no conjunto $\mathrm{Z}$. Com isto, fica garantida a existência de vetores tecnicamente eficientes.

A propriedade $Z_{3}$ garante que para cada vetor finito de insumos pertencente ao conjunto de produção, haja uma quantidade máxima de produto que se possa extrair, isto é, não é possível produzir infinitos produtos com um vetor finito de insumos.

As propriedades $Z_{4}$ e $Z_{5}$, também conhecidas como monotonicidade fraca, garantem que expansões radiais do vetor de insumos e contrações radiais do vetor de produtos sejam factíveis.

Por fim, a propriedade $\mathrm{Z}_{6}$ garante que os conjuntos de insumos e produtos, que serão apresentados a seguir nas Definições 3.2 e 3.3, respectivamente, também sejam convexos. A relevância da convexidade ficará explícita no decorrer deste capítulo.

Definição 3.2: O Conjunto de Insumos, $X(y)=\{x:(x, y) \in Z\}$, descreve todos os vetores de insumos factíveis para cada vetor de produtos $y \in R_{+}^{M}$. 
Definição 3.3: O Conjunto de Produtos, $Y(x)=\{y:(x, y) \in Z\}$, descreve todos os vetores de produtos factíveis para cada vetor de insumos $x \in R_{+}^{N}$.

O fato do conjunto $X(y)$ ser definido a partir do conjunto $Z$ propriedades confere-lhe as seguintes propriedades, segundo Kumbhakar e Lovell (2000):

$X_{1}: 0 \notin X(y)$ para $y \geq 0$ e $X(0)=R_{+}^{N}$.

$X_{2}: X(y)$ é um conjunto fechado.

$X_{3}: x$ é finito $\rightarrow x \notin X(y)$ se $y$ é infinito.

$X_{4}: x \in X(y) \rightarrow \phi x \in X(y)$ se $\phi \geq 1$.

$X_{5}: X(\phi y) \subseteq X(y)$ se $\phi \geq 1$.

$X_{6}: X(y)$ é um conjunto convexo.

A propriedade $\mathrm{X}_{1}$ elimina a possibilidade de produção a partir de um vetor de insumos nulo e diz que para qualquer vetor positivo existe a possibilidade de não produção. A segunda propriedade permite a existência de uma fronteira de vetores eficientes. A propriedade $\mathrm{X}_{3}$ garante que um vetor finito não é capaz de produzir um vetor infinito de insumos. As propriedades $\mathrm{X}_{4}$ e $\mathrm{X}_{5}$ são as propriedades de monotonicidade fraca e, por fim, a propriedade $\mathrm{X}_{6}$ é uma conseqüência da propriedade $\mathrm{Z}_{6}$.

O Conjunto de Insumos, para um vetor de insumos com duas componentes, pode ser visualizado na figura a seguir. Toda a área acima da curva $H H$ ” pertence ao conjunto $X(y)$.

FIG URA 3.2 - CONJUNTO DE INSUMOS -

( 2 insum os)

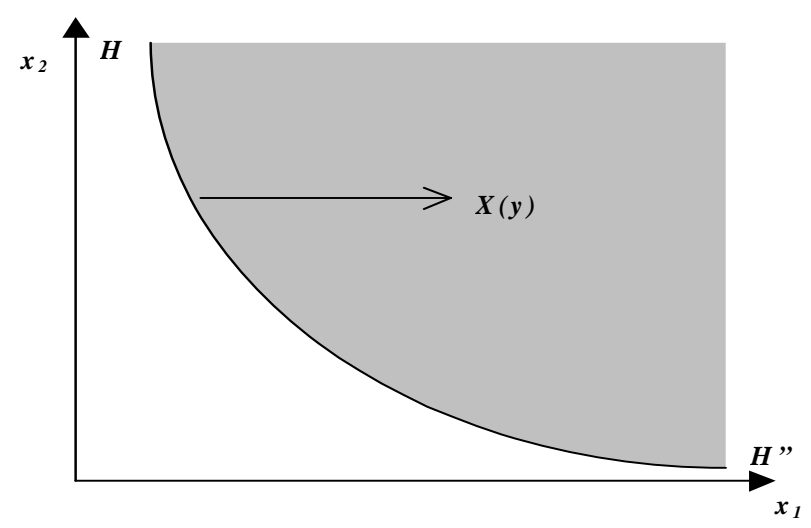


Partindo agora para o Conjunto de Produtos, $Y(x)$, como este também é definido a partir do conjunto $Z$, tem-se, analogamente ao conjunto $X(y)$ as seguintes propriedades, conforme Kumbhakar e Lovell (2003):

$$
\begin{aligned}
& Y_{1}: Y(0)=\{0\} \\
& Y_{2}: Y(x) \text { é um conjunto fechado } \\
& Y_{3}: Y(x) \text { é um conjunto limitado para } x \in R_{+}^{N} \\
& Y_{4}: Y(\phi x) \supseteq Y(x) \text { para } \phi \geq 1 . \\
& Y_{5}: y \in Y(x) \rightarrow \phi y \in Y(x) \text { para } \phi \in[0,1] \\
& Y_{6}: \text { é um conjunto convexo }
\end{aligned}
$$

A primeira propriedade $Y_{l}$ não permite que um vetor positivo de produtos seja produzido a partir de um vetor nulo de insumos. Analogamente ao conjunto de insumos, a segunda propriedade é necessária para existência de uma fronteira de vetores eficientes enquanto que a terceira propriedade não permite que infinitos produtos sejam produzidos a partir de vetores finitos de $x$. As propriedades $Y_{4}$ e $Y_{5}$ são as propriedades tradicionais de monotonicidade fraca enquanto $Y_{6}$ é uma conseqüência direta de $Z_{6}$. A seguir o conjunto de produtos para o caso de uma tecnologia com $n$ insumos (todos fixos) e 2 produtos pode ser visualizado na Figura 3.3. Ele consiste na área interna da curva $T T$ ”.

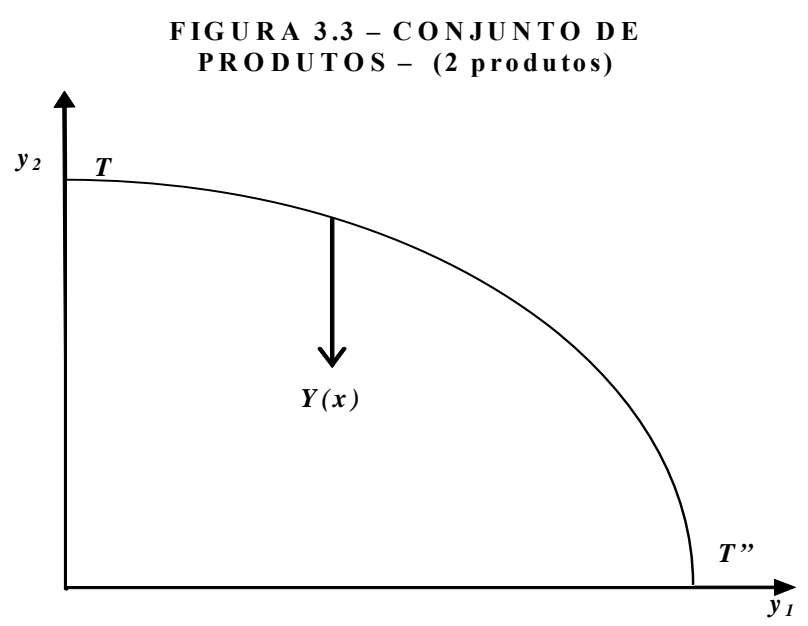

Definidos os conjuntos de tecnologia de produção, de insumos e de produtos, atenção especial deve ser dada às fronteiras destes conjuntos que constituem subconjuntos cujas propriedades apresentam relevância na teoria da produção. Assim, do conjunto de insumos, define-se os 
conjuntos de isoquantas de insumos e o conjunto de vetores eficientes de insumos conforme as definições 3.4 e 3.5 respectivamente.

Definição 3.4: $O$ Conjunto de Isoquantas de Insumos, Iso $X(y)=\{x: x \in X(y), \phi x \notin X(y)$ para $\phi<1\}$, descreve todos os vetores de insumos capazes de produzir um dado $y$, mas que as contrações radiais não são capazes de produzir $y$.

Definição 3.5: $O$ Conjunto Eficiente de Insumos, $\operatorname{Efic} X(y)=\left\{x: x \in X(y), x^{\prime} \leq x \rightarrow x^{\prime} \notin X(y)\right\}$, descreve todos os vetores de insumos capazes de produzir um dado $y$, mas que as contrações radiais não são capazes de produzir $y$.

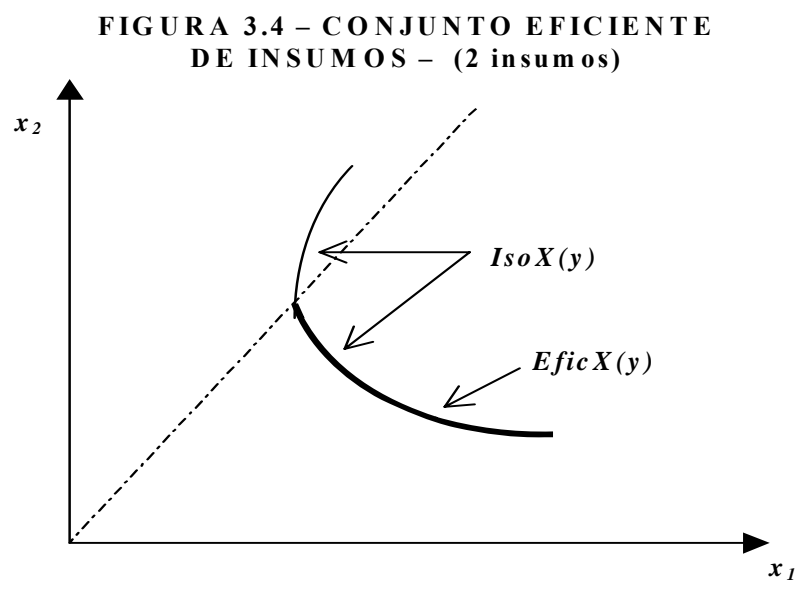

Na figura acima, toda a curva $X^{\prime}$ pertence ao conjunto IsoX(y) mas apenas a parte mais escura pertence ao conjunto de vetores tecnicamente eficientes. Percebe-se que na parte mais clara é possível contrair, simultaneamente, as quantidades de $x_{1}$ e $x_{2}$ e ainda assim produzir a mesma quantidade de $y^{\prime}$. Entretanto, contrações radiais, ou seja, uma redução proporcional de $x_{1}$ e $x_{2}$, não permitem que se produza a mesma quantidade $y^{\prime}$. Já a parte mais escura da curva não permite qualquer contração nos vetores eficientes. Verifica-se, desta maneira, que o conjunto de vetores eficientes está contido no conjunto de isoquantas e, caso a propriedade de convexidade $Z_{6}$ seja atendida, estes conjuntos são coincidentes ${ }^{9}$.

\footnotetext{
${ }^{9}$ Kumbhakar e Lovell (2000, p.24) argumentam que algumas formas funcionais empregadas nas análises econométricas atendem estas condições como, por exemplo, a Cobb-Douglas. Entretanto, segundo os autores, formas funcionais mais flexíveis como a Translog não permitem assumir prontamente que IsoX $(y)=\operatorname{Efic} X(y)$.
} 
Define-se, portanto, a região mais clara da curva como sendo a região não econômica.

A mesma análise pode ser feita para o conjunto de produtos. Considere o conjunto IsoY(x) como o conjunto de isoquantas de produtos, isto é, tal conjunto define, numa tecnologia multi-produto, todas as combinações de $y$ possíveis a partir de um vetor de insumos dado. A definição é apresentada a seguir.

Definição 3.6: $O$ Conjunto de Isoquantas de Produtos, $\operatorname{Iso} Y(x)=\{y: y \in Y(x), \phi y \notin Y(x), \phi>1\}$, descreve, numa tecnologia multiprodutora, todos os vetores de produtos possíveis de serem produzidos a um dado $x$, mas cujas as expansões radiais não são capazes de serem produzidas por $x$.

Já o conjunto de vetores eficientes de produção são todos aqueles que, numa tecnologia multiprodutora, são capazes de extrair o máximo de produto de um vetor de insumos qualquer. Sua definição é apresentada abaixo.

Definição 3.6: $O$ Conjunto de Produtos Eficiente, $\operatorname{Efic} Y(x)=\left\{y: y \in Y(x), y^{\prime} \geq y \rightarrow y^{\prime} \notin Y(x)\right\}$, descreve, numa tecnologia multiprodutora, todos os vetores de produtos possíveis de serem produzidos a um dado $x$, mas que qualquer expansão para a quantidade $y$ 'é incapaz de ser produzida por $x$.

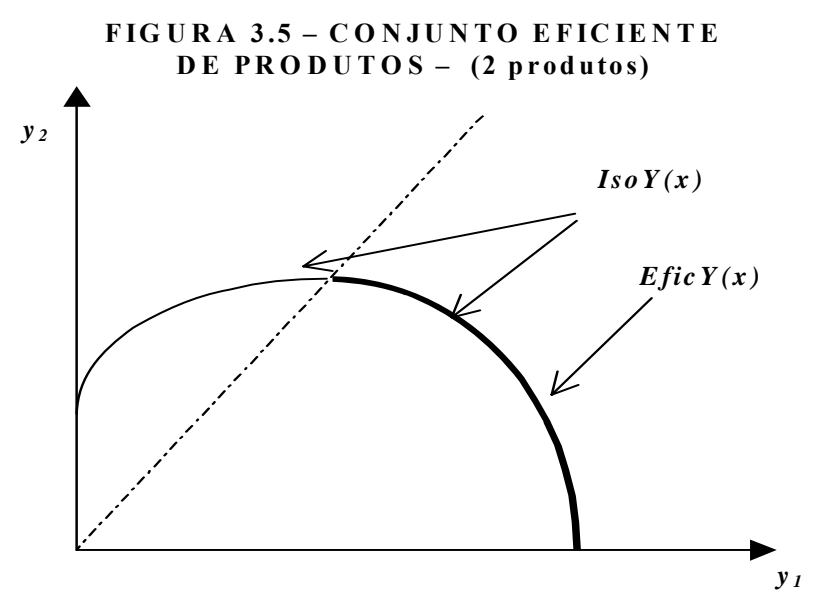

Na figura acima, toda a curva $Y^{\prime}$ faz parte do conjunto $I s o Y(x)$ ao passo que o conjunto $E f i c Y(x)$ contempla somente a parte escura. Novamente, com a propriedade de convexidade $Z_{6}$ 
garantida, a parte crescente da curva $Y^{\prime}$ pode ser desconsiderada, fazendo, conseqüentemente, parte da região não econômica.

Uma vez explicitada as propriedades dos conjuntos pertencentes ao espaço de produção, a seção subseqüente se encarrega de fornecer uma relação funcional para as fronteiras destes conjuntos o que permitirá, posteriormente, a aplicação de métodos econométricos para estimação empírica de tais conjuntos.

\section{2) Caracterização Funcional.}

Conforme já colocado, as fronteiras dos conjuntos de produção são subconjuntos de especial interesse para a teoria da firma por possibilitar caracterizações funcionais e, conseqüentemente, permitir estimações econométricas. Nesta seção, são apresentadas relações funcionais para descrever tecnologias de produção monoprodutoras e multiprodutoras a partir de um vetor múltiplo de insumos.

Para tecnologias monoprodutoras são estabelecidas as fronteiras de produção, enquanto que para as tecnologias multiprodutoras definem-se as funções distância.

$\mathrm{Na}$ análise para o caso múltiplos insumos e produto único tem-se a fronteira de produção como sendo a relação funcional que descreve a máxima quantidade de produto que se pode obter de um vetor de insumos. Assim a definição abaixo descreve esta relação.

Definição 3.7: A fronteira de produção é uma função $f(x)$ tal que $f(x)=\operatorname{Max}\{y: y \in Y(x)\}$ ou $\operatorname{Max}\{y: x \in X(y)\}{ }^{\mathbf{1 0}}$

Kumbhakar e Lovell (2000) estabelecem as seguintes propriedades para esta função:

$$
\begin{aligned}
& f_{1}: f(0)=0 . \\
& f_{2}: f(x)>0 \rightarrow f(\phi x) \rightarrow \infty \text { se } \phi \rightarrow \infty . \\
& f_{3}: f(\phi x) \geq f(x) \text { se } \phi \geq 1 . \\
& f_{4}: \text { é quasiconcava em } R_{+}^{N} .
\end{aligned}
$$

\footnotetext{
${ }^{10}$ A Fronteira de Produção também pode ser chamada de Função de Produção.
} 
Para tecnologias multiprodutoras, as funções distância apresentam uma forma de caracterização funcional factível de mensuração da fronteira. Segundo Coelli, Rao e Battese (1998) as funções distância:

Permitem descrever uma tecnologia de produção multi-insumos, multi-produtos sem a necessidade de se especificar um objetivo comportamental (como custominimizador ou lucro-maximizador). Uma função distância considera a máxima expansão proporcional de um vetor de produção dado um vetor de insumos ${ }^{11}$.

A definição matemática das funções distância é apresentada abaixo para caso o de uma função insumo-orientada.

Definição 3.8: Uma função distância insumo-orientada, $D_{I}(x, y)$ é uma relação tal que $D_{I}(x, y)=\max _{\phi}\{\phi, \phi \geq 1: x / \phi \in X(y)\}$.

Desta forma, a função distância insumo-orientada nada mais é do que a máxima contração eqüiproporcional possível do vetor de insumos, $x=\left(x_{1}, \ldots, x_{n}\right) \in R_{+}^{N}$, que permite manter fixa a quantidade produzida.

As funções distância também podem ser produto-orientadas. Neste caso, ela representa a máxima expansão eqüiproporcional do vetor de produtos, $y=\left(y_{1}, \ldots, y_{m}\right) \in R_{+}^{M}$, mantendo constante o vetor de insumos. Matematicamente temos:

Definição 3.9: Uma função distância produto-orientada, $D_{O}(x, y)$ é uma relação tal que $\operatorname{Do}(x, y)=\operatorname{mim}_{\lambda}\{\lambda, 0<\lambda \leq 1: y / \lambda \in Y(x)\}$.

As funções insumo-orientadadas têm as seguintes propriedades, conforme Coelli, Rao e Battese (1998):

$D_{I 1}: e ́$ não decrescente em $x$ e não crescente em $y$.

$D_{I 2}$ :é homogênia de grau 1 em $x$.

$D_{\text {I3 }}$ : se $x \in X(y) \rightarrow D_{I}(x, y) \geq 1$.

$D_{I 4}:$ se $D_{I}(x, y)=1, x$ pertence à fronteria do conjunto de insumos, isto é, $x \in \operatorname{IsoX}(y)$.

\footnotetext{
${ }^{11}$ Tradução do autor, Coelli, Rao e Battese (1998), pg. 222, cap.10.
} 
Já as funções produto-orientadas possuem, ainda segundo Coelli, Rao e Battese (1998), as propriedades:

Do1 :é não crescente em $x$ e crescente em $y$.

Do2 :é homogênia de grau 1 em $y$.

Dоз : se $y \in Y(x) \rightarrow D o(x, y) \leq 1$.

Do4: se Do $(x, y)=1, y$ pertence à fronteria do conjunto de insumos, isto

$\dot{e}, y \in \operatorname{Iso} Y(x)$.

Dos: Do $(x, y)$ é côncava em $x$.

Considerando, desta forma, uma tecnologia que utiliza apenas um insumo para produzir um único bem, a Figura 3.6 permite visualizar simultaneamente as funções distância insumoorientada e produto-orientada, ou seja, o par $(\phi, \lambda)$. Neste caso, a partir do ponto $X$, pode-se produzir a mesma quantidade que vem sendo produzida ( $\left.y^{\prime}\right)$ com o uso de menos insumo $\left(x / \phi^{*}\right)$. Da mesma maneira, com a quantidade atual de insumo $\left(x^{\prime}\right)$, pode ser obtido mais produto $\left(y / \lambda^{*}\right)$.

FIGURA 3.6 - REPRESENTAÇÃO

GRÁFICA DAS FUNÇÕES DISTÂNCIA

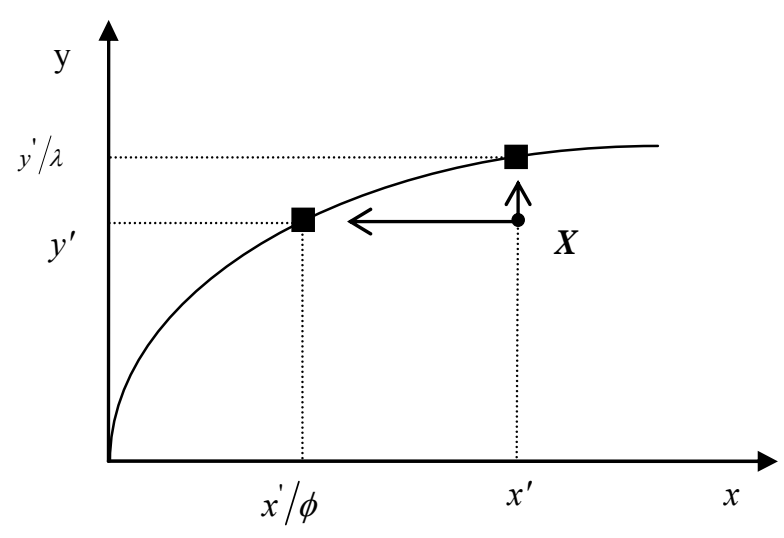

As funções distância apresentam uma relação íntima com a definição de eficiência técnica (que será apresentada mais adiante). Assim, se a função distância possui valor unitário, o vetor é tecnicamente eficiente. 
Uma importante questão a ser colocada é que as funções insumo-orientada e produtoorientada não fornecem valores idênticos para a distância de uma firma que não atua na fronteira.

Coelli, Rao e Battese (1998), apresentam uma interessante relação entre as funções insumoorientado e produto-orientadas. Para que o vetor de insumos $y \in Y(x)$, é necessário que $x \in X(y)$. Desta forma, tem-se a seguinte relação entre as funções distância: $D_{I}(x, y) \geq 1 \Leftrightarrow D_{o}(x, y) \leq 1$. Portanto, se a tecnologia de produção exibe Retornos Constante de Escala, $D_{I}(x, y)=1 / D_{o}(x, y) \forall(x, y), x \in X(y)$ e $y \in Y(x)$, ou seja, uma é o recíproco da outra.

Antes de passar à próxima seção, cabe salientar que uma fronteira de produção, conforme descrita no início da seção, também comporta uma tecnologia multiprodutora desde que seja possível agregar todos os produtos em uma medida única, como a construção de um numerário (para casos onde é possível a agregação ou o vetor de produtos é um escalar as funções distância e as fronteiras de produção são equivalentes) ${ }^{12}$. Neste estudo opta-se pela estimação desta metodologia. Sendo a Indústria Farmacêutica multiprodutora, utiliza-se como medida de agregação o Valor da Transformação Industrial. A descrição detalhada desta variável, por sua vez, será apresentada no capítulo 5 que trata da base de dados e das estimações realizadas. A seguir, são apresentadas as medidas utilizadas para ineficiência técnica, eficiência alocativa, e produtividade.

\section{3) Eficiência Técnica, Alocativa e Produtividade}

\footnotetext{
12 Caves, Christensen e Diewert (1982) argumentam que as Funções de Produção e as Funções Distância possuem as mesmas propriedades para descrever uma tecnologia de produção. Os autores relacionam ambas definindo a Função Distância como $D_{o}(\vec{y}, \vec{x})=\operatorname{mim}_{\lambda}\{\lambda: f(\vec{y} / \lambda, \vec{x}) \leq 1\}$ onde $f(\vec{y} / \lambda, \vec{x})$ é a Função de Produção que permite a insumos e produtos múltiplos.
} 
Esta seção apresenta, dentro do arcabouço matemático utilizado até aqui, as medidas de ineficiência técnica, alocativa e as medidas de produtividade delas derivadas. Para mensuração da ineficiência técnica, as análises realizadas concentram-se na distância existente entre o ponto de operação da firma e a fronteira tecnológica. Assim, estabelecidas as medidas de ineficiências, para que se possa extrair medidas de produtividade de uma firma, é necessária uma análise compreendendo um horizonte temporal mais amplo. Desta forma, analisa-se, tanto o deslocamento das firmas em direção à fronteira a cada período de tempo, como também o deslocamento da fronteira.

A definição de eficiência técnica remonta ao trabalho de Debreu (1951) no qual é desenvolvido o conceito de coeficiente de utilização de recursos ${ }^{13}$, que seria uma medida de utilização da capacidade produtiva total da economia.

Posteriormente, Farrell (1957), apoiando-se no coeficiente definido por Debreu (1951), desenvolveu o conceito de eficiência técnica e, ainda no mesmo estudo, o conceito de eficiência alocativa. Sua motivação repousava na necessidade de desenvolver uma medida que captasse a eficiência econômica como um todo, ou seja, considerando todos os fatores empregados no processo produtivo (o que não ocorria com o popular método de produtividade do trabalho) sem, entretanto, incorrer nos problemas existentes nos números índices como, por exemplo, a escolha arbitrária de um vetor de ponderação ${ }^{14}$.

Assim, o conceito de eficiência técnica diz respeito às relações entre as quantidades produzidas de produto e as quantidades de fatores utilizados na produção. Quando a quantidade produzida por uma firma, dada combinação de fatores, fica aquém do máximo possível de ser atingido com aquela combinação tem-se a presença de ineficiência técnica. Do ponto de vista do vetor de produtos, considera-se a situação na qual, fixa a quantidade de produto, uma firma produz com quantidades de insumos acima das necessárias tem-se, também, a presença de ineficiência técnica. Em termos formais, as definições para vetores de insumos e de produtos tecnicamente eficientes, respectivamente.

\footnotetext{
${ }^{13}$ Tradução do inglês "coefficient of resource utilization".

${ }^{14}$ Farrell (1957) chama atenção para o fato de apesar dos preços dos insumos serem um vetor de ponderação "natural", sua escolha só é justificada (fazendo com que o número índice mensure adequadamente o que se deseja), caso as empresas se defrontem com um vetor de preços idêntico. Isto porém, além de não ser factível na realidade, reduz-se a uma simples análise de custos. Portanto, a escolha de um vetor de preços torna-se, segundo o autor, também arbitrária.
} 
Definição 3.10: Um vetor de insumos $x$ será Tecnicamente Eficiente, se, e somente se, pertencer ao Conjunto Eficiente de Insumos, isto é: $\{x$ é tecnicamente eficiente $\Leftrightarrow x \in \operatorname{Efic} X(y)\}$.

\section{Definição 3.11: Um vetor de produtos y será Tecnicamente Eficiente, se, e somente se, pertencer ao Conjunto de Produção Eficiente, isto é: $\{y$ é tecnicamente eficiente $\Leftrightarrow x \in \operatorname{Efic} Y(x)\}$.}

Desta forma, assumindo a hipótese de convexidade do conjunto de produção, $\mathbf{Z}$, para que os vetores de insumos e de produtos sejam tecnicamente eficientes basta que estes pertençam às suas respectivas Isoquantas.

Já o conceito de eficiência alocativa refere-se à escolha ótima da proporção de insumos, dado o vetor de preços. A ineficiência alocativa surge quando a combinação de fatores em uso não é consistente com a minimização dos custos. Desta forma, os produtores, na presença de ineficiência alocativa, não atuam em ponto onde o retorno marginal dos fatores é equalizado aos preços dos mesmos.

A Figura 3.7, a seguir, ilustra as medidas de ineficiência técnica e alocativa. Considere uma firma numa tecnologia monoprodutora que se utiliza de dois insumos $\left(x_{1}, x_{2}\right)$. Aqui, a isoquanta $Y Y^{\prime \prime}$ representa todas as combinações eficientes de $\left(x_{1}, x_{2}\right)$ para produzir a quantidade $\bar{y}$. Portanto, uma firma atuando no ponto $\boldsymbol{B}$ e produzindo $\bar{y}$ é tecnicamente ineficiente. A medida da ineficiência é dada pela contração radial do vetor $\left(x_{1}, x_{2}\right)$ até o ponto A. Sendo assim, a ineficiência técnica da firma em questão é mensurada através da razão entre os segmentos de reta $\overline{O A} / \overline{O B}$ (neste caso tem-se a medida de ineficiência técnica insumoorientada). Antes de concentrar as atenções na eficiência alocativa, algumas considerações devem ser feitas sobre a eficiência técnica. Conforme pode ser observado, a definição matemática da eficiência técnica encontra-se intimamente ligada à definição de função distância. Assim, conforme colocado na seção anterior, se a tecnologia de produção exibe retornos constantes de escala, as funções distância insumo-orientada e produto-orientada possuem a seguinte propriedade: $D_{I}(x, y)=1 / D_{o}(x, y) \forall(x, y), x \in X(y)$ e $y \in Y(x)$. Portanto, se os retornos constantes de escala podem ser garantidos, tem-se que a ineficiência técnica medida a partir do vetor de insumos (i.e., a partir de uma contração de $\vec{x}$ mantendo $\vec{y}$ 
fixo) é o recíproco da ineficiência técnica mensurada a partir do vetor de produtos (i.e. a partir de uma contração de $\vec{y}$ mantendo fixo $\vec{x}$ ).

Partindo agora para a ineficiência alocativa, esta deve ser abordada analisando a relação de preços dos insumos empregados. A reta $P P$ " representa esta relação. Aqui, uma firma atuando no ponto $\boldsymbol{A}$, apesar de tecnicamente eficiente, não utiliza a proporção ótima de insumos dados os preços. Desta maneira, para que a firma possa operar em ponto onde haja eficiência técnica e alocativa, simultaneamente, ela deve alterar a proporção de insumos utilizada, convergindo para o ponto $\boldsymbol{D}$. A mensuração da ineficiência alocativa se dá pela razão entre os segmentos $\overline{O C} / \overline{O A}$.

Farrell (1957) a partir destes dois conceitos define uma terceira medida por ele denominada de "Overall Efficiency". Esta medida capta a eficiência econômica total de uma firma. Sua mensuração de dá pelo produto das duas razões anteriormente obtidas: $\frac{\overline{O C}}{\overline{O A}} \times \frac{\overline{O A}}{\overline{O B}}=\frac{\overline{O C}}{\overline{O B}}$. Ou seja, esta medida nada mais é do que o produto entre a Eficiência Técnica e a Eficiência Alocativa.

FIG URA 3.7 - M E D ID A DE E FIC IÊ NCIA

SEG U NDO FARRELL (1957)

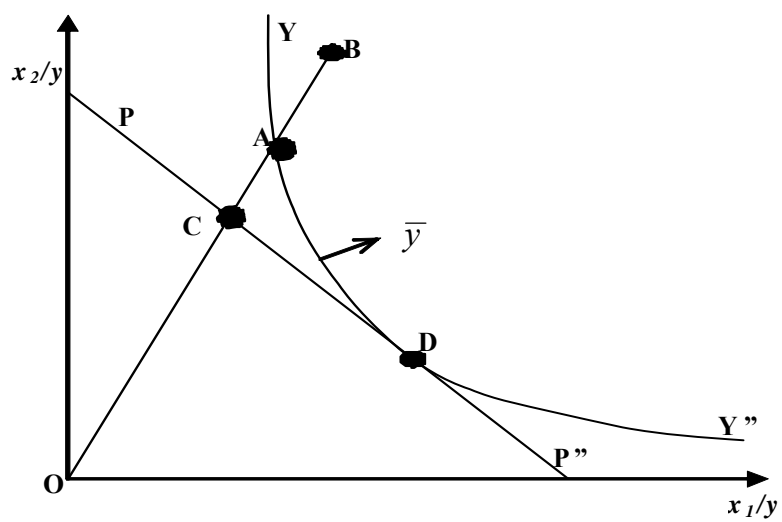

Apesar da relevância inequívoca da ineficiência alocativa, não faz parte do escopo deste estudo sua mensuração. Segundo Farrell (1957) observa, esta só faz sentido quando se deseja verificar se as firmas agem dentro de um arcabouço lucro-maximizador ou custominimizador. Como o objetivo aqui é a obtenção de uma relação técnica de produção (isto é, uma função de produção) não é possível, portanto, mensurá-la com as ferramentas disponíveis 
uma vez que nenhuma informação sobre os preços dos fatores e dos produtos é tratada. Uma função de produção permite apenas a mensuração da ineficiência técnica.

Entretanto, é possível afirmar que se uma firma é tecnicamente ineficiente, então tal firma não maximiza lucro:

Proposição 3.1: Uma firma $i$ agindo no ponto $\left(x_{i}, y_{i}\right)$, estará maximizando lucro somente se $x_{i} \in \operatorname{Efic} X(y)$ e $y_{i} \in \operatorname{Efic} Y(x)$.

Prova: Considere os vetores de preços dos insumos e produtos positivos $p_{x}, p_{y}$, respectivamente, e o vetor $x_{i}$ como dados. Se uma firma agindo no ponto $\left(x_{i}, y_{i}\right)$, é tecnicamente ineficiente, então $\exists \tilde{y}_{i} \geq y_{i}, \tilde{y}_{i} \in Y(x)$ tal que $\left(p_{y}^{\prime} \tilde{y}_{i}-p_{x}^{\prime} x_{i}\right) \geq\left(p_{y}^{\prime} y_{i}-p_{x}^{\prime} x_{i}\right) \rightarrow\left(x_{i}, y_{i}\right)$ não é um ponto de lucro máximo.

Por outro lado, uma firma produzindo em um ponto tecnicamente eficiente não necessariamente está maximizando seus ganhos. Isto ficou evidenciado anteriormente e pode ser visualizado na figura (3.7) onde a firma atuando no ponto $\boldsymbol{A}$ escolhe uma proporção entre os insumos que não equaliza a razão de preços com a razão entre os retornos marginais de $\left(x_{1}, x_{2}\right)$.

Esclarecidos estes pontos as atenções se voltam, agora, para a definição de produtividade e como esta se relaciona com a ineficiência. Defini-se produtividade como a relação existente entre a quantidade de bens e serviços produzidos e os recursos utilizados para a produção. Esta variável é resultado da divisão da produção física obtida em uma unidade de tempo por um dos fatores empregados na produção (capital, trabalho, terra), expressando a utilização eficiente dos recursos produtivos. Desta forma, quando se avalia apenas um insumo empregado em relação à produção tem-se a medida de produtividade deste fator. Quando todos os fatores são considerados nesta razão tem-se a Produtividade Total dos Fatores (PTF). Avaliar o desempenho de uma unidade produtiva considerando a produtividade de apenas um fator pode conduzir a erros de análise uma vez que não se consegue isolar a contribuição dos demais fatores para a produção. O estudo da PTF tomou fôlego com trabalho seminal de 
Sollow (1957) onde é apresentada uma forma de se separar as variações no produto decorrentes de variações técnicas daquelas fruto de mudanças no emprego de fatores.

Utilizando-se de uma metodologia paramétrica, Sollow (1957) estima uma função de produção agregada (tal qual a fronteira de produção apresentada na definição 3.7) para a economia Norte-Americana compreendida entre 1909 a 1949. Assumindo que a remuneração dos fatores de produção (capital e trabalho) seja equalizada ao seu retorno marginal, toda variação no produto não decorrente de mudanças nos fatores é atribuída a variações na produtividade advinda de choques tecnológicos (i.e. deslocamento da fronteira de produção no tempo) Desta forma, assume-se a seguinte função de produção:

(3.1) $Y_{t}=A_{t} f\left(K_{t}, L_{t}\right)$

Diferenciando o logaritmo de tal função com respeito ao tempo tem-se:

(3.2) $\frac{\dot{Y}_{t}}{Y_{t}}=\frac{\partial Y}{\partial K} \frac{K_{t}}{Y_{t}} \frac{\dot{K}_{t}}{K_{t}}+\frac{\partial Y}{\partial L} \frac{L_{t}}{Y_{t}} \frac{\dot{L}_{t}}{L_{t}}+\frac{\dot{A}_{t}}{A_{t}}$

Os dois primeiros termos do lado direito representam as variações das quantidades empregadas de insumos (deslocamentos ao longo da curva) enquanto o último representaria o choque o tecnológico exógeno que faria com que a curva se deslocasse. Rearranjando os termos de (3.2) e substituindo os produtos marginais dos fatores pelos seus respectivos preços, pode-se estabelecer o termo $\left(\dot{A}_{t} / A_{t}\right)$ como o resíduo de uma equação estimada ou, como se convencionou chamar na literatura internacional, o resíduo de Sollow:

(3.3) $\frac{\dot{A}_{t}}{A_{t}}=\frac{\dot{Y}_{t}}{Y_{t}}-\frac{r_{t}}{P_{t}} \frac{K_{t}}{Y_{t}} \frac{\dot{K}_{t}}{K_{t}}-\frac{w_{t}}{P_{t}} \frac{L_{t}}{Y_{t}} \frac{\dot{L}_{t}}{L_{t}}$

Este resíduo é, portanto, o componente que capta a variação da PTF no tempo. Uma deficiência deste método (que ficou conhecido como contabilidade do crescimento) é atribuir toda variação da PTF às variações tecnológicas e desconsiderar a possibilidade das firmas agirem em um lócus ineficiente.

Uma segunda abordagem que se tornou bastante popular é a mensuração da PTF através de índices de Malmquist. Este índice, elaborado pioneiramente no trabalho de Malmquist (1953) 
para teoria do consumidor, estabelecer um redimensionamento das quantidades do período base levando o consumidor a manter estático o seu nível de utilidade.

Posteriormente, Caves, Christensen e Diewert (1982) adaptaram a análise de teoria do consumidor baseada em funções distância realizada por Malmquist (1953) para a teoria da firma. Os autores argumentam que a metodologia empregada em Sollow (1957), ao associar a PTF à derivada da função de produção no tempo, conduz a erros do ponto de vista da teoria dos números índices uma vez que estes devem ser tomados usando pontos discretos do tempo. Sendo assim, para a correta mensuração é necessária uma aproximação discreta desta derivada.

Entretanto, antes de elucidar a metodologia aplicada para obtenção do índice de Malmquist, é importante mostrar como as medidas de eficiência se relacionam com um índice de PTF. Conforme apresentado em Coelli, Rao e Battese (1998) uma tecnologia de produção que emprega um único insumo $(x)$ para produção um único produto $(y)$ em dois períodos distintos $(t, t+1)$. Neste caso, a variação da produtividade pode ser estabelecida segundo a fórmula abaixo:

$$
P T F=\frac{y_{t+1} / y_{t}}{x_{t+1} / x_{t}}
$$

Sejam $f_{t}(x)$ e $f_{t+1}(x)$ as funções de produção que descrevem a tecnologia em $t$ e $t+1$ respectivamente. Supondo que haja ineficiência técnica entre as firmas que compõe a indústria, ou seja:

$$
y_{i} \leq f\left(x_{i}\right) \quad \rightarrow y_{t}=\mu_{t} f_{t}\left(x_{t}\right) \quad \text { onde } \quad 0 \leq \mu_{t} \leq 1
$$

Substituindo (3.5) em (3.4) tem-se:

$$
P T F=\frac{\mu_{t+1}}{\mu_{t}} \times \frac{f_{t+1}\left(x_{t+1}\right) / x_{t+1}}{f_{t}\left(x_{t}\right) / x_{t+1}}
$$


Se considerarmos o nível de insumo idêntico nos dois períodos $\left(x_{t}=x_{t+1}=x^{*}\right)$ tem-se o seguinte:

$$
P T F=\frac{\mu_{t+1}}{\mu_{t}} \times \frac{f_{t+1}\left(x^{*}\right)}{f_{t}\left(x^{*}\right)}
$$

Portanto, vê-se de (3.7) que a PTF pode ser decomposta em variação da eficiência técnica, $\left(\frac{\mu_{t+1}}{\mu_{t}}\right)$, e variação tecnológica, $\left(\frac{f_{t+1}\left(x^{*}\right)}{f_{t}\left(x^{*}\right)}\right)$. Se for permitida, agora variação na quantidade de $x$ multiplicando este por um fator maior que 1 (i.e., $\left.x_{t+1}=\xi x_{t+1}, \xi>1\right)^{15}$ tem-se que:

$$
P T F=\frac{\mu_{t+1}}{\mu_{t}} \times \xi^{\Psi(t+1)-1} \times \frac{f_{t+1}\left(x_{t+1}\right)}{f_{t}\left(x_{t}\right)},
$$

onde $\Psi$ é o grau de homogeneidade em $(t+1)$ de $f_{t+1}$

Desta forma, o novo termo $\left(\xi^{\Psi(t+1)-1}\right)$, representa a variação na escala de operação. Esta é a decomposição completa de um índice de PTF segundo Coelli, Rao e Battese (1998). Voltando as atenções novamente para o índice de Malmquist, Caves, Christensen e Diewert (1982), conforme já colocado, "traduziram" a linguagem deste índice da teoria do consumidor para a teoria da firma. Entretanto, na busca por um método que fosse consistente com a teoria dos números índices ${ }^{16}$, hipóteses de que todas as firmas são eficientes do ponto de vista técnico e alocativo além de uma tecnologia com retornos constantes de escala são impostas. Sua decomposição é a seguinte:

$$
M_{o}^{t}\left(y_{t}, y_{t+1}, x_{t}, x_{t+1}\right)=\frac{D_{o}^{t}\left(y_{t+1}, x_{t+1}\right)}{D_{o}^{t}\left(y_{t}, x_{t}\right)}
$$

onde $D_{o}^{t}$ representa a função distância produto-orientada e $m_{o}^{t}$ representa o índice com base na tecnologia do período t. Como Caves, Christensen e Diewert (1982) assumem eficiência técnica tem-se que o numerador da equação (3.9) é igual a 1. Assim, com a eficiência técnica

\footnotetext{
${ }^{15} \mathrm{O}$ raciocínio análogo pode ser feito para caso em que $\xi<1$.

${ }^{16}$ Caves, Christensen e Diewert (1982) mostram que se a tecnologia pode ser descrita por uma função Translog com os termos de segunda ordem idênticos para as firmas contempladas no estudo, o índice de Malmquist colapsa para o índice de Törnqvist.
} 
garantida e retornos de escala constantes levam o primeiro e o segundo termo da equação (3.8) a desaparecerem, respectivamente. Tal formulação, portanto, atribui toda variação da PTF a variações técnicas incorrendo no mesmo problema da contabilidade do crescimento.

Posteriormente, Färe et al. (1994), em estudo para PTF de 17 países pertencentes à OCDE, desenvolveram uma decomposição deste índice que permite abrir mão da eficiência técnica. Em sua definição o índice de Malmquist é mensurado através de uma média geométrica dos índices da equação (3.9) para os diferentes períodos de tempo contemplados na análise. Moorsteen (1961) mostra que a escolha do ano base afeta os resultados obtidos. Desta maneira, ao estabelecer a média geométrica, evita-se a escolha arbitrária de um ano base ${ }^{17}$. Färe et al. (1994) definem a seguinte fórmula:

$$
M_{o}\left(y_{t}, y_{t+1}, x_{t}, x_{t+1}\right)=\left[M_{o}^{t}\left(y_{t}, y_{t+1}, x_{t}, x_{t+1}\right) \times M_{o}^{t+1}\left(y_{t}, y_{t+1}, x_{t}, x_{t+1}\right)\right]^{0,5}
$$

Reescrevendo a equação acima tem-se:

$$
M_{o}\left(y_{t}, y_{t+1}, x_{t}, x_{t+1}\right)=\frac{D_{o}^{t+1}\left(y_{t+1}, x_{t+1}\right)}{D_{o}^{t}\left(y_{t}, x_{t}\right)} \times\left[\frac{D_{o}^{t}\left(y_{t+1}, x_{t+1}\right)}{D_{o}^{t+1}\left(y_{t+1}, x_{t+1}\right)} \times \frac{D_{o}^{t}\left(y_{t}, x_{t}\right)}{D_{o}^{t+1}\left(y_{t}, x_{t}\right)}\right]^{0,5}
$$

Como na fórmula de Färe et al. (1994) não se impõe a restrição de eficiência técnica, o primeiro termo não desaparece. Entretanto, as hipóteses de eficiência alocativa e tecnologia com retornos constantes de escala não são desprezadas.

A imposição de retornos constantes de escala à tecnologia de produção é, segundo GrifellTatjé e Lovell (1995), importante pois os índices de Malmquist, quando mensurados sob uma tecnologia com retornos variáveis, não fornecem valores adequados para a PTF.Os autores mostram que a PTF é superestimada quando os insumos aumentam na presença de retornos decrescentes e subestimada quando aumentam na presença de retornos crescentes. A direção do viés é revertida em ambos os casos quando se verifica uma contração na quantidade de insumos.

\footnotetext{
${ }^{17}$ Estabelecer a média geométrica é necessário apenas nos casos onde a tecnologia não é Hicks-Neutra, ou seja, a função de produção subjacente não apresenta homoteticidade.
} 
Portanto, se a tecnologia subjacente não apresentar retornos constantes de escala, as variações obtidas na PTF podem estar refletindo mudanças na escala ao invés de mudanças tecnológicas ou de eficiência. Além da importância atribuída aos índices, permitir que uma tecnologia tenha retornos não-crescentes torna a equação estimada seja consistente com hipótese de convexidade do conjunto de produção colocada anteriormente. Outro ponto relevante, conforme colocado por Färe, Grosskopf e Ross (1998), é que o índice de Malmquist quando derivado a partir de uma função de produção que não exibe retornos constantes de escala não apresentam transitividade. A transitividade em números índices (também chamada de propriedade de circularidade) determina que um número índice avaliado nos períodos $t_{1}$ e $t_{3}$ seja igual ao produto dos índices avaliado entre $t_{1}$ e $t_{2}$ e $t_{2}$ e $t_{3}$. Portanto tem-se:

$$
I\left(t_{1}, t_{3}\right)=I\left(t_{1}, t_{2}\right) \times I\left(t_{2}, t_{3}\right)
$$

Apesar da imposição de retornos constantes de escala ser necessária para que o índice de Malmquist não viole as hipóteses de circularidade e neutralidade quanto a escolha da base temporal, do ponto de vista da teoria econômica isto pode parecer bastante restritivo. Entretanto, parece haver evidências, como mostra Bjurek, Førsund e Hjalmarsson (1998), que caso se esteja interessado em valores médios (isto é, para a indústria) a escolha entre retornos constantes e retornos variáveis perde importância. Entretanto, caso o interesse repouse em índices individuais (isto é, para firmas) a diferença existente entre os retornos parece ser mais clara. Considerando este "trade-off" este estudo opta por adotar os retornos constantes de escala, ciente das limitações que tal escolha possa trazer à analise do ponto de vista teóricoanalítico. Além disto, o fato de impor retornos constantes de escala não significa que esta seja desconsiderada. Färe et al. (1994) decompõe o índice de Malmquist em mais um componente, além dos dois anteriormente apresentados, que é a variação na escala.

Este componente consiste na razão, para cada período, entre funções distâncias avaliadas sob tecnologia com retornos constantes à escala e sob retornos variáveis à escala. Assim este novo termo assume a seguinte forma:

$$
\frac{D_{o}^{t+1}\left(y^{t+1}, x^{t+1}\right)}{D_{V_{o}}^{t+1}\left(y^{t+1}, x^{t+1}\right)} \div \frac{D_{o}^{t}\left(y^{t}, x^{t}\right)}{D_{V_{o}}^{t}\left(y^{t}, x^{t}\right)},
$$


onde $D_{V_{o}}^{t+1}\left(y^{t+1}, x^{t+1}\right)$ denota a função de produção sob a hipótese de retornos variáveis à escala.

Esta decomposição, como pode ser observado, nada mais é que a comparação entre medida de ineficiência técnica entre as tecnologias com retornos constantes e retornos variáveis. Desta forma, o componente de variação da eficiência técnica se torna o produto entre (3.13) e um componente, chamado por Färe et al (1994) de variação pura da eficiência técnica, que é avaliado sob retornos variáveis:

(3.14) $\frac{D_{V_{o}}^{t+1}\left(y^{t+1}, x^{t+1}\right)}{D_{V_{o}}^{t}\left(y^{t}, x^{t}\right)}$

Verifica-se que o produto entre (3.13) e (3.14) fornece o primeiro termo da equação (3.11).

Uma vez apresentados os conceitos que formam a base deste estudo, o próximo passo se encarrega de explorar a metodologia quantitativa da Fronteiras Estocásticas de Produção que será empregada para a obtenção das variações na ineficiência técnica e na variação técnica necessárias para o cálculo do índice de Malmquist conforme sugerido por Färe et al. (1994). 


\section{4) Metodologia Quantitativa}

\section{1) Estimação de Fronteiras Estocásticas}

Este capítulo pauta-se por apresentar a metodologia quantitativa a ser empregada no estudo para o cálculo da eficiência e da produtividade da indústria farmacêutica. $\mathrm{O}$ método escolhido é o das fronteiras estocásticas de produção que permite a decomposição do resíduo em dois componentes: um termo de ineficiência e um choque puramente aleatório. Estes modelos foram introduzidos na literatura econômica, simultaneamente por Aigner, Lovell e Schmidt (1977) e Meeusen e van den Broeck (1977) com a seguinte especificação para dados em Cross-Section:

(4.1) $\ln y_{i}=\beta_{0}+f\left(\beta_{k}, x_{i}^{k}\right)+v_{i}-u_{i}, \quad i=1, \ldots, I ; k=1, \ldots, n$,

onde:

$\ln y_{i t}$ é o logaritmo da quantidade produzida pela firma $i$;

$\beta_{0}$ é o intercepto da equação;

$f\left(\beta_{k}, x_{i}^{k}\right)$ é a forma funcional adequada;

$\beta_{k}$ é o vetor de coeficientes tecnológicos;

$x_{i}^{k}$ é o vetor de insumos utilizado na produção pela firma $i$;

$v_{i}$ é o choque aleatório não correlacionado com $x_{i}^{k}$ e $u_{i}$ e com

distribuição $N\left(0, \sigma_{v}^{2}\right)$;

$u_{i}$ é o termo de ineficiência não negativo da firma $i$ também não correlacionado $\operatorname{com} x_{i}^{k}$.

Posteriormente, Pitt e Lee (1981) especificaram o modelo de Aigner, Lovell e Schmidt (1977) para dados em painel. Assim, a função de produção assume a seguinte forma:

$$
\ln y_{i t}=\beta_{0}+f\left(\beta_{k}, x_{i t}^{k}\right)+v_{i t}-u_{i t}, \quad i=1, \ldots, I ; k=1, \ldots, n, t=1, \ldots, T,
$$


sendo que todas as hipóteses para (4.1) são válidas para (4.2).

Para a estimação dos coeficientes tecnológicos das fronteiras estocásticas de produção são empregados os estimadores de máxima verossimilhança ${ }^{18}$. É necessário que se assuma hipóteses distributivas sobre o termo de ineficiência $u_{i t}$. Diversas distribuições assimétricas têm sido utilizadas para o termo $u_{i t}$. As mais populares são a distribuição semi-normal, distribuição normal-truncada, distribuição exponencial e distribuição gama. Neste estudo, o modelo a ser implementado é de Battese e Coelli (1995) ${ }^{19}$ que desenvolveram uma metodologia de estimação para painéis desbalanceados que utiliza uma distribuição normaltruncada, pioneiramente implementada por Stevenson (1980), para o termo de ineficiência $u_{i t}{ }^{20}$. A escolha da normal-truncada está baseada na flexibilidade que esta traz em relação a formas funcionais mais simples como a semi-normal ou a exponencial. A normal-truncada consiste na truncagem de uma distribuição normal com média $\mu$ e variância $\sigma^{2}$ em zero enquanto a distribuição semi-normal é a truncagem em zero de uma normal $\left(0, \sigma^{2}\right)$. Neste prisma, a distribuição semi-normal torna-se um caso particular da normal truncada (i.e, quando $\mu=0$ ). A distribuição gama também é uma distribuição considerada flexível e sua relação com a distribuição exponencial é análoga àquela entre normal-truncada e a seminormal $^{21}$.

O modelo especificado por Battese e Coelli (1995) também permite a variação da ineficiência técnica no tempo ${ }^{22}$. Sendo assim, considere a equação:

\footnotetext{
18 Outros estimadores podem utilizados para o cálculo dos coeficientes. Aqui se opta pela máxima verossimilhança por ser esta uma metodologia consolidada literatura sobre ineficiência técnica, além de possuir propriedades interessantes sobre os demais estimadores. Como não é do escopo deste trabalho dissertar sobre as diversas metodologias possíveis para a estimação de fronteiras estocásticas, sugere-se ao leitor interessado que verifique Kumbhakar e Lovell (2000).

${ }^{19}$ Resultados do modelo implementado em Battese \& Coelli também são reportados.

${ }^{20}$ Para detalhes de estimações com distribuição semi-normal ou exponencial, sugere-se o artigo seminal de Aigner, Lovell e Schmidt (1977). Para o leitor interessado em estimações usando distribuições gama sugere-se Greene (1990).

${ }^{21}$ A escolha da normal truncada em detrimento da gama se deve ao fato desta última gerar uma função de verossimilhança de difícil maximização para o termo de erro composto, $\varepsilon$, conforme argumentam Coelli, Rao e Battese (1998) e Ritter e Simar (1997). Estes últimos chamam a atenção, também, para a mesma dificuldade na distribuição normal-truncada. Coelli, Rao e Battese (1998) argumentam que a normal-truncada parece sofrer menos problemas computacionais que a gama.

${ }^{22}$ De maneira diferente da especificação para dados em Cross-Section, a especificação para dados em painel permite que o termo $u_{i t}$ varie entre firmas e no tempo. Aqui se opta por esta metodologia por acreditar não haver motivos razoáveis para a imposição de uma restrição de ineficiência fixa no tempo. Além disto, segundo Battese e Coelli (1995) o modelo de ineficiência fixa é um caso particular do modelo aqui aplicado. Isto ocorre quando os coeficientes associados à ineficiência são iguais a zero.
} 


$$
\ln y_{i t}=\beta_{0}+f\left(\beta_{k}, x_{i t}^{k}, t\right)+\varepsilon_{i t}, \quad i=1, \ldots, I ; k=1, \ldots, n, t=1, \ldots, T
$$

onde,

$t$ é variável tempo que mensura o deslocamento da função ao longo do período em análise;

$\varepsilon_{i t}=v_{i t}-u_{i t}$

$v_{i t}$ é o choque aleatório iid $N\left(0, \sigma_{v}^{2}\right)$ não correlacionado com $x_{i t}^{k}$ e $u_{i t}$;

$u_{i t} \sim N^{+}\left(z_{i t} \delta, \sigma_{u}^{2}\right)$ é o termo de ineficiência não negativo da firma $i$ no período $t$

também não correlacionado com $x_{i t}^{k}$;

$z_{i t} \boldsymbol{\delta}$, a média da ineficiência, é composta pelo vetor de variáveis específicas das

firmas $z_{i t}$ e $\delta$ o vetor de coeficientes associados a essas variáveis.

O termo de ineficiência é modelado da seguinte maneira:

$$
u_{i t}=z_{i t} \boldsymbol{\delta}+w_{i t}
$$

O termo $w_{i t}$ é uma variável correspondente a truncagem de uma normal com média zero e variância $\boldsymbol{\sigma}_{u}^{2}$ no ponto $\left(-z_{i t} \boldsymbol{\delta}\right)$,ou seja, $w_{i t} \geq\left(-z_{i t} \boldsymbol{\delta}\right)$.

A forma funcional aqui aplicada é a Flexível de Fourrier que é uma aproximação global que inclui os termos padrões de uma trans-log mais os termos trigonométricos de Fourrier. A equação a equação (4.3), portanto, se transforma em:

(4.5) $\ln y_{i t}=\boldsymbol{\beta}_{0}+\boldsymbol{\beta}_{t} t+\boldsymbol{\beta}_{t t} t^{2} \sum_{k=1}^{n} \boldsymbol{\beta}_{k} \ln x_{i t}^{k}+\sum_{j \leq k} \sum_{k=1}^{n} \boldsymbol{\beta}_{j k} \ln x_{i t}^{j} \ln x_{i t}^{k}+\sum_{k=1}^{n} \boldsymbol{\beta}_{k t} \ln x_{i t}^{k} t+$ $\sum_{k=1}^{n}\left[\phi_{k} \cos \left(h_{k}\right)+\boldsymbol{\omega}_{k} \operatorname{sen}\left(h_{k}\right)\right]+\sum_{k=1}^{n} \sum_{q=k}^{n}\left[\phi_{k q} \cos \left(h_{k}+h_{q}\right)+\boldsymbol{\omega}_{k q} \operatorname{sen}\left(h_{k}+h_{q}\right)\right]+v_{i t}-u_{i t}$, $i=1, \ldots, I ; k=1, \ldots, n, t=1, \ldots, T$

Conforme Berger e Mester (1997), esta forma funcional é uma aproximação global pelo fato dos termos $\cos \left(h_{k}\right), \operatorname{sen}\left(h_{k}\right), \cos \left(h_{k}+h_{q}\right)$ e $\operatorname{sen}\left(h_{k}+h_{q}\right)$ são mutuamente ortogonais no intervalo $[0 ; 2 \pi]$ aproximando a função a ser estimada de seu verdadeiro caminho. Neste 
estudo é seguida a sugestão dos autores para o corte de $10 \%$ de cada cauda do intervalo $[0 ; 2 \pi]$ evitando-se, desta maneira, problemas de aproximação nas fronteiras do intervalo. Desta forma, os termos $h_{k}$ são calculados seguindo a fórmula:

(4.6) $h_{k}=0,2 \times \boldsymbol{\pi}-\boldsymbol{\mu} \times a+\boldsymbol{\mu} \times x_{k}$.

Sendo [a,b] o intervalo transformado em radianos e $\mu \equiv(0,9 \times 2 \pi-0,1 \times 2 \pi) /(b-a)$. Portanto, para obter as estimativas dos parâmetros da equação acima por máxima verossimilhança, basta maximizar a função de verossimilhança de $\varepsilon_{i t}$.

Portanto, para obter as estimativas dos parâmetros da equação acima por máxima verossimilhança, basta maximizar a função de verossimilhança de $\boldsymbol{\varepsilon}_{i t}$. Para tal, é preciso conhecer a distribuição de $\boldsymbol{\varepsilon}_{i t}$.

Sendo $v_{i t}$ e $u_{i t}$ independentes com suas respectivas distribuições conhecidas, a distribuição conjunta $v_{i t}$ e $u_{i t}$ é dada por $f\left(v_{i t}, u_{i t}\right)=f\left(u_{i t}\right) \times f\left(v_{i t}\right)$ e desde que $\varepsilon_{i t}=v_{i t}-u_{i t}$ tem-se que $f\left(v_{i t}, u_{i t}\right)=f\left(u_{i t}+\varepsilon_{i t}, u_{i t}\right)=f\left(\varepsilon_{i t}, u_{i t}\right)$. A função de distribuição conjunta assume, portanto, a seguinte forma:

$$
f(\boldsymbol{\varepsilon}, u)=\frac{e^{-\frac{1}{2}\left\{\left[\frac{(\varepsilon+u)^{2}}{\sigma_{v}}\right]+\left[\frac{(u-z \delta)^{2}}{\sigma_{u}}\right]\right\}}}{2 \pi \sigma_{u} \sigma_{v} \Phi\left(z \boldsymbol{\delta} / \boldsymbol{\sigma}_{u}\right)} \text { ou, alternativamente }
$$

$$
f(\varepsilon, u)=\frac{e^{\left.-\frac{1}{2}\left\{\left[\frac{\left(u-\mu_{*}\right)^{2}}{\sigma_{*}^{2}}\right]+\left[\frac{(\varepsilon-z \delta)^{2}}{\left(\sigma_{v}^{2}+\sigma_{u}^{2}\right.}\right]\right]\right\}}}{2 \pi \sigma_{u} \sigma_{v} \Phi\left(z \boldsymbol{\delta} / \boldsymbol{\sigma}_{u}\right)}
$$

onde:

$$
\begin{aligned}
& \boldsymbol{\mu}_{*}=\frac{\boldsymbol{\sigma}_{v}^{2} z \boldsymbol{\delta}-\boldsymbol{\sigma}_{u}^{2} \boldsymbol{\varepsilon}}{\boldsymbol{\sigma}_{v}^{2}+\boldsymbol{\sigma}_{u}^{2}} \\
& \boldsymbol{\sigma}_{*}^{2}=\frac{\boldsymbol{\sigma}_{u}^{2} \boldsymbol{\sigma}_{v}^{2}}{\boldsymbol{\sigma}_{v}^{2}+\boldsymbol{\sigma}_{u}^{2}}
\end{aligned}
$$


e $\Phi\left(z \boldsymbol{\delta} / \boldsymbol{\sigma}_{u}\right)$ é a função de distribuição acumulada da normal padrão avaliada no ponto $\left(z \delta / \sigma_{u}\right)$.

O passo seguinte é obter a distribuição do erro idiossincrático $\varepsilon$. Para tal integra-se a função descrita em (4.7b) com respeito a $u: f(\varepsilon)=\int_{0}^{\infty} f(\varepsilon, u) d u$. Resolvendo esta integração tem-se:

$$
f(\boldsymbol{\varepsilon})=\frac{e^{\left\{-\frac{1(\boldsymbol{\varepsilon}+z \boldsymbol{\delta})^{2}}{2}\left(\boldsymbol{\sigma}_{v}^{2}+\boldsymbol{\sigma}_{u}^{2}\right)\right\}}}{\sqrt{2 \pi}\left(\boldsymbol{\sigma}_{v}^{2}+\boldsymbol{\sigma}_{u}^{2}\right)^{0,5}\left[\Phi\left(z \boldsymbol{\delta} / \boldsymbol{\sigma}_{u}\right) / \Phi\left(\boldsymbol{\mu}_{*} / \boldsymbol{\sigma}_{*}\right)\right]},-\infty \leq \boldsymbol{\varepsilon} \leq \infty
$$

As estimativas dos parâmetros são obtidas a partir maximização do logaritmo da função de verossimilhança dada a seguir ${ }^{23}$ :

$$
\begin{aligned}
L\left(\boldsymbol{\beta}, \boldsymbol{\delta}, \boldsymbol{\sigma}_{u}, \boldsymbol{\sigma}_{v}\right)= & -\frac{1}{2}\left(\sum_{i=1}^{N} T_{i}\right)\left\{\ln 2 \pi+\ln \boldsymbol{\sigma}_{s}^{2}\right\}-\frac{1}{2} \sum_{i=1}^{N} \sum_{t=1}^{T_{i}}\left\{\left(y_{i t}-x_{i t} \boldsymbol{\beta}+z_{i t} \boldsymbol{\delta}\right)^{2} / \boldsymbol{\sigma}_{s}^{2}\right\} \\
& -\sum_{i=1}^{N} \sum_{t=1}^{T_{i}}\left\{\ln \Phi\left(d_{i t}\right)-\ln \Phi\left(d_{i t}^{*}\right)\right\}
\end{aligned}
$$

onde:

$$
\begin{aligned}
& d_{i t}=z_{i t} \boldsymbol{\delta} /\left(\gamma \boldsymbol{\sigma}_{s}^{2}\right)^{0,5} \\
& d_{i t}^{*}=\boldsymbol{\mu}_{i t}^{*} /\left[\gamma(1-\gamma) \boldsymbol{\sigma}_{s}^{2}\right]^{0,5} \\
& \boldsymbol{\mu}_{i t}^{*}=(1-\boldsymbol{\gamma}) z_{i t} \boldsymbol{\delta}-\boldsymbol{\gamma}\left(y_{i t}-x_{i t} \boldsymbol{\beta}\right)
\end{aligned}
$$

Sendo, $\sigma_{s}^{2} \equiv \sigma_{u}^{2}+\sigma_{v}^{2}$ e $\gamma \equiv \sigma_{u}^{2} / \sigma_{s}^{2}$. Esta ultima reparametrização torna-se bastante útil ao permitir a verificação da relevância do termo de ineficiência. Assim, se o termo $\gamma$ converge para 1 o termo de ineficiência predomina o erro idiossincrático. Já quando $\gamma$ converge para zero, a ineficiência torna-se irrelevante para explicar o termo $\varepsilon$. Neste último caso, as firmas são, portanto, tecnicamente eficientes e o índice de Malmquist apresentado na fórmula (3.11) passa a possuir apenas o segundo termo, isto é, a produtividade passa a ser explicada apenas

\footnotetext{
${ }^{23} \mathrm{O}$ leitor interessado em obter as formas das derivadas primeiras deve consultar Battese e Coelli (1995).
} 
pelos choques tecnológicos. Neste prospecto, o emprego da técnica de fronteira estocástica não traz ganhos sendo, desta forma, plausível a aplicação de mínimos quadrados ordinários ${ }^{24}$.

Caso não se rejeite a hipótese da existência de ineficiência técnica, obtêm-se as estimativas desta a partir da distribuição condicional de $u_{i t}$ em $\varepsilon_{i t}$. Ou seja, as estimativas são obtidas a partir de:

$$
E\left(e^{u_{i t}} \mid \boldsymbol{\varepsilon}_{i t}\right)=\int e^{u_{i t}} f_{u \mid \boldsymbol{\varepsilon}}(u \mid \boldsymbol{\varepsilon}) d u
$$

Resolvendo a equação acima tem-se:

$$
E\left(e^{u_{i t}} \mid \boldsymbol{\varepsilon}_{i t}\right)=\left\{\exp \left[-\boldsymbol{\mu}_{*}+\frac{1}{2} \boldsymbol{\sigma}_{*}^{2}\right]\right\}\left\{\Phi\left[\left(\boldsymbol{\mu}_{*} / \boldsymbol{\sigma}_{*}\right)-\boldsymbol{\sigma}^{*}\right] / \Phi\left(\boldsymbol{\mu}_{*} / \boldsymbol{\sigma}_{*}\right)\right\}
$$

Antes de prosseguir para próxima seção, é importante ressaltar alguns pontos sobre as formas existentes na literatura de fronteiras estocásticas acerca do termo de ineficiência.

Uma primeira classe de estimadores para a ineficiência é a dos estimadores invariantes no tempo. O trabalho pioneiro de Pitt e Lee (1981) apresenta um estimador para dados em painel cujo termo de ineficiência se distribui por uma Semi-Normal. Posteriormente, Kumbhakar (1987) e Battese e Coelli (1988) desenvolveram modelos apoiados na distribuição NormalTruncada $^{25}$.

Os estimadores de ineficiência fixa no tempo são desconsiderados neste estudo por não permitirem a aplicação da fórmula da PTF conforme descrita na equação (3.11). Ademais, a ineficiência fixa no tempo torna-se cada vez menos plausível à medida que o leque temporal dos dados se expande. Outra observação a ser realizada é que os modelos que consideram a ineficiência fixa no tempo constituem um caso particular dos modelos onde estas variam no tempo.

\footnotetext{
${ }^{24}$ A aplicação de mínimos quadrados parte do pressuposto de que não existe correlação entre o termo residual e a matriz de variáveis independentes $\mathbf{X}$. Se esta hipótese não puder ser sustentada, então torna-se necessário o uso de estimadores de efeito fixo ou mínimos quadrados de dois estágios.

${ }^{25}$ Há, ainda, estimadores do tipo Mínimos Quadrados Corrigidos que consideram possíveis efeitos fixos ou efeitos aleatórios para a ineficiência. Maiores detalhes destes estimadores podem ser vistos na seção a seguir. Sugere-se, entretanto, ao interessado, Kumbhakar e Lovell (2000).
} 
Partindo para a análise dos modelos de ineficiência variante no tempo, diversos modelos são sugeridos na literatura com a seguinte forma: $u_{i t}=\boldsymbol{\beta}(t) u_{i}$. Sendo $\beta(t)$ uma função monótona no tempo e $u_{i}$ o termo de ineficiência para a firma $i$ no primeiro ano da série. Dentro desta classe de modelos, os mais populares são os formulados por Kumbhakar (1990) e Battese e

Coelli (1992). Suas formulações são, respectivamente: $\boldsymbol{\beta}(t)=\left[1+\exp \left(\kappa t+\omega t^{2}\right)\right]^{-1}$ e $\boldsymbol{\beta}(t)=\exp [-\boldsymbol{\kappa}(t-T)]$. Estas funções podem ser crescentes ou decrescentes de acordo com os valores obtidos dos parâmetros estimados $\kappa$ e $\omega$. A desvantagem desta modelagem encontra-se no fato de todas as firmas exibirem o mesmo padrão de comportamento ao longo do tempo: elas convergem ou divergem, em conjunto, da fronteira. Além disto, este tipo de modelagem não permite também a alternância de posições no ranking de eficiência. Cuesta (2000) desenvolveu uma modelagem que permite relaxar a convergência em bloco das firmas através da estimação de parâmetros individuais. Sua fórmula é dada por: $\boldsymbol{\beta}(t)=\exp \left[-\boldsymbol{\kappa}_{i}(t-T)\right]$. Embora este modelo contorne o a convergência em bloco, ele não permite a alternância das firmas e impõe a elas um padrão fixo no tempo, isto é: ou as firmas, individualmente, convergem para fronteira ou divergem desta. Além disto, à medida que número de firmas cresce na amostra, cresce também o número de parâmetros $\kappa_{\mathrm{i}}$ a serem estimados. Portanto, este modelo pode se tornar impraticável à medida que $I \rightarrow \infty$.

Uma vez explicitado o método econométrico a ser aplicado, o passo seguinte é verificar algumas das vantagens, deficiências e críticas ao mesmo além de apresentar métodos alternativos para o cálculo de produtividade.

\section{2) Vantagens, Deficiências e Críticas à Metodologia de Fronteiras Estocásticas e Métodos Alternativos.}

Quando se escolhe um método econométrico, deve-se avaliar as vantagens existentes entre a escolha feita e as alternativas possíveis. A primeira questão que se coloca é porque não utilizar mínimos quadrados ordinários (MQO). Conforme colocam Kumbhakar e Lovell (2000), o estimador de mínimos quadrados, apesar de ser consistente para o vetor de 
coeficientes tecnológicos é inconsistente para o intercepto da equação a ser estimada ${ }^{26}$. Além disto, tal metodologia não permite a existência de ineficiência técnica, atribuindo toda variação na produção que possa ser explicada por variação dos insumos a choques aleatórios. Nesta situação, caso não haja presença de ineficiência MQO é o estimador mais adequado para a função de produção, levando os índices de produtividade a captarem somente a variação tecnológica. Assim, MQO assume firmas plenamente eficientes enquanto a metodologia de fronteiras estocásticas não assume esta hipótese.

Outro ponto importante é a escolha arbitrária de uma distribuição para a ineficiência. Muito embora haja distribuições flexíveis que não impõem restrições sobre a média da ineficiência, esta pode sofrer alterações de acordo com distribuição escolhida. Entretanto, há evidências de que a posição relativa das empresas no ranking de eficiências não é muito sensível à forma distributiva como mostra Greene (1990). Neste mesmo estudo, o autor mostra que, para 123 geradoras de eletricidade dos Estados Unidos, as médias das distribuições não variam abruptamente. Seus resultados reportam valores médios de ineficiências iguais a 0,8766 para a distribuição semi-normal, 0,8949 para a distribuição gama, 0,8961 para a distribuição normal truncada e 0,9011 para a exponencial.

Uma deficiência da metodologia de fronteira estocástica obtida a partir de estimadores de máxima verossimilhança é não permitir a correlação entre a ineficiência $\left(u_{i t}\right)$ e a matriz de regressores. Assim, a ineficiência não pode possuir covariância com a demanda por fatores. Caso a endogeneidade seja atribuída a fatores fixos no tempo mas variantes na Cross-Section, pode-se aplicar um método de estimação por efeitos fixos. Cornwell, Schmidt e Sickles (1990) apud Kumbhakar (1990) propõem a seguinte equação para o termo de ineficiência:

$$
u_{i t}=\Omega_{0 i}+\Omega_{1 i} t+\Omega_{2 i} t^{2}
$$

onde $\left(\Omega_{0}, \Omega_{1}, \Omega_{2}\right)$ são parâmetros específicos da firma levando a equação (4.4) a ser reespecificada para:

\footnotetext{
${ }^{26}$ Kumbhakar (1990) argumenta que caso se esteja utilizando dados em painel e a ineficiência for variante no tempo, o estimador de MQO será inconsistente para os coeficientes da matriz de regressores. Além disto, o autor argumenta que esta inconsistência pode ser evitada usando-se máxima verossimilhança.
} 
(4.13)

$$
\begin{aligned}
\ln y_{i t} & =\sum_{k=1}^{n} \boldsymbol{\beta}_{k} \ln x_{i t}^{k}+\sum_{j \leq k} \sum_{k=1}^{n} \boldsymbol{\beta}_{j k} \ln x_{i t}^{j} \ln x_{i t}^{k}+\sum_{k=1}^{n} \boldsymbol{\beta}_{k t} \ln x_{i t}^{k} t \\
& +\Lambda_{0 i}+\Lambda_{1 i} t+\Lambda_{2 i} t^{2}+v_{i t} \\
& i=1, \ldots, I ; k=1, \ldots, n, t=1, \ldots, T
\end{aligned}
$$

tem-se assim que:

$$
\Lambda_{0 i}=\boldsymbol{\beta}_{0}+\Omega_{0 i} \text { e } \Lambda_{1 i}=\boldsymbol{\beta}_{t}+\Omega_{1 i}
$$

Note que com esta especificação, a variável tempo $(t)$ usada como proxy para a variação técnica não faz mais parte do vetor de variáveis explicativas. Esta passa a ser incorporada pela ineficiência técnica. Para obter as estimativas de ineficiência técnica, relativas à firma mais eficiente, procede-se da seguinte maneira:

$$
T E_{i t}=\left(\hat{\Lambda}_{0 i}+\hat{\Lambda}_{1 i} t+\hat{\Lambda}_{2 i} t^{2}\right)-\max _{i}\left(\hat{\Lambda}_{0 i}+\hat{\Lambda}_{1 i} t+\hat{\Lambda}_{2 i} t^{2}\right), \quad i=1, \ldots, I ; t=1, \ldots, T
$$

Portanto, esta metodologia realiza o controle para efeitos fixos além de não assumir hipóteses distributivas ${ }^{27}$. Entretanto, isto é obtido ao custo de não ser possível separar o efeito do choque tecnológico da ineficiência no uso dos recursos e, portanto, não permite aplicação do índice de Malmquist apresentado na equação (3.11). Outro ponto criticado desta metodologia é, segundo Cuesta (2000), o fato deste estimador ponderar as firmas eficientes e ineficientes da mesma maneira ao passo que a máxima verossimilhança atribui mais peso as firmas eficientes.

Greene (2005) mostra que é possível considerar a presença de efeitos fixos no contexto de estimadores de máxima verossimilhança com a inclusão de dummies de indivíduo na equação principal. Assim o modelo é descrito pela equação:

$$
\begin{gathered}
\ln y_{i t}=\boldsymbol{\alpha}_{i}+\sum_{k=1}^{n} \boldsymbol{\beta}_{k} \ln x_{i t}^{k}+\sum_{j \leq k} \sum_{k=1}^{n} \boldsymbol{\beta}_{j k} \ln x_{i t}^{j} \ln x_{i t}^{k}+\sum_{k=1}^{n} \boldsymbol{\beta}_{k t} \ln x_{i t}^{k} t+\boldsymbol{\beta}_{t} t+ \\
\boldsymbol{\beta}_{t t} t^{2}+v_{i t}-u_{i t}, \quad i=1, \ldots, I ; k=1, \ldots, n, t=1, \ldots, T
\end{gathered}
$$

\footnotetext{
${ }^{27}$ Assumir hipóteses distributivas acerca do termo de ineficiência também pode ser considerada uma restrição desta metodologia. Mais adiante, serão feitas considerações sobre os métodos não paramétricos que não assumem tal restrição.
} 
onde $\alpha_{i}$ é o intercepto de indivíduo.

Segundo o autor, este modelo tem sido pouco aplicado na literatura uma vez que pode se tornar impraticável à medida que $I \rightarrow \infty$. Um problema ainda levantado por Greene (2005) é o fato do estimador de efeitos fixos ser inconsistente para pequenas amostras do ponto de vista temporal. Assim, para um $T$ "pequeno" há, segundo o autor, o problema dos parâmetros incidentais que parece afetar mais a variância dos estimadores do que as declividades do modelo conforme método de Monte Carlo realizado ${ }^{28}$. Uma vez que os parâmetros $\sigma_{s}$ e $\gamma$ são cruciais para os resultados do modelo, o uso deste método pode levar a consideráveis vieses. Desta forma, o pesquisador se defronta com duas alternativas: a inclusão de dummies de indivíduo, ciente do problema dos parâmetros incidentais, ou assumir a inexistência dos efeitos fixos.

Outro ponto a ser colocado é uma possível heterogeneidade não observada da ineficiência ou do choque puramente aleatório. Conforme argumenta Kumbhakar e Lovell (2000) caso isto ocorra as estimativas por máxima verossimilhança tornam-se impraticáveis uma vez que há uma variância a ser estimada para cada observação da amostra (para o caso de heterocedasticidade no tempo e na cross-section). Entretanto, os autores argumentam que, para o caso de heterogeneidade não observada em $u_{i t}$, uma extensão do modelo proposto por Battese e Coelli (1995) pode ser utilizada para "contornar" este problema. Neste caso, modela-se a variância do termo de ineficiência $u_{i t}$. Assim, tem-se que $\sigma_{\text {uit }}^{2}=\alpha z_{i t}$, onde $z_{i t}$ são variáveis não correlacionadas com a matriz de regressores $\mathbf{X}$ uma vez que, por hipótese, o termo de ineficiência é independente da demanda por insumos.

Assumir a exogeneidade dos regressores ao estimar funções de produção pode ser problemático uma vez que a demanda por insumos pode estar correlacionada com a eficiência da firma. Assim para as firmas mais ineficientes, torna-se mais atrativo, no longo prazo, liquidar seus ativos e retirar-se do mercado. Desta forma, a produtividade está positivamente correlacionada com a demanda de insumos. Tal questão pode ser mais visível quando se trabalha com dados em painel. As firmas, neste caso, podem desaparecer da amostra tanto por fatores aleatórios quanto por liquidação dos seus ativos. Sendo assim, a metodologia de

\footnotetext{
${ }^{28}$ Ver Greene, W. (2005), "Reconsidering heterogeneity in panel data estimators of the stochastic frontier model", Journal of Econometrics, v. 126, pp 282-283.
} 
Fronteiras Estocásticas, ao não considerar tal possibilidade, abre espaço para a existência de viés de seleção. Uma solução para tal é a aplicação do algoritmo de Olley e Pakes (1996) ${ }^{29}$.

Neste estudo, os autores desenvolvem um modelo que considera a possibilidade da firma retirar-se do mercado atenuando, assim, o viés de seleção. O modelo parte de uma função de produção do tipo $\mathrm{y}_{\mathrm{it}}=f\left(\beta x_{\mathrm{it}}, \alpha q_{\mathrm{it}}\right)+\mu_{\mathrm{it}}$, onde $\mathrm{y}_{\mathrm{it}}$ é a quantidade de produto da firma i no período t, $x_{\mathrm{it}}$ é o vetor de insumos variáveis, $q_{\mathrm{it}}$ é o vetor de insumos fixos e quase-fixos, $\beta$ é o vetor de coeficientes tecnológicos dos insumos variáveis, $\alpha$ é o vetor de coeficientes tecnológicos dos insumos fixos e quase-fixos e $\mu_{\text {it }}$ é o termo residual que pode ser decomposto da seguinte maneira: $\mu_{\mathrm{it}}=\omega_{\mathrm{it}}+\varepsilon_{\mathrm{it}}$, sendo $\omega_{\mathrm{it}}$ um termo de eficiência produtiva não observado e $\varepsilon_{\mathrm{it}} \mathrm{um}$ choque aleatório. A firma, portanto, busca maximizar seu fluxo de lucro presente e futuro e decide, a cada período, se vai produzir ou deixar o mercado.

O ponto crucial desta metodologia é supor que o termo não observável $\omega_{\text {it }}$, é variável explicativa de uma função de demanda de insumos. Assumindo que a produtividade não observada $\omega_{\text {it }}$ segue um processo de Markov de $1^{\circ}$ ordem: $\omega_{\text {it }}=\omega_{\text {it- } 1}+\tau_{\text {it }}$ e que a demanda por insumos possui declividade sempre positiva em $\omega_{i t}$, é possível a construção de uma função inversa tendo $\omega_{i t}$ como variável dependente e as variáveis observáveis de insumos. Uma suposição deste modelo é que as quantidades demandadas de insumos $x_{\text {it }}$ se ajustam prontamente às variações em $\omega_{\text {it }}$ ao passo que $q_{\text {it }}$ leva mais tempo devidos aos custos de ajustamento. Considerando a função de demanda de insumos $d_{i t}=h\left(x_{\mathrm{it}}, q_{\mathrm{it}}, \omega_{\mathrm{it}}\right)$ e sua inversa $\omega_{\mathrm{it}}=h^{-1}\left(x_{\mathrm{it}}, q_{\mathrm{it}}, d_{i t}\right)$, tem-se que a função de produção toma a seguinte forma: $\mathrm{y}_{\mathrm{it}}=g\left(x_{\mathrm{it}}, q_{\mathrm{it}}, d_{i t}\right)$ $+\varepsilon_{\mathrm{it}}$. A função $g\left(x_{\mathrm{it}}, q_{\mathrm{it}}, d_{i t}\right)$ é composta pela soma das funções $f\left(\beta x_{\mathrm{it}}, \alpha q_{\mathrm{it}}\right)+h^{-1}\left(x_{\mathrm{it}}, q_{\mathrm{it}}, d_{i t}\right)$ sendo esta uma aproximação de um polinômio composto pelas variáveis observáveis. Assim, estimar a função $g\left(x_{\mathrm{it}}, q_{\mathrm{it}}, d_{i t}\right)$ é primeiro passo para a implementação desta metodologia ${ }^{30}$.

Como o termo de eficiência produtiva segue uma cadeia de Markov de $1^{\mathrm{o}}$ ordem, tem-se que $\mathrm{E}\left(\omega_{\mathrm{it}} \mid \omega_{\mathrm{it}-1}\right)=s\left(\omega_{\mathrm{it}-1}\right)+\tau_{\mathrm{it}}$. Desta forma, pode-se escrever: $s\left(\omega_{\mathrm{it}-1}\right)=s\left(h^{-1}\left(x_{\mathrm{it}-1}, q_{\mathrm{it}-1}, d_{i t-1}\right)\right) \equiv$ $s\left(g\left(x_{i t}, q_{i t}, d_{i t}\right)-f\left(\beta x_{i t}, \alpha q_{i t}\right)\right)$. Por fim, com os valores de $g\left(x_{\mathrm{it}}, q_{\mathrm{it}}, d_{i t}\right)$ estimados anteriormente, estima-se a função de produção $\mathrm{y}_{\mathrm{it}}=f\left(\beta x_{\mathrm{it}}, \alpha q_{\mathrm{it}}\right)+s\left(g\left(x_{i t}, q_{i t}, d_{i t}\right)-f\left(\beta x_{i t}, \alpha q_{i t}\right)\right)+\tau_{\mathrm{it}}+\varepsilon_{\mathrm{it}}$ por

\footnotetext{
${ }^{29}$ Ver Olley e Pakes (1996), "The Dynamics of Productivity in the Telecomunications Equipement Industry", Econometrica V.64, 1263-1297.

${ }^{30}$ Para maiores detalhes desta aproximação e da estimação sugere-se Olley e Pakes (1996) e Pavcnick (2000).
} 
mínimos quadrados não lineares. Além de considerar o efeito da auto- seleção na amostra, este método não impõe hipóteses distributivas sobre os resíduos da função de produção.

A não opção por pelo algoritmo de Olley e Pakes (1996) se deve ao fato desta metodologia não permitir de maneira direta a modelagem do termo de ineficiência além do fato de ter sido desenvolvida para o controle de um viés de seleção oriundo da liquidação dos ativos de uma determinada firma. Observaram-se nos dados disponíveis poucas ocorrências de firmas que se retiraram do mercado. A maior parte das firmas que desapareciam da amostra o faziam em função de processos de fusões, aquisições e cisões.

Em grande medida, tais fusões, aquisições e cisões ocorriam, com empresas transnacionais cujos processos se deram em escala mundial e, conforme colocado no capítulo 2, McKelvey e Orsenigo (2001) argumentam que os fatores que levam a tais fusões são determinados, primordialmente, por atributos inerentes à fase de $\mathrm{P} \& \mathrm{D}$ (ao passo que este estudo se encarrega de avaliar a fase de produção de medicamentos) que leva a crer que estas decisões não sofreram ou foram parcialmente influenciadas pela produtividade local. Para lidar com isto, talvez fosse necessária uma adaptação do algoritmo que contemplasse estes casos.

O pesquisador preocupado com a imposição das distribuições de probabilidade sobre os termos de ineficiência e erro idiossincrático pode, também fazer uso de métodos de estimação não paramétricos. Os mais difundidos na literatura são o Data Envelopment Analisys (DEA) e o Free Disposal Hull (FDH).

O DEA é um método de programação linear que realiza uma "envoltória" nos dados de maneira que o conjunto de produção seja convexo, sendo a distância da firmas abaixo da fronteira a medida de ineficiência. Tal método não assume a possibilidade de haver choques aleatórios no processo produtivo atribuindo todo desvio de uma firma em relação a fronteira à ineficiência. Originalmente, Charnes, Cooper e Rhodes (1978) propuseram um modelo insumo-orientado com retornos constantes de escala. Assim o cálculo da fronteira de produção, a partir do modelo de Charnes, Cooper e Rhodes (1978), é realizado resolvendo o seguinte problema de maximização: 


$$
\text { (4.17) } \begin{aligned}
& \operatorname{Max}_{u, v}\left(u^{\prime} y_{i} / v^{\prime} x_{i}\right) \\
& \text { S.a }\left(u^{\prime} y_{i} / v^{\prime} x_{i}\right) \leq 1 \\
& u, v \geq 0
\end{aligned}
$$

Onde $y_{i}$ e $x_{i}$ representam os vetores de produto e insumos da firma $i$ respectivamente. Como observam Coelli, Battese e Rao (1998), o problema acima envolve achar valores de $u$ e $v$ tais que a eficiência da i-ésima firma seja maximizada sujeitos à restrição destes escores de eficiência (isto é, a razão $u^{\prime} y_{i} / v^{\prime} x_{i}$ ) serem menores ou iguais a um. Para se evitar que este problema tenha infinitas soluções (isto é se $x^{*}, y^{*}$ é solução, $\alpha x^{*}, \alpha y^{*}$ também será), uma restrição adicional se faz necessária: $v^{\prime} x_{i}=1$. Refazendo, a partir desta restrição o problema de maximização tem-se:

$$
\begin{aligned}
& \text { (4.18) } \operatorname{Max}_{u, v}\left(u^{\prime} y_{i}\right) \\
& \text { s.a } \quad v^{\prime} x_{i}=1 \\
& u^{\prime} y_{i}-v^{\prime} x_{i} \leq 0 \\
& u, v \geq 0
\end{aligned}
$$

Uma maneira equivalente, segundo Coelli, Battese e Rao (1998), de se escrever este problema é:

$$
\begin{aligned}
& \text { (4.19) } \operatorname{Min}_{\boldsymbol{\theta}, \lambda} \boldsymbol{\theta} \\
& \text { s.a }-y_{i}+Y \lambda \geq 0 \\
& \theta x_{i}-X \lambda \geq 0 \\
& \lambda \geq 0
\end{aligned}
$$

Onde $\theta$ é um escalar, $\lambda$ é um vetor Ix 1 de constantes, $Y$ é matriz dos $k$ produtos das $I$ firmas e $X$ a matriz dos $n$ insumos das $I$ firmas. Segundo os autores, esta formulação envolve menos restrições que a anterior e, por isso, é uma forma preferida de se solucionar o problema proposto.

$$
\begin{aligned}
& \text { (4.20) } \operatorname{Min}_{\boldsymbol{\theta}, \lambda} \boldsymbol{\theta} \\
& \text { s.a }-y_{i}+Y \lambda \geq 0 \\
& \theta x_{i}-X \lambda \geq 0 \\
& \lambda \geq 0
\end{aligned}
$$


A figura abaixo representa a fronteira de produção estimada, a partir do problema acima, numa situação hipotética de cinco firmas usando um insumo para se produzir um produto. Nela, apenas as firmas A e C são tecnicamente eficientes enquanto as demais, por se localizarem abaixo da fronteira são unidades ineficientes.

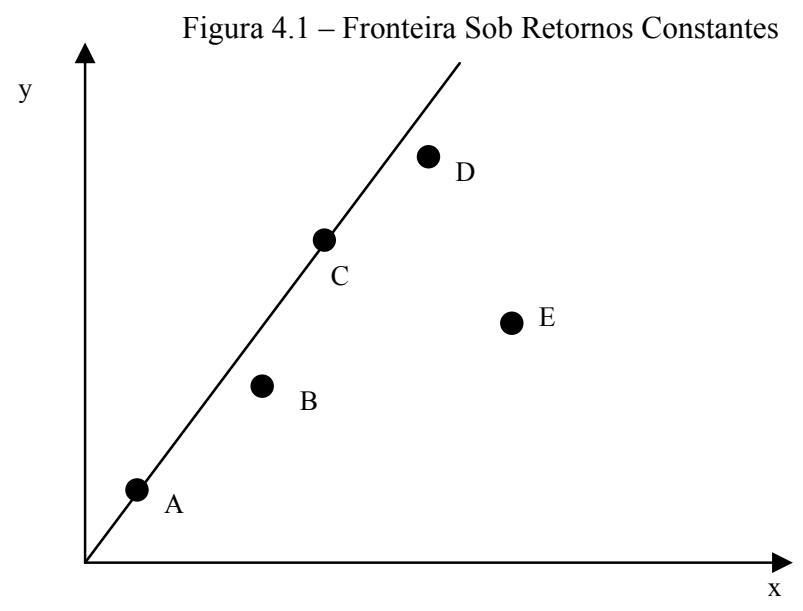

Para se abrir mão da restrição de retornos constantes de escala e calcular uma fronteira com retornos variáveis Banker, Charnes e Cooper (1984) sugerem a modificação do modelo anterior através da introdução da restrição de convexidade I1' $\lambda=1$ :

$$
\begin{aligned}
& \text { (4.21) } \operatorname{Min}_{\theta, \lambda} \boldsymbol{\theta} \\
& \text { s.a }-y_{i}+Y \lambda \geq 0 \\
& \theta x_{i}-X \lambda \geq 0 \\
& \mathrm{I}^{\prime} \boldsymbol{\lambda}=1 \\
& \lambda \geq 0
\end{aligned}
$$

Onde I1' $\lambda$ é um vetor Ix1 de uns. A figura seguinte ilustra uma fronteira calculada a partir de retornos variáveis. Agora, de maneira distinta da situação anterior, a firma D passa a ser tecnicamente eficiente. 


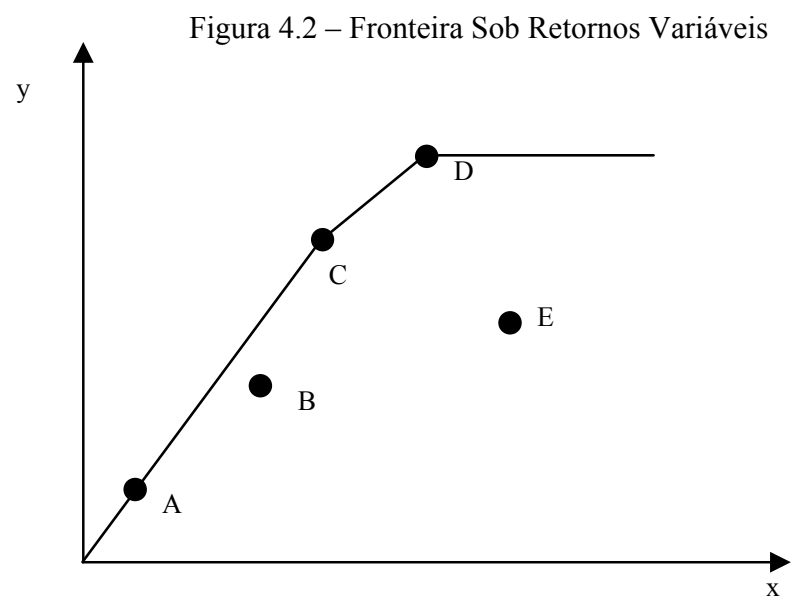

O FDH, por sua vez, diferentemente do DEA, realiza uma envoltória nos dados sem impor a convexidade do conjunto de produção subjacente. Similarmente ao DEA, neste método um produtor é considerado ineficiente se existe outro produzindo a mesma quantidade com menos insumos ou, dada a quantidade de insumos, se existe outro produzindo quantidade superior. Sua principal vantagem é não impor qualquer hipótese acerca da tecnologia de produção. A única hipótese na qual se baseia, segundo Gupta e Verhoeven (2001) é a de livre descarte dos insumos e produtos (i.e. free diposal assumption). Desta forma é possível tanto elevar-se a quantidade de produto a um vetor de insumo qualquer como se reduzir a quantidade de insumos a um nível de produção dado. Para se obter os escores de eficiência insumoorientado e produto-orientado os seguintes problemas são resolvidos respectivamente

$$
\begin{aligned}
& \text { (4.22) } \operatorname{Min}_{i \in I} \operatorname{Max}_{m \in M} \frac{x_{m}(i)}{x_{m}(A)} \\
& \text { (4.23) } \operatorname{Max}_{i \in I} \operatorname{Min}_{p \in P} \frac{y_{p}(A)}{y_{p}(i)}
\end{aligned}
$$

Onde, $x_{m}(i)$ denota a quantidade do m-ésimo tipo de insumo pelo $i$-ésimo produtor e $x_{m}(A)$ denota quantidade do m-ésimo tipo de insumo pelo produtor $A$. Assim, tem-se uma comparação entre o $i$-ésimo produtor e o produtor $A$. Já $y_{p}(i)$ denota a quantidade produzida pelo $i$-ésimo produtor enquanto $y_{p}(A)$ representa quantidade produzida por $A$. 


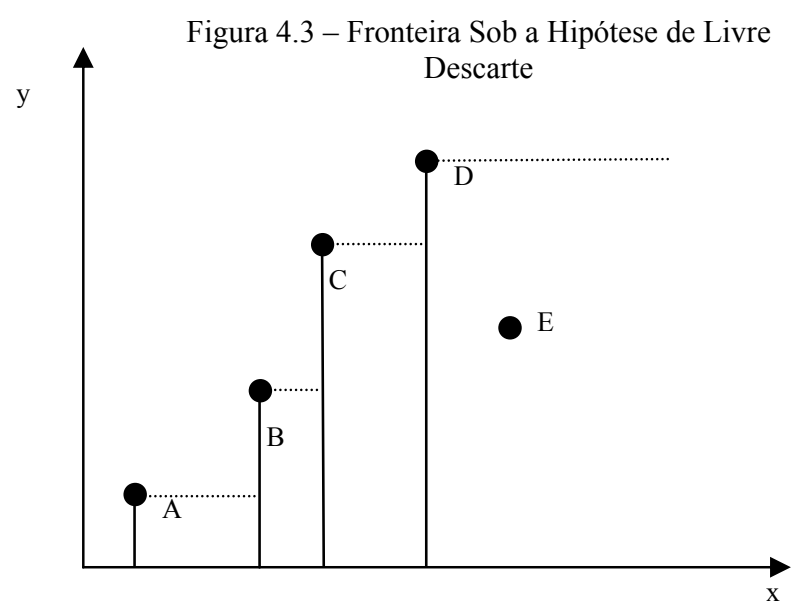

Da figura acima, nota-se que apenas a firma E pertence ao conjunto daquelas tecnicamente ineficientes. Este método, a depender da amostra, pode produzir resultados onde todas as firmas são tecnicamente eficientes (para se verificar isto, basta imaginar o exemplo acima sem a existência da firma E).

Além da não necessidade de imposição de uma distribuição de probabilidade para o termo de ineficiência este tipo de modelo também permite o cálculo de uma fronteira de produção sem a imposição de uma forma funcional ex-ante ao traçar uma envoltória nos dados. Entretanto, conforme já observado este método não permite que se decomponha as variações de uma firma, em relação à fronteira, em variações na eficiência técnica e choques aleatórios. Ademais, por ser um método de cálculo da fronteira e não de estimação da mesma, testes de hipóteses não podem ser realizados impedindo assim, que o pesquisador infira, a partir da amostra, quais variáveis realmente contribuem para a explicação da variável dependente. Tais características restringem a avaliação de um setor a partir destes métodos 


\section{5) Base de Dados, Variáveis e Principais Resultados}

\section{1) Fonte de dados e construção de variáveis.}

Neste estudo, a fonte dos dados é a Pesquisa Industrial Anual, PIA - Empresa, realizada anualmente pelo IBGE. A pesquisa inclui empresas de caráter industrial registradas no Cadastro Nacional de Pessoas Jurídicas. O objetivo da pesquisa é conhecer as características estruturais das atividades industriais no Brasil. A amostra inclui dois tipos de estratos: o estrato fixo e estrato aleatório. No estrato fixo estão incluídas as grandes empresas de cada setor que são pesquisadas ano a ano. Já o estrato aleatório é compreendido por empresas, geralmente, de menor porte e podem desaparecer da pesquisa em determinados anos.

O período escolhido está compreendido entre 1996 e 2003. A justificativa para tal escolha do limite inferior está no fato de se desejar, neste estudo, uma análise que contemple a evolução recente do setor. Quanto ao limite superior, a justificativa reside no fato das pesquisas para os anos posteriores não terem sido divulgadas.

As empresas que compõe a amostra foram selecionadas através da Classificação Nacional de Atividades Econômicas (CNAE4). As classificações inseridas foram 24.51 (Fabricação de Produtos Farmoquímicos) e 24.52 (Fabricação de medicamentos para uso humano). Posteriormente foram eliminadas da amostra, com base na razão social da empresa, farmácias de manipulação e medicamentos de uso veterinário. O objetivo desta triagem é capturar tão somente o setor farmacêutico industrial.

Apesar dos procedimentos realizados acima, cabe salientar que o resultado da amostra não se encontra livre de erros de seleção, isto é, devido à falta de informações mais detalhadas sobre as empresas é possível que empresas fora do escopo deste estudo estejam ainda presentes.

A variável selecionada para o produto (variável dependente) foi o Valor da Transformação Industrial que é a diferença entre o valor bruto da produção industrial e o custo das operações industriais. O insumo trabalho está subdivido em dois vetores: 1) trabalhadores ligados à produção e 2) trabalhadores não ligados à produção mais proprietários e sócios. Para captar a 
quantidade exata de trabalho a variável mais indicada é o número de horas contratadas. Como a PIA não fornece esta informação, foi incluída a variável "gasto médio anual com salários, retiradas e outras remunerações do pessoal ligado à produção" e "gasto médio anual com salários, retiradas e outras remunerações do pessoal não ligado à produção mais proprietários e sócios".

Para o estoque de capital foi adaptada a metodologia aplicada em Young (1995) uma vez que a informação sobre tal variável não está disponível. Esta metodologia sugere que o valor do capital inicial seja $\mathrm{K}_{\mathrm{j}}(0)=\mathrm{I}_{\mathrm{j}}(0) /\left(\delta_{\mathrm{j}}+\mathrm{g}_{\mathrm{j}}\right)$, onde $\delta_{j}$ é a taxa de depreciação do bem $j$ e $g_{j}$ é a taxa de crescimento do investimento médio no bem $j$ nos cinco primeiros anos da série. Na geração do capital inicial três hipóteses são atribuídas ao termo $\left(\delta_{j}+g_{j}\right)$ com o objetivo de checar a robustez: $8 \%, 9 \%$ e 10\%. Posteriormente, a partir destas três taxas de depreciação, aplicou-se ao cálculo do estoque de capital o método do inventário perpétuo que consiste na seguinte equação: $\mathrm{K}_{\mathrm{t}}=(1-\delta) \mathrm{K}_{\mathrm{t}-1}+\mathrm{I}_{\mathrm{t}}$. Para a aplicação deste método de cálculo do estoque de capital, um segundo critério de seleção considerado foi a disponibilidade das informações utilizadas na estimação por pelo menos quatro anos consecutivos. Isto se fez necessário para que possuísse mais graus de liberdade, numa tentativa de minimizar o erro de medida inerente a este método.

Os resultados das estimações são reportados para as três séries e parecem robustos às três hipóteses. Na construção da variável investimento, considerou-se as Aquisições e Melhorias ao Ativo Imobilizado.

Como todas as variáveis inclusas na equação principal estão em Reais, estes valores foram deflacionados pelo IPCA (dez $93=100$ ). Adotou-se como base o ano final da série, isto é todas as variáveis estão expressas em Reais de 2003.

Para as variáveis que compõe o vetor $\mathbf{Z}$ (vetor de variáveis que explicam a eficiência técnica) foram incluídas variáveis dummies referentes ao estado da federação ou à região à qual a empresa pertence, dummies de ano além das variáveis "percentual de vendas no mercado externo" e "percentual de insumos importados". A justificativa para a inclusão destas duas variáveis repousa no fato do setor possuir uma relação comercial intensa com o mercado externo como ficou evidenciado na revisão da literatura sobre o mercado farmacêutico 
brasileiro. Além disto, o fato destas variáveis não serem constantes no tempo atribuem ao termo de ineficiência um caráter variante no tempo (hipótese necessária à construção do índice de Malmquist).

Além das variáveis descritas anteriormente, um termo de tendência foi incluído na estimação como proxy para a variação tecnológica.

Antes da apresentação dos resultados estimados, uma breve análise do setor a partir da amostra obtida pode fornecer informações prévias sobre o comportamento da produção e, conseqüentemente, dos índices de produtividade. Verifica-se a priori que o Valor da Transformação Industrial, em Reais de 2003, valor da adicionado apesar das vendas apresentarem um comportamento estável até o ano de 1998. Já no período seguinte, há uma queda em tal variável sendo que esta tendência só é revertida no ano de 2001. Tal situação é descrita no gráfico 5.1 .

Uma vez que as importações de insumos têm ampla significância nos custos ${ }^{31}$ do setor, esta queda pode estar associada à desvalorização do Real, frente ao Dólar, ocorrida em janeiro de 1999. Conforme apresentado na tabela 2.1, mesmo sob condições cambiais adversas, o setor elevou seu volume de exportações, em relação ao ano anterior, em aproximadamente $25 \%$, possivelmente devido à rigidez contratual. Os reflexos negativos da maxidesvalorização, portanto, foram verificados no ano 2000 quando a compra de insumos importados registrou queda de 6\% em relação a 1999. Desta forma, se emprego dos fatores de produção, nos anos em que se verifica a queda no Valor da Transformação Industrial, não apresentar uma queda relativamente maior, os índices de produtividade deverão apresentar uma redução. Isto posto, a análise agora volta-se para os vetores de trabalho.

\footnotetext{
${ }^{31}$ Para que a análise seja mais precisa, deve-se considerar ainda, expurgando o efeito das variações cambiais, o comportamento dos preços relativos dos produtos farmoquímicos neste período. Entretanto, tal informação não está disponível o que limita a análise.
} 


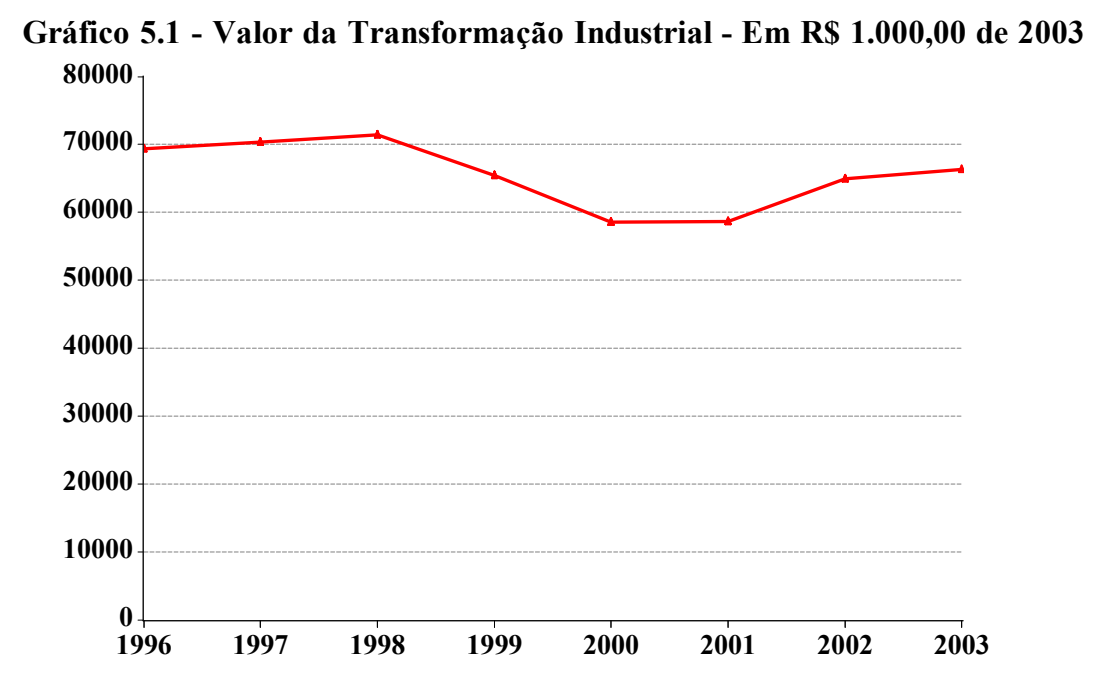

Conforme já colocado, como medida dos fatores Trabalho Empregado na Produção e Trabalho Empregado na Administração, foram utilizadas as informações acerca do valor total pago a estes fatores. Desta forma, ao se avaliar como tais variáveis se comportam ao longo do período contemplado, deve-se ter cuidado na sua interpretação. Aqui as variáveis sofrem influência da variação das horas trabalhadas e das variações no salário real. Assim movimentos de elevação da quantidade de trabalho empregada podem ser amenizados por uma redução do salário real, ou o contrário, levando à possíveis vieses nas elasticidades estimadas. Neste sentido, cabe aqui a classificação destas como variáveis proxy. Feitas estas ressalvas, ao se observar tais variáveis verifica-se uma variabilidade maior do Trabalho Empregado na Administração ao passo que o Trabalho Empregado na Produção apresenta uma trajetória mais suave. Vale lembrar que a variável Trabalho Empregado na Administração aqui empregada considera também a remuneração aos proprietários e sócios pois acredita-se que estes alocam de alguma maneira parte sua força de trabalho na gestão das empresas.

Desta forma, nota-se que há uma queda considerável nesta remuneração no ano 2000. Tal ano, a partir do que pôde ser visto na trajetória do Valor da Transformação Industrial e, também, na avaliação do setor no capítulo 2 , foi um ano de crise para a indústria. Como a remuneração de sócios está intimamente ligada ao desempenho das empresas, parece natural que tal variável apresente este comportamento. Os fatos descritos anteriormente podem ser visualizados nos gráficos 5.2 e 5.3 . 


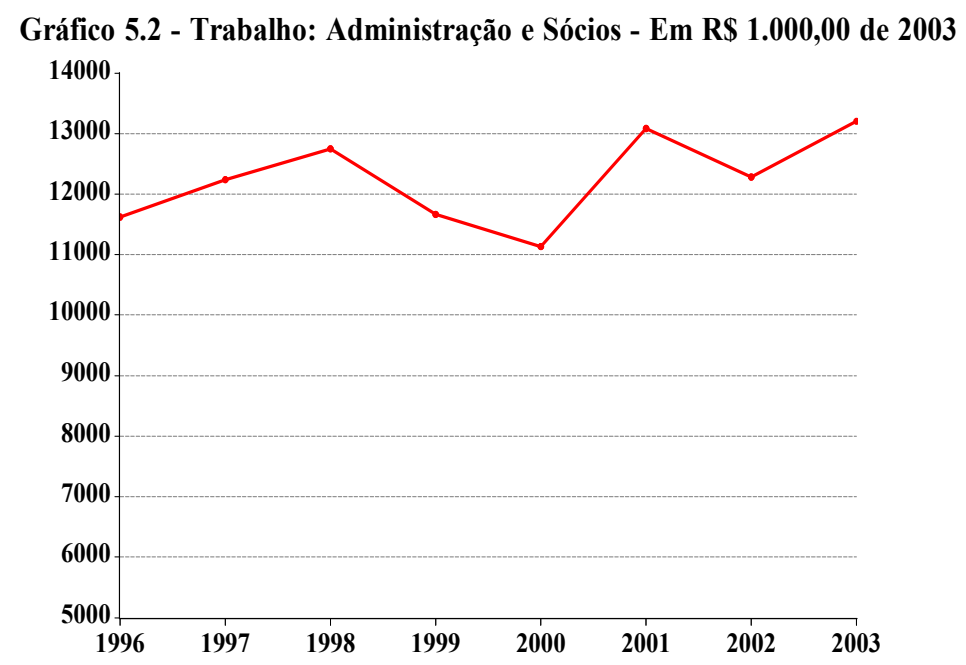

Gráfico 5.3 - Trabalho: Produção - Em R\$ 1.000,00 de 2003

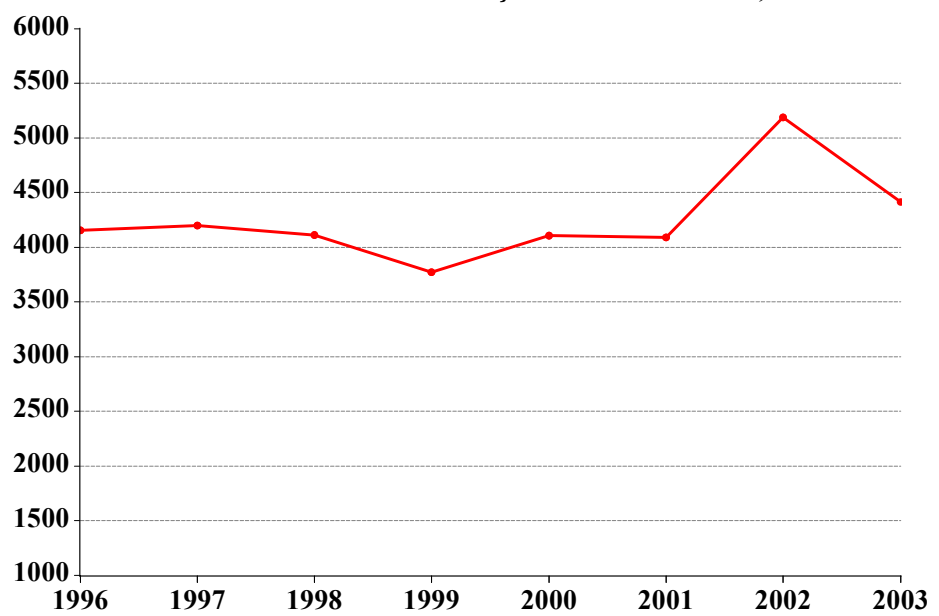

No tocante ao fator capital, conforme já explicitado, a informação do verdadeiro valor do estoque não está disponível na PIA. Desta maneira, devido à construção do estoque de capital baseado na metodologia anteriormente discutida, optou-se por uma avaliação do comportamento do investimento. Os valores médios bem como o valor do menor e do maior investimento podem ser vistos a seguir na tabela 5.1. Nota-se que o ano de 1999 foi o que apresentou o maior investimento segundo os dados da PIA. É possível verificar, ainda, que os valores desta variável são bastante diversificados. Há, na amostra, empresas que realizaram investimento em capital de aproximadamente $\mathrm{R} \$ 2.000,00$ até valores superiores a $\mathrm{R} \$ 17$ milhões. 


\begin{tabular}{|c|c|c|c|}
\hline \multicolumn{4}{|c|}{ TABELA 5.1 INVESTIMENTO REAL - EM R\$ 1.000,00 de 2003} \\
\hline Ano & Mínimo & Média & Máximo \\
\hline 1996 & 15,19 & $8.763,37$ & $177.722,80$ \\
\hline 1997 & 4,52 & $6.596,74$ & $76.888,12$ \\
\hline 1998 & 2,37 & $7.503,33$ & $87.595,16$ \\
\hline 1999 & 15,15 & $10.380,32$ & $157.222,40$ \\
\hline 2000 & 4,55 & $7.276,28$ & $90.343,94$ \\
\hline 2001 & 2,26 & $6.564,23$ & $96.255,99$ \\
\hline 2002 & 17,67 & $6.600,01$ & $115.982,60$ \\
\hline 2003 & 16,50 & $5.825,33$ & $102.547,70$ \\
\hline
\end{tabular}

Fonte: Elaboração Própria a partir de dados do IBGE.

Além dos problemas inerentes à forma como as séries de capital são obtidas a partir do investimento (atribui-se exogenamente um fator de depreciação, além do fato do método de cálculo poder levar a um capital inicial menos preciso quanto menor for a série de investimento) outra questão que deve ser abordada é quanto à mensuração exata séries no que diz respeito à quantidade de capital produtivo de facto. As séries de investimento coletadas pela PIA consideram as aquisições e melhorias ao ativo imobilizado. Portanto, possivelmente parte dos valores reportados não necessariamente se aplica ao conceito de estoque de capital produtivo, ou seja, aqueles bens que de alguma forma prestaram seus serviços à produção.

A evolução dos estoques de capital construídos pela metodologia proposta por Young (1995) apresenta um padrão decrescente no tempo conforme pode ser observado no gráfico a seguir, onde, as legendas $k 08, k 09$ e $k 10$ representam as séries com taxas de depreciação iguais a $8 \%$, $9 \%$ e $10 \%$ respectivamente. Tal comportamento se mostra natural uma vez que, avaliando a série de investimento real, nota-se que esta apresenta um fluxo decrescente no período analisado, exceção feita aos anos de 1998 e 1999. 


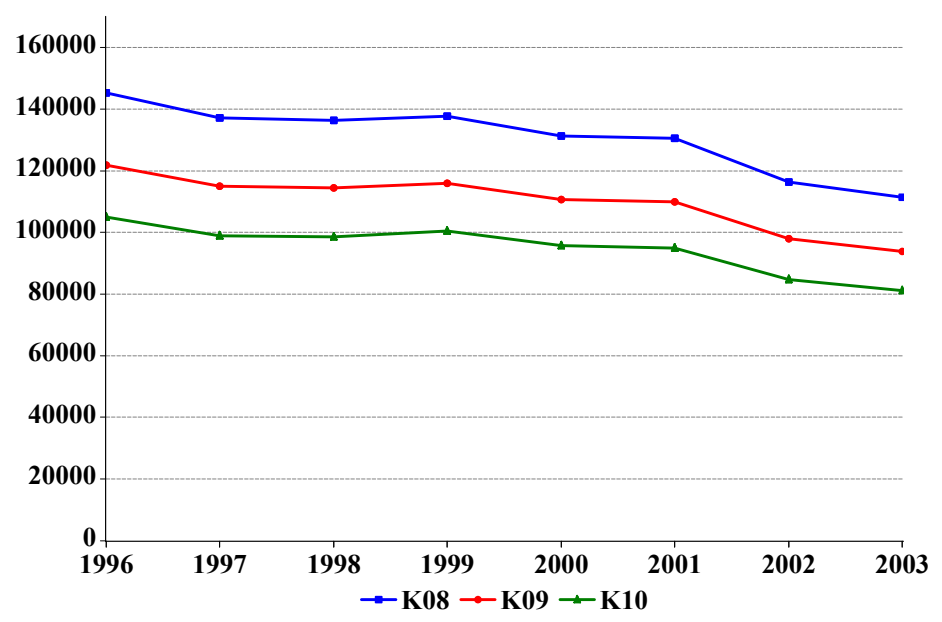

Antes de prosseguir com a análise descritiva, cabe salientar que a literatura brasileira de ciclos reais de negócios utiliza, de modo geral, valores mais elevados da taxa de depreciação. Por exemplo, Ellery, Gomes e Sachsida (2002) utilizam um valor de 16\%. Já Bugarin et al.(2003) empregam um valor de $9 \%$ (valor empregado também neste estudo). Por outro lado, Ferreira e Val (2001) adotaram 6,5\%. Incluir as taxas de depreciação dentro de um intervalo utilizado pela literatura de ciclos reais é a justificativa, portanto, para os valores aqui implementados.

Voltando as atenções para o vetor de variáveis que explicam a ineficiência técnica, conforme exposto, foram construídas dummies de ano e de estado/região para verificar, respectivamente, a influência de choques macroeconômicos e das idiossincrasias de cada local nesta variável. Observando a dispersão espacial da amostra, nota-se que a indústria está concentrada na região sudeste, mais particularmente no Estado de São Paulo que possui $54,89 \%$ das empresas incluídas neste trabalho, seguido pelo Rio de Janeiro com $20,3 \%$. A Região Sul aparece com apenas 7,52\% das empresas componentes da amostra enquanto o Nordeste aparece com apenas 6,77\%. O Estado de Goiás representa 6,02\% e Minas Gerais é local com menor participação amostral: 4,51\%. Os demais Estados da Região Centro-Oeste e Região Norte, após os critérios de seleção utilizados ${ }^{32}$ não apresentaram participação. Optouse pela agregação das empresas nas Regiões Sul e Nordeste uma vez que cada Estado componente destes locais não apresentou número superior a três empresas ${ }^{33}$. Os valores absolutos de tal dispersão são apresentados a seguir na tabela 5.2.

\footnotetext{
${ }^{32}$ Isto é, disponibilidade de informações.

${ }^{33}$ Restrição imposta pelo IBGE para não identificação das empresas prevalecendo, assim, o sigilo estatístico.
} 


\begin{tabular}{cc}
\hline \multicolumn{2}{c}{ TABELA 5.2 - Dispersão Regional da Amostra } \\
\hline Estado/Região & Número de Empresas \\
\hline SP & 73 \\
MG & 6 \\
RJ & 27 \\
GO & 8 \\
NE & 9 \\
SUL & 10 \\
TOTAL & 133 \\
Fonte: Elaboração Própria a partir de dados do IBGE.
\end{tabular}

Quanto a variável Percentual de Insumos Importados, boa parte das empresas reportou consumir entre 0 e $10 \%$ de insumos importados apenas. Apesar disto, nota-se, a exemplo do já foi colocado que a presença de insumos importados é marcante na estrutura produtiva deste setor. A quantidade de empresas que consomem de $91 \%$ a $100 \%$ de insumos elevou-se de 2,02\% em 1996 para 8\% em 2003, dentro da amostra considerada. Aproximadamente 35\% das empresas investigadas importam mais da metade de seus insumos, caracterizando a relevância desta informação ao estudar o setor. Esta variável, embora não permita avaliar o quanto se consumiu de produtos importados no processo produtivo, ela fornece informações acerca do comportamento das empresas na hora de adquirir tais insumos.

O conjunto de histogramas a seguir mostra a evolução ano a ano dos percentuais de empresas inclusas em cada decil. $\mathrm{O}$ decil de valor 1 representa as empresas que consomem de $0 \%$ a $10 \%$, o segundo decil, a porcentagem de empresas que consomem entre $11 \%$ e $20 \%$, e assim sucessivamente até o último decil onde os valores representam as empresas que consomem de $91 \%$ a $100 \%$ de insumos importados. 


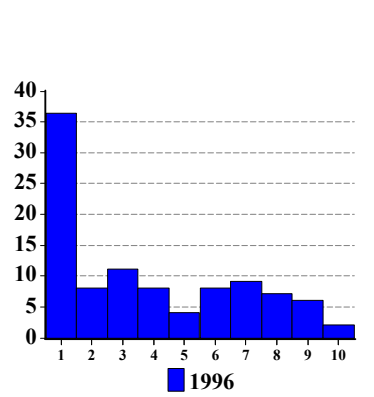

Gráfico 5.5 - Percentual de Compra de Insumos Importados Ano a Ano
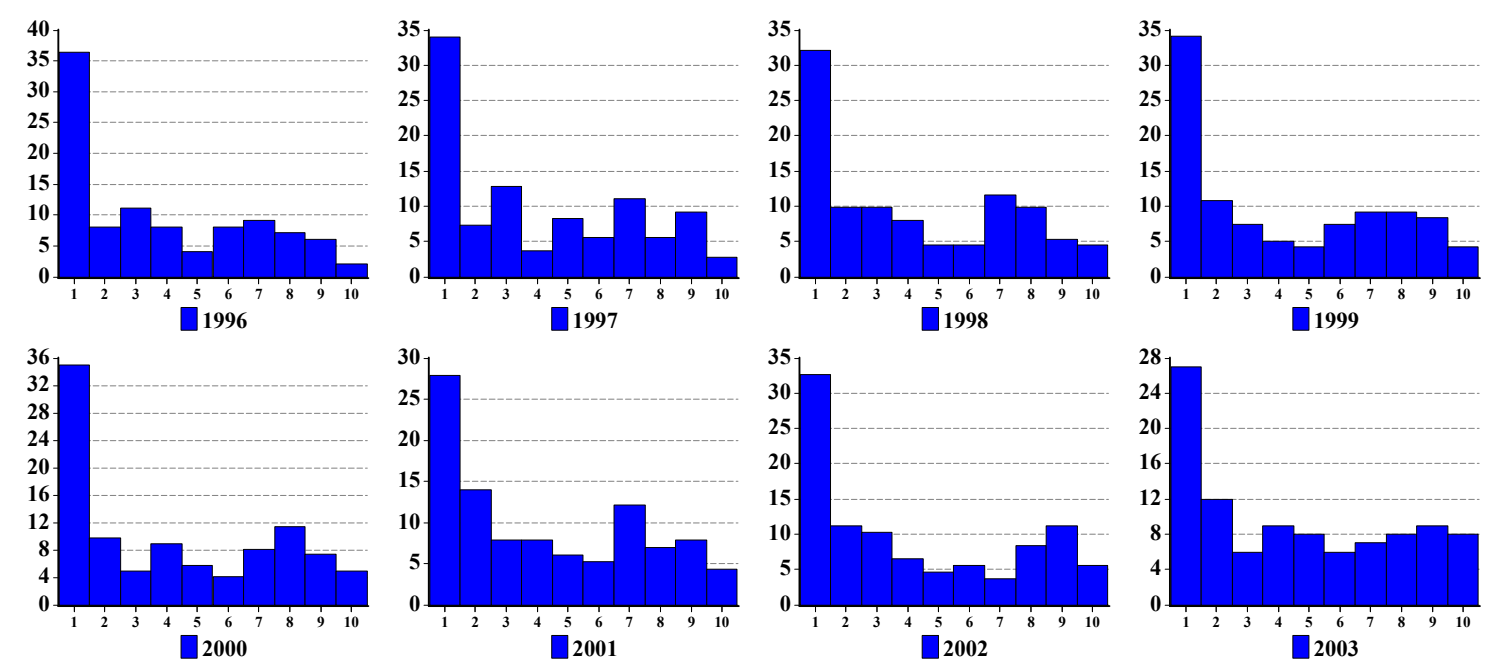

Analisando o comportamento da variável Vendas ao Mercado Externo nota-se que a presença de empresas exportadoras bem como a parcela de sua produção destinada a outros países é tímida, corroborando o fato estilizado do setor apresentar déficits na balança comercial. Novamente, vale ressaltar que esta variável não revela o volume de exportações realizado. Assim, tal volume pode estar se expandindo (ou contraindo) em função do comportamento de poucas empresas. O papel desta variável é captar, tão somente, como as diferenças de comportamento entre exportadores e não exportadores afetam a eficiência técnica.

Em função do exposto acima se opta, de maneira distinta daquela realizada para a análise das importações, por reportar tais valores em quartis que são apresentados a seguir.

\begin{tabular}{|c|c|c|c|c|c|c|c|c|}
\hline \multicolumn{9}{|c|}{ Quartil } \\
\hline Ano & 1996 & 1997 & 1998 & 1999 & 2000 & 2001 & 2002 & 2003 \\
\hline Não exportaram & 68,69 & 69,72 & 70,54 & 68,33 & 69,92 & 66,09 & 66,36 & 64,00 \\
\hline $\begin{array}{l}1^{\circ} \text { Quartil (inclui } \\
\text { as empresas que } \\
\text { não exportam) }\end{array}$ & 95,96 & 97,25 & 98,21 & 95 & 98,36 & 97,41 & 98,09 & 98,00 \\
\hline $2^{\circ}$ Quartil & 3,03 & 1,84 & 0,00 & 0,00 & 0,81 & 0,87 & 0,93 & 0,00 \\
\hline $3^{\circ}$ Quartil & 1,01 & 0,92 & 0,89 & 0,83 & 0,81 & 1,74 & 0,00 & 1,00 \\
\hline $4^{\circ}$ Quartil & 0,00 & 0,00 & 0,89 & 0,83 & 0,00 & 0,00 & 0,93 & 1,00 \\
\hline
\end{tabular}

Fonte: Elaboração Própria a partir de dado da PIA - IBGE. 
Por fim, constata-se que maior parte das empresas que compõe a amostra selecionada não realiza exportação. Entretanto, um fato que deve ser destacado é que parece haver uma tendência de busca de novos mercados pelas empresas. Isto é, a participação das empresas que não realizam exportação alguma, após uma elevação entre 1996 e 1998, apresenta redução nos anos subseqüentes como pode ser avaliado na tabela anterior.

Uma vez realizada a análise descritiva da amostra, reporta-se, a seguir, os resultados obtidos a partir das estimações realizadas. O programa utilizado para tanto foi o Frontier 4.1c escrito por Tim Coelli (1996).

\section{2) Resultados}

Antes de estimar as fronteiras estocásticas ao conjunto de dados selecionados, realizou-se a estimação de uma função de produção por mínimos quadrados ordinários nas três séries de capital com o objetivo de verificar a aderência das variáveis explicativas à variável dependente. Os resultados destas estimações sob a hipótese de retornos constantes de escala para as séries de capital com $\delta_{j}$ iguais a $8 \%, 9 \%$ e $10 \%$ mostram uma aderência mostram que a aderência do conjunto de variáveis explicativas é $69,61 \%, 69,59 \%$ e $69,57 \%$, respectivamente. Os valores dos coeficientes estimados bem como os desvios-padrões se encontram no Apêndice I.

Posteriormente, o teste proposto em Coelli (1995a) para verificação da presença de ineficiência a partir dos resíduos do MQO foi aplicado. Este teste consiste na verificação de assimetria negativa nos mesmos. Desta forma, calculam-se o segundo e o terceiro momento amostral dos resíduos (aqui denotados por $m_{2}$ e $m_{3}$, respectivamente) e constrói-se a seguinte estatística de teste: $m_{3} /\left(6 m_{2}{ }^{2} / N\right)^{1 / 2}$, onde $N$ representa o número de observações. Conforme pode ser visto em Coelli (1995a), tal estatística segue uma distribuição assintótica $N(0,1)$. 
Sabendo-se que a assimetria negativa só ocorrerá quando $m_{3}<0$, testa-se a hipótese de $m_{3} \geq$ $0^{34}$. Os resultados dos testes para as três séries de capital são reportados a seguir. Em todos os modelos estimados rejeitou-se a hipótese nula.

\begin{tabular}{lccr}
\hline \multicolumn{3}{c}{ Tabela 5.4 - Testes de Assimetria nos Resíduos do MQO } \\
\hline \hline Modelo & Estatística & P-valor & Decisão \\
$\delta=8 \%$ & $-12,8781$ & 0,0000 & Rejeita $\mathrm{H}_{0}$ \\
$\delta=9 \%$ & $-12,9101$ & 0,0000 & Rejeita $\mathrm{H}_{0}$ \\
$\delta=10 \%$ & $-12,9385$ & 0,0000 & Rejeita $\mathrm{H}_{0}$ \\
\hline
\end{tabular}

Fonte: Elaboração própria a partir de dados do IBGE.

Após a aplicação dos testes procedeu-se a estimação dos modelos especificados em Battese e Coelli (1995) nas três séries de capital sob a hipótese de retornos constantes de escala e retornos variáveis. Os resultados dos modelos especificados em Battese e Coelli (1995) são apresentados a seguir na tabela 5.5. A variável ano refere-se ao termo de tendência. As variáveis Trab. Adm., Trab. Prod., capital são os salários e retiradas dos trabalhadores não ligados à produção, os salários e retiradas dos trabalhadores ligados à produção, estoque de capital e o vetor de matérias primas, respectivamente. As variáveis trigonométricas de Fourrier foram omitidas da tabela uma vez que, conforme já colocado, tais coeficientes não apresentam relevância econômica, apenas relevância estatística.

Na tabela 5.5 vê-se que os coeficientes associados à interação entre o termo de tendência e os insumos são, em todos os três modelos, estatisticamente não significativos. A opção por sua manutenção na equação se deve ao fato destes serem numericamente próximos a zero, levando, desta maneira, a uma influência pequena nos índices de variação técnica. Deve-se ressaltar que, a partir das informações disponíveis neste estudo, as variações tecnológicas (e consequentemente de produtividade) aqui obtidas são referentes às "linhas de produção" do setor. Uma vez que a indústria farmacêutica concentra grande parte de seus esforços de avanços técnicos em atividades de $\mathrm{P} \& \mathrm{D}$ (atividades estas que estão presentes em pequena escala no Brasil conforme explicitado no capítulo 2) é compreensível que a parte da indústria aqui contemplada apresente esses resultados.

\footnotetext{
${ }^{34}$ Este teste está baseado no fato do erro idiossincrático possuir a seguinte construção teórica: $\varepsilon_{i t}=v_{i t}-u_{i t}$. Assim, se o termo de ineficiência é positivo, os resíduos estimados por mínimos possuem assimetria negativa.
} 
Outro ponto a ser destacado é o fato do termo $\gamma$ apresentar valores próximos a 1. Seus valores são $0,9438,0,94413$ e 0,9424 para os modelos com $\delta_{j}$ iguais a $8 \%, 9 \%$ e $10 \%$ respectivamente. Isso significa que a variância do termo de ineficiência predomina a variabilidade do erro idiossincrático. Desta maneira, não apenas a ineficiência está presente como é relevante nos modelos acima.

\begin{tabular}{|c|c|c|c|c|c|c|c|}
\hline \multicolumn{8}{|c|}{ Tabela 5.5 - Funções de Produção Estocásticas - Modelo B\&C 1995.} \\
\hline COEFICIENTES & $\begin{array}{c}\text { Série com } \\
\delta=8 \%\end{array}$ & $\begin{array}{c}\text { Série com } \\
\delta=9 \%\end{array}$ & $\begin{array}{l}\text { Série com } \\
\delta=10 \%\end{array}$ & $\begin{array}{c}\text { COEFICIENTES } \\
\text { (equação de ineficiência) }\end{array}$ & $\begin{array}{c}\text { Série } \operatorname{com} \delta= \\
8 \%\end{array}$ & $\begin{array}{c}\text { Série } \operatorname{com} \delta= \\
9 \%\end{array}$ & $\begin{array}{c}\text { Série com } \delta= \\
10 \%\end{array}$ \\
\hline $\boldsymbol{\beta}_{0}$ & $\begin{array}{l}-2,9383 * \\
(0,9336)\end{array}$ & $\begin{array}{l}-1,6692 \\
(1,0808)\end{array}$ & $\begin{array}{l}-1,6941 * \\
(0,8424)\end{array}$ & $\boldsymbol{\delta}_{0}$ & $\begin{array}{l}-10,0490^{*} \\
(2,3497)\end{array}$ & $\begin{array}{l}-10,1429^{*} \\
(1,2055)\end{array}$ & $\begin{array}{l}-10,0134 * \\
(2,7282)\end{array}$ \\
\hline Ano & $\begin{array}{l}0,0881 * * \\
(0,0453)\end{array}$ & $\begin{array}{l}0,0874 * * \\
(0,0448)\end{array}$ & $\begin{array}{l}0,0840 * * \\
(0,0439)\end{array}$ & Perc. Insumos Import. & $\begin{array}{l}-0,0210^{*} \\
(0,0056)\end{array}$ & $\begin{array}{l}-0,0209 * \\
(0,0031)\end{array}$ & $\begin{array}{l}-0,0208^{*} \\
(0,0061)\end{array}$ \\
\hline $\mathbf{A n o}^{2}$ & $\begin{array}{l}-0,0140 * * \\
(0,0081)\end{array}$ & $\begin{array}{l}-0,0130 \\
(0,0082)\end{array}$ & $\begin{array}{c}-0,0137 * * \\
(0,0082)\end{array}$ & $\begin{array}{c}\text { Vendas ao mercado } \\
\text { externo }\end{array}$ & $\begin{array}{l}0,0255^{*} \\
(0,0072)\end{array}$ & $\begin{array}{l}0,0250^{*} \\
(0,0057)\end{array}$ & $\begin{array}{l}0,0253^{*} \\
(0,0078)\end{array}$ \\
\hline Ano*Trab.Prod. & $\begin{array}{c}0,0097 \\
(0,0075)\end{array}$ & $\begin{array}{l}0,0109 \\
(0,0075)\end{array}$ & $\begin{array}{c}0,0092 \\
(0,0074)\end{array}$ & 1997 & $\begin{array}{l}3,9184 * \\
(0,8896)\end{array}$ & $\begin{array}{l}3,9447 * \\
(0,6097)\end{array}$ & $\begin{array}{l}3,9634 * \\
(1,0327)\end{array}$ \\
\hline Ano*Trab.Adm. & $\begin{array}{l}-0,0017 \\
(0,0076)\end{array}$ & $\begin{array}{l}-0,0003 \\
(0,0077)\end{array}$ & $\begin{array}{l}-0,0008 \\
(0,0077)\end{array}$ & 1998 & $\begin{array}{l}1,1070 * \\
(0,4110)\end{array}$ & $\begin{array}{l}1,0989 * \\
(0,2981)\end{array}$ & $\begin{array}{l}1,1197 * \\
(0,4545)\end{array}$ \\
\hline Ano*Capital & $\begin{array}{l}-0,0080 \\
(0,0084)\end{array}$ & $\begin{array}{l}-0,0106 \\
(0,0084)\end{array}$ & $\begin{array}{l}-0,0084 \\
(0,0084)\end{array}$ & 1999 & $\begin{array}{l}4,0063 * \\
(0,9992)\end{array}$ & $\begin{array}{l}4,0719^{*} \\
(0,7165)\end{array}$ & $\begin{array}{l}3,9574 * \\
(1,0932)\end{array}$ \\
\hline Trab. Prod. & $\begin{array}{l}-0,7061 \\
(0,8890)\end{array}$ & $\begin{array}{l}-0,2059 \\
(0,8760)\end{array}$ & $\begin{array}{l}-0,7616 \\
(0,8919)\end{array}$ & 2000 & $\begin{array}{l}3,8778^{*} \\
(0,8934)\end{array}$ & $\begin{array}{l}3,9783^{*} \\
(0,6808)\end{array}$ & $\begin{array}{l}3,9030^{*} \\
(1,0180)\end{array}$ \\
\hline Trab. Adm. & $\begin{array}{l}-3,4204 * \\
(0,6224)\end{array}$ & $\begin{array}{l}-3,5403^{*} \\
(0,6438)\end{array}$ & $\begin{array}{l}-3,3461 * \\
(0,5751)\end{array}$ & 2001 & $\begin{array}{l}3,9333^{*} \\
(0,9444)\end{array}$ & $\begin{array}{l}4,0212 * \\
(0,6640)\end{array}$ & $\begin{array}{l}3,9401 * \\
(1,0661)\end{array}$ \\
\hline Capital & $\begin{array}{l}5,1265^{*} \\
(0,7108)\end{array}$ & $\begin{array}{l}3,7462 * \\
(0,0078)\end{array}$ & $\begin{array}{l}5,1076^{*} \\
(0,8492)\end{array}$ & 2002 & $\begin{array}{l}3,3462 * \\
(0,9077)\end{array}$ & $\begin{array}{l}3,3341^{*} \\
(0,3707)\end{array}$ & $\begin{array}{l}3,3734^{*} \\
(1,0637)\end{array}$ \\
\hline $\begin{array}{c}\text { Trab. } \\
\text { Prod.*Trab.Adm. }\end{array}$ & $\begin{array}{l}-0,2177^{*} \\
(0,0282)\end{array}$ & $\begin{array}{l}-0,2194 * \\
(0,0286)\end{array}$ & $\begin{array}{l}-0,2162^{*} \\
(0,0290)\end{array}$ & 2003 & $\begin{array}{l}2,9662 * \\
(0,7732)\end{array}$ & $\begin{array}{l}2,8739^{*} \\
(0,4158)\end{array}$ & $\begin{array}{l}2,9512 * \\
(0,8663)\end{array}$ \\
\hline $\begin{array}{c}\text { Trab. } \\
\text { Prod.*Capital }\end{array}$ & $\begin{array}{c}0,3086 \\
(0,2134)\end{array}$ & $\begin{array}{c}0,2061 \\
(0,2192)\end{array}$ & $\begin{array}{c}0,3496 \\
(0,2360)\end{array}$ & MG & $\begin{array}{l}3,3349 * \\
(0,8178)\end{array}$ & $\begin{array}{l}3,2747^{*} \\
(0,3238)\end{array}$ & $\begin{array}{l}3,3189^{*} \\
(0,9506)\end{array}$ \\
\hline Trab.Adm.*Capital & $\begin{array}{l}0,8124^{*} \\
(0,1236)\end{array}$ & $\begin{array}{l}0,8644^{*} \\
(0,1309)\end{array}$ & $\begin{array}{l}0,8466^{*} \\
(0,1221)\end{array}$ & RJ & $\begin{array}{l}2,1471^{*} \\
(0,6471)\end{array}$ & $\begin{array}{l}2,0616^{*} \\
(0,4540)\end{array}$ & $\begin{array}{l}2,1240 * \\
(0,7361)\end{array}$ \\
\hline Trab. Prod. ${ }^{2}$ & $\begin{array}{l}-0,0909 \\
(0,2155)\end{array}$ & $\begin{array}{c}0,0133 \\
(0,2196)\end{array}$ & $\begin{array}{l}-0,1334 \\
(0,2337)\end{array}$ & GO & $\begin{array}{l}4,1045^{*} \\
(0,9189)\end{array}$ & $\begin{array}{l}4,0572 * \\
(0,3029)\end{array}$ & $\begin{array}{l}4,0915^{*} \\
(1,0633)\end{array}$ \\
\hline Trab. Adm. ${ }^{2}$ & $\begin{array}{l}-0,5946^{*} \\
(0,1114)\end{array}$ & $\begin{array}{l}-0,6450^{*} \\
(0,1184)\end{array}$ & $\begin{array}{l}-0,6304 * \\
(0,1097)\end{array}$ & NE & $\begin{array}{l}1,8729^{*} \\
(0,6051)\end{array}$ & $\begin{array}{l}1,7630^{*} \\
(0,5021)\end{array}$ & $\begin{array}{l}1,8575^{*} \\
(0,6762)\end{array}$ \\
\hline Capital $^{2}$ & $\begin{array}{l}-1,1210^{*} \\
(0,1842)\end{array}$ & $\begin{array}{l}-1,0705^{*} \\
(0,2134)\end{array}$ & $\begin{array}{l}-1,1962 * \\
(0,2307)\end{array}$ & SUL & $\begin{array}{l}3,1554^{*} \\
(0,8068)\end{array}$ & $\begin{array}{l}3,1447^{*} \\
(0,3458)\end{array}$ & $\begin{array}{l}3,2246^{*} \\
(0,9215)\end{array}$ \\
\hline$\gamma$ & $\begin{array}{l}0,9438 * \\
(0,0116)\end{array}$ & $\begin{array}{l}0,94413^{*} \\
(0,0097)\end{array}$ & $\begin{array}{l}0,9424^{*} \\
(0,0128)\end{array}$ & $\sigma^{2}$ & $\begin{array}{l}2,2747^{*} \\
(0,4124)\end{array}$ & $\begin{array}{l}2,3092^{*} \\
(0,3062)\end{array}$ & $\begin{array}{l}2,2598^{*} \\
(0,4710)\end{array}$ \\
\hline
\end{tabular}

Notas: *significativo a $5 \%, * *$ significativo a $10 \%$. Entre parênteses os desvios padrões. Fonte: Elaboração Própria a partir de dados do IBGE. 
Considerando agora os coeficientes do vetor $\boldsymbol{Z}$, as variáveis "Percentual de Insumos Importados" e "Percentual de Vendas ao Mercado Externo" apresentam sinal negativo e positivo, respectivamente, sugerindo que as empresas que consomem matérias primas importadas reduzem sua ineficiência enquanto que um número maior de vendas no mercado interno também reduzem a ineficiência. Uma possível explicação para o fato da variável "Percentual de Vendas ao Mercado Externo" elevar a ineficiência pode estar associada a maiores custos transação inerentes à atividade exportadora o que torna mais fácil as vendas internas. Quanto à variável de importação de insumos, dado que o setor produtor de farmoquímicos nacional é pequeno, isto pode estar refletindo a qualidade destes insumos.

Quanto às dummies de estado e região, nota-se que nas três equações estimadas, todas apresentaram sinal positivo. Assim, o fato de uma empresa estar instalada fora do estado de São Paulo (categoria de referência) tende a elevar sua ineficiência. A partir deste resultado pode-se inferir que a indústria farmacêutica paulista representa a fronteira em relação aos demais estados da federação. Isto possivelmente se deve à presença de algum tipo de externalidade positiva na produção dos medicamentos, presente no estado de São Paulo, que estudo não tem capacidade de avaliar. Explorados estes pontos, são apresentados a seguir os testes de hipótese realizados.

Foram testadas as seguintes hipóteses para esses modelos: presença de ineficiência, formas funcionais Trans-Log e Cobb-Douglas, ausência de modelagem na ineficiência. Foi testada, ainda, a adequação de uma distribuição Semi-Normal do termo de ineficiência.

Nos três modelos estimados não se rejeita a hipótese de existência de ineficiência técnica. As formas funcionais Trans-log e Cobb-Douglas também são testadas para as três séries. Nos três modelos tais hipóteses são rejeitadas.

O teste de hipótese realizado para ausência de modelagem na ineficiência, isto é, com exceção de $\delta_{0}$, os demais coeficientes na equação $u_{i t}=z_{i t} \boldsymbol{\delta}+w_{i t}$ são conjuntamente iguais a zero. Neste teste a hipótese nula também foi rejeitada para as três equações. Os testes para adequação da distribuição Semi-Normal ao termo de ineficiência levam à rejeição da hipótese nula. Este teste, que nada mais é do que uma extensão do teste descrito anteriormente, considera todos os coeficientes inclusos no vetor $\mathrm{Z}$ mais o coeficiente $\delta_{0}$ sejam conjuntamente iguais a zero. 
Os resultados de todos os testes descritos acima podem ser vistos a seguir na tabela 5.6. Além dos testes de hipóteses citados, estimou-se a densidade Kernel de Epanechnikov para o termo de ineficiência e para o choque aleatório com o objetivo de checar a adequação das distribuições Normal-Truncada e Normal respectivamente. As densidades, por sua vez apresentam o comportamento esperado. Os resultados das funções Kernel podem ser vistos no Apêndice II.

\begin{tabular}{|c|c|c|c|}
\hline \multicolumn{4}{|c|}{ Tabela 5.6 - Testes de Hipótese } \\
\hline \multicolumn{4}{|c|}{ Testes no modelo para $\delta=8 \%$} \\
\hline Hipótese Nula & Estatísitca LR & P-valor & Decisão \\
\hline Modelo sem ineficiência* & 163,31 & 0,00 & Rejeita $\mathrm{H}_{0}$ \\
\hline Trans-log & 63,05 & 0,00 & Rejeita $\mathrm{H}_{0}$ \\
\hline Cobb-Douglas & 187,16 & 0,00 & Rejeita $\mathrm{H}_{0}$ \\
\hline Ausência de modelagem em $u_{i}$ & 42,63 & 0,00 & Rejeita $\mathrm{H}_{0}$ \\
\hline Semi-normal & 114,59 & 0,00 & Rejeita $\mathrm{H}_{0}$ \\
\hline \multicolumn{4}{|c|}{ Testes no modelo para $\delta=9 \%$} \\
\hline Hipótese Nula & Estatísitca LR & P-valor & Decisão \\
\hline Modelo sem ineficiência* & 164,26 & 0,00 & Rejeita $\mathrm{H}_{0}$ \\
\hline Trans-log & 64,14 & 0,00 & Rejeita $\mathrm{H}_{0}$ \\
\hline Cobb-Douglas & 188,03 & 0,00 & Rejeita $\mathrm{H}_{0}$ \\
\hline Ausência de modelagem em $u_{i}$ & 43,47 & 0,00 & Rejeita $\mathrm{H}_{0}$ \\
\hline Semi-normal & 115,46 & 0,00 & Rejeita $\mathrm{H}_{0}$ \\
\hline \multicolumn{4}{|c|}{ Testes no modelo para $\delta=\mathbf{1 0} \%$} \\
\hline Hipótese Nula & Estatísitca LR & P-valor & Decisão \\
\hline Modelo sem ineficiência* & 163,55 & 0,00 & Rejeita $\mathrm{H}_{0}$ \\
\hline Trans-log & 63,32 & 0,00 & Rejeita $\mathrm{H}_{0}$ \\
\hline Cobb-Douglas & 187,05 & 0,00 & Rejeita $\mathrm{H}_{0}$ \\
\hline Ausência de modelagem em $\mathrm{u}_{\mathrm{i}}$ & 42,56 & 0,00 & Rejeita $\mathrm{H}_{0}$ \\
\hline Semi-normal & 114,67 & 0,00 & Rejeita $\mathrm{H}_{0}$ \\
\hline
\end{tabular}

Fonte: Elaboração Própria. *Distribuição Qui-quadrado mista. Valores críticos segundo Koode \& Palm (1986)

A partir da estimação dos modelos anteriores procedeu-se o cálculo dos índices de Malmquist. Os índices de variação técnica, variação na eficiência (e sua decomposição em eficiência técnica pura e eficiência em escala) e PTF são apresentados a seguir. Os índices de eficiência técnica pura e eficiência em escala, conforme colocado no capítulo 3 requerem o cálculo da 
variação na eficiência técnica em relação a uma tecnologia sob a hipótese de retornos variáveis à escala. Os resultados das estimações sob a hipótese de Retornos Variáveis são apresentados no Apêndice III.

Índices de variação técnica e variação da eficiência técnica foram obtidos a partir da média geométrica dos valores individuais e, posteriormente, o produto destes convertido no índice de Malmquist conforme sugere Coelli, Battese e Rao (1998). Além desta especificação, foi criado, ainda, um índice de média ponderada usando como peso a participação do valor da transformação industrial de cada firma em relação ao mercado contemplado na amostra ${ }^{35}$. A tabela 5.7 a seguir apresenta os valores dos índices calculados nas três séries de capital.

Os índices reportados apresentam as variações relativas ao período anterior ${ }^{36}$. Tanto os índices de média geométrica quanto os de média ponderada parecem robustos às três hipóteses de taxa de depreciação. Entretanto quando comparados entre si os índices de média geométrica e média ponderada apresentam diferenças significativas não apenas em magnitude mas também em evolução. No quesito magnitude, o índice de média ponderada apresenta variações menores que o índice de média geométrica. Já em relação à evolução dos índices, uma diferença substancial aparece no período 2000/1999, quando há uma elevação em torno de $5 \%$, na média geométrica, e um decréscimo médio de $0,4 \%$ no índice ponderado. Os gráficos 5.6, 5.7 e 5.8 ilustram a situações descritas acima.

\footnotetext{
${ }^{35}$ A fórmula do peso para a firma $i \operatorname{nos} \operatorname{anos} j$ e $j+1$, portanto, é: $p_{i}=\frac{v t i_{j}^{i}+v t i_{j+1}^{i}}{\sum_{i=1}^{n}\left(v t i_{j}^{i}+v t i_{j+1}^{i}\right)}$.

${ }^{36}$ Desta forma, para se obter a variação percentual ano a ano basta subtrair o valor por um e multiplica-lo por 100.
} 


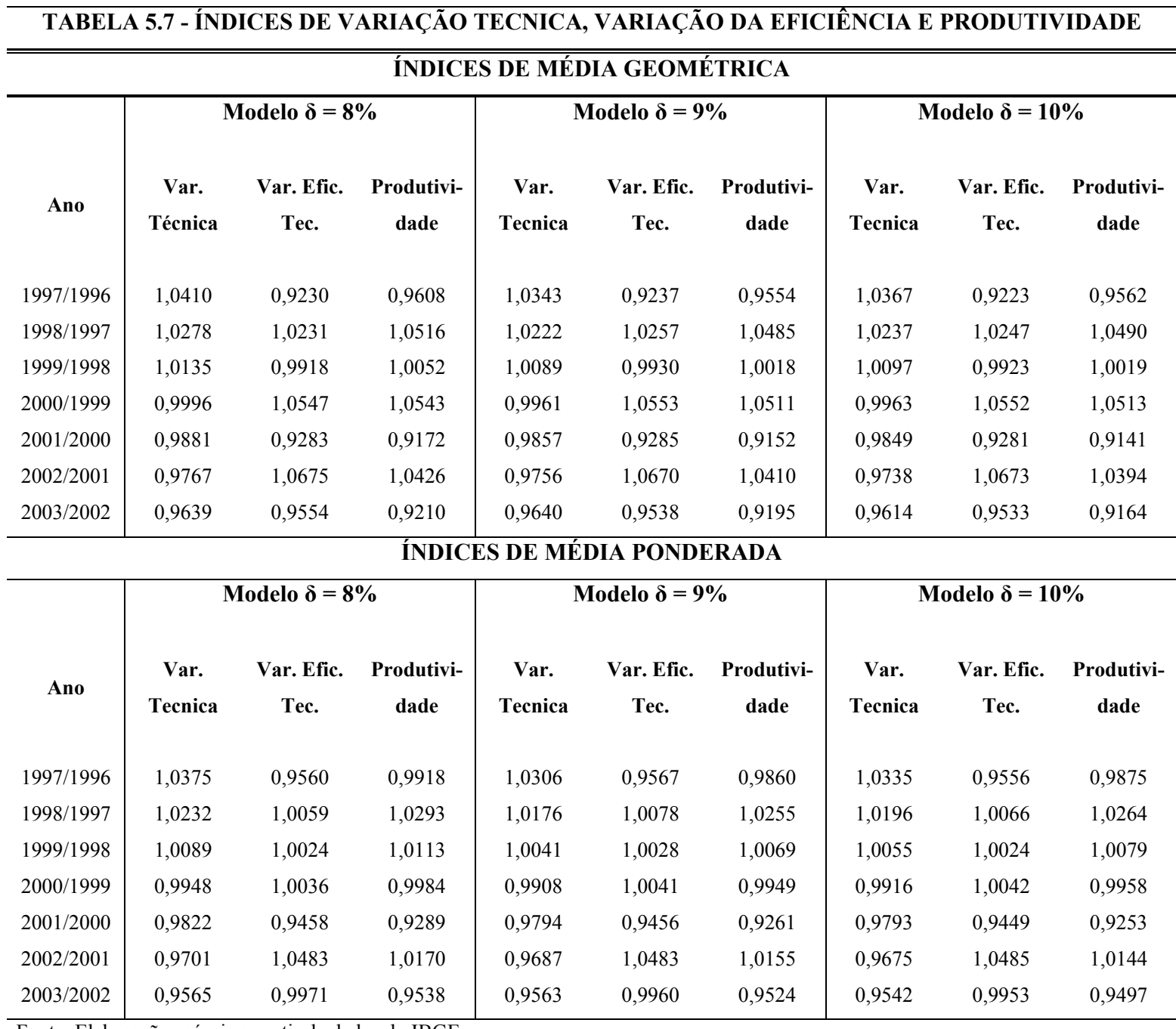

Fonte: Elaboração própria a partir de dados do IBGE.

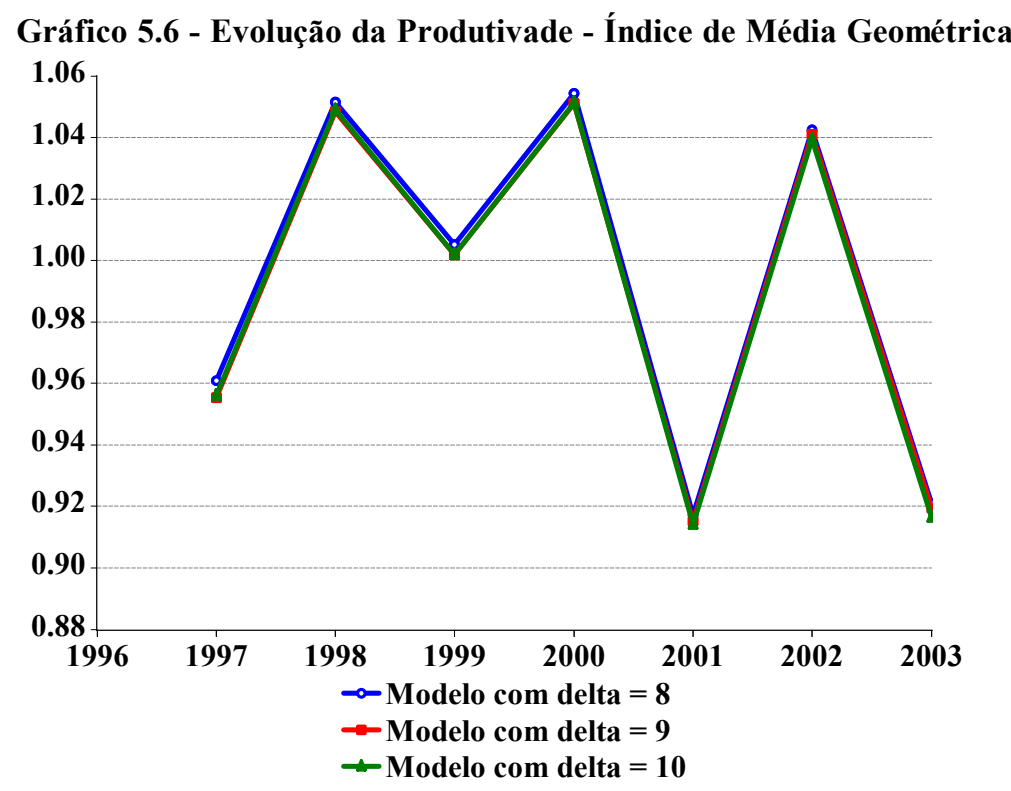


Gráfico 5.7 - Evolução da Produtivade - Índice de Média Ponderada

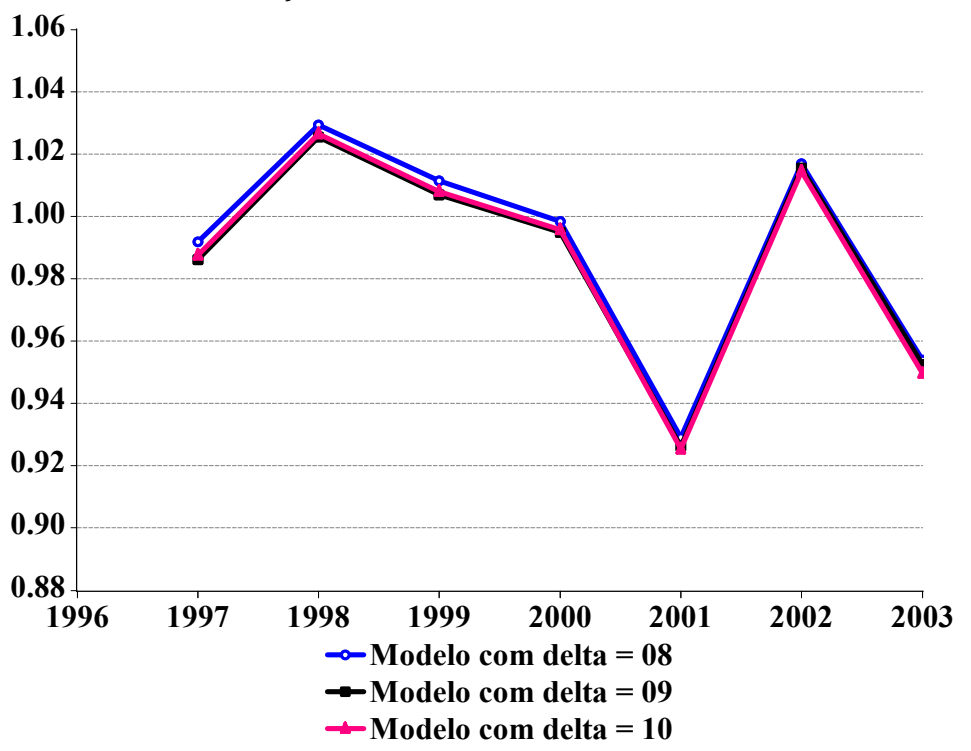

Gráfico 5.8 - Evolução da Produtivade - Índices de Média Geométrica e Ponderada

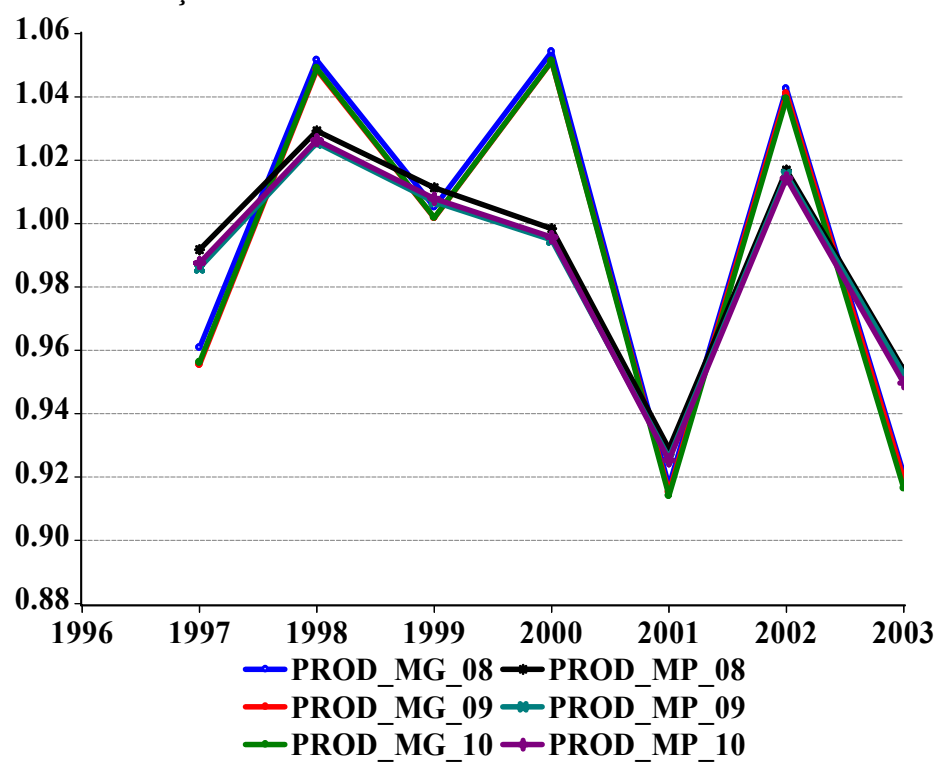

Com relação à variação técnica há, em todos os índices calculados, uma elevação de tecnologia nos três anos iniciais da série e um retrocesso nos quatro anos subseqüentes. Mesmo no período onde há elevação dos índices de variação técnica, esta apresenta um caráter decrescente. Desta forma tal variável apresenta um decréscimo monótono ao longo dos anos avaliados conforme pode ser visualizado no gráfico a seguir. 


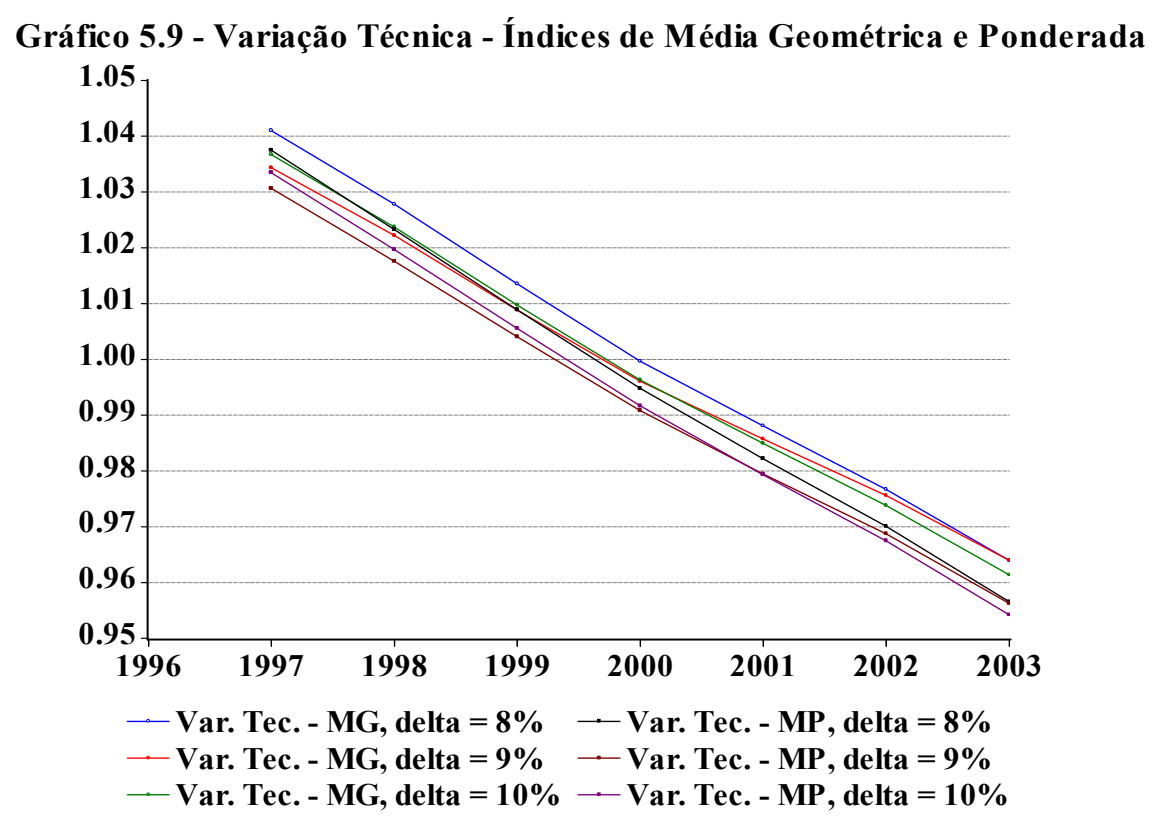

Já a variação na eficiência técnica, de maneira diferente da variação tecnológica, apresenta um comportamento errático e não similar entre os índices de média geométrica e a ponderada. Tal situação pode ser visualizada a seguir no gráfico 5.10.

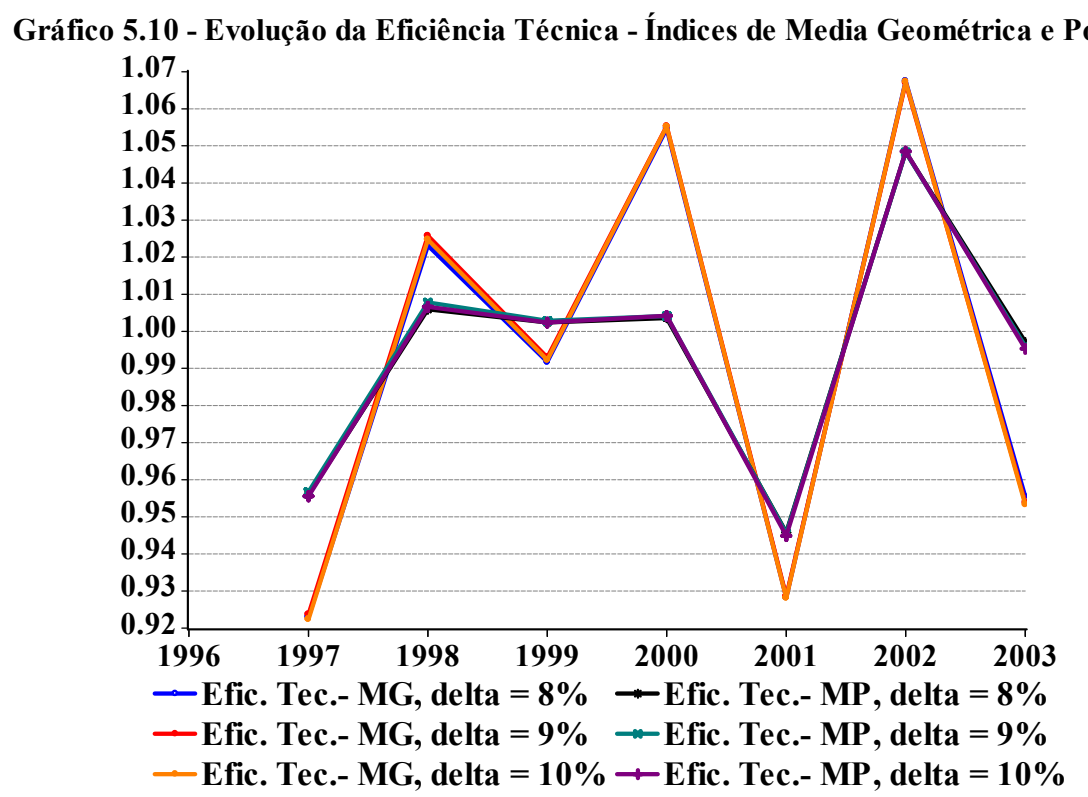

A eficiência técnica, conforme já exposto, refere-se a movimentos de aproximação e distanciamento das firmas em relação à fronteira de produção. A literatura acerca do tema trata estas variações, em parte, como fruto de mudanças na forma de gestão das empresas. A 
falta de informações desta natureza impossibilita uma análise minuciosa das variações ocorridas com a eficiência técnica. Apesar da perda de explicação acerca das forças que atuam no movimento da ineficiência, é importante ressaltar que a sua ausência não traz maiores complicações no tocante à posição relativa das firmas, apesar de afetar o valor absoluto das medidas de eficiência conforme observa Greene (1990).

Partindo agora para a decomposição da variação da eficiência técnica em variação em escala e variação pura da eficiência técnica (conforme visto no capítulo 3, a partir das equações $3.13 \mathrm{e}$ 3.14) constata-se, novamente, diferenças sistemáticas entre os índices de média geométrica e ponderada. A variação pura da eficiência técnica (isto é, parte da variação da eficiência técnica livre de restrições na escala) apresenta uma elevação acentuada entre os anos 1998 e 1999 para o índice de média geométrica. Consequentemente a variação na escala, apresenta um decréscimo considerável no mesmo período. Já os índices na média ponderada apresentam uma evolução mais suave na eficiência técnica pura o que leva aos índices de escala a apresentarem variações mais estáveis, de menor magnitude. Considerando os índices de média ponderada, as variações de produtividade no setor devido às variações na escala apresentam um comportamento intuitivo uma vez que, conforme Nightingale (2000), e segundo já exposto no capítulo 2 , os ganhos de escala na indústria farmacêutica são mais freqüentes na fase de P\&D. A seguir, apresenta-se a variação nos índices de escala e de eficiência técnica pura. 


\begin{tabular}{|c|c|c|c|c|c|c|}
\hline \multicolumn{7}{|c|}{ Tabela 5.8 - Variação na Escala e na Eficiência Técnica Pura } \\
\hline \multicolumn{7}{|c|}{ Variação na Escala } \\
\hline & \multicolumn{3}{|c|}{ Média Geométrica } & \multicolumn{3}{|c|}{ Média ponderada } \\
\hline Ano & Modelo $\delta=8 \%$ & Modelo $\delta=9 \%$ & Modelo $\delta=10 \%$ & Modelo $\delta=8 \%$ & Modelo $\delta=9 \%$ & Modelo $\delta=10 \%$ \\
\hline 1996 & 0,9626 & 0,9606 & 0,9644 & 0,9749 & 0,9741 & 0,9740 \\
\hline 1997 & 0,8984 & 0,9018 & 0,9067 & 0,9892 & 0,9907 & 0,9915 \\
\hline 1998 & 0,7621 & 0,7671 & 0,7650 & 0,9960 & 1,0002 & 0,9980 \\
\hline 1999 & 0,8791 & 0,8752 & 0,8789 & 1,0005 & 0,9984 & 0,9990 \\
\hline 2000 & 0,9637 & 0,9620 & 0,9679 & 0,9822 & 0,9814 & 0,9820 \\
\hline 2001 & 1,0013 & 0,9980 & 1,0090 & 1,0144 & 1,0117 & 1,0162 \\
\hline 2002 & 0,9904 & 0,9936 & 0,9983 & 1,0031 & 1,0047 & 1,0054 \\
\hline \multicolumn{7}{|c|}{ Variação Pura na Eficiência Técnica } \\
\hline & \multicolumn{3}{|c|}{ Média Geométrica } & \multicolumn{3}{|c|}{ Média ponderada } \\
\hline Ano & Modelo $\delta=8 \%$ & Modelo $\delta=9 \%$ & Modelo $\delta=10 \%$ & Modelo $\delta=8 \%$ & Modelo $\delta=9 \%$ & Modelo $\delta=10 \%$ \\
\hline 1996 & 0,9589 & 0,9617 & 0,9564 & 0,9806 & 0,9822 & 0,9811 \\
\hline 1997 & 1,1389 & 1,1375 & 1,1303 & 1,0169 & 1,0173 & 1,0153 \\
\hline 1998 & 1,3014 & 1,2946 & 1,2972 & 1,0064 & 1,0026 & 1,0044 \\
\hline 1999 & 1,1997 & 1,2058 & 1,2006 & 1,0031 & 1,0057 & 1,0051 \\
\hline 2000 & 0,9633 & 0,9652 & 0,9589 & 0,9629 & 0,9635 & 0,9622 \\
\hline 2001 & 1,0660 & 1,0692 & 1,0578 & 1,0334 & 1,0362 & 1,0318 \\
\hline 2002 & 0,9647 & 0,9601 & 0,9549 & 0,9941 & 0,9913 & 0,9900 \\
\hline
\end{tabular}

Fonte: Elaboração própria a partir de dados do IBGE.

Uma vez colocadas as questões acerca da variação da escala e da eficiência técnica pura, uma avaliação regional destes índices é realizada. Conforme já exposto, seis localidades foram discriminadas na amostra. São elas: Estado de São Paulo, Rio de Janeiro, Goiás, Minas Gerais mais as Regiões Nordeste e Sul.

Nesta avaliação vê-se que o Estado de São Paulo apresenta um comportamento similar àquele registrado para a indústria nacional. Este resultado é natural uma vez que as observações para tal localidade representam mais da metade das informações contidas na amostra. Conforme já exposto, o Estado de São Paulo apresenta uma eficiência média maior que as demais localidades (tal fato pode ser visualizado a partir dos coeficientes estimados na tabela 5.5) o que o caracteriza como a fronteira da indústria nacional. Sendo assim, o desempenho negativo observado pela indústria nacional está fortemente relacionado ao desempenho da indústria paulista. 
Ao se observar as demais Regiões e Estados nota-se que alguns apresentam um desempenho superior ao Estado de São Paulo no tocante à produtividade acumulada, isto é, tomando o ano de 1996 como base. São eles: Goiás, Minas Gerais e Região Nordeste. Uma vez que os índices de variação técnica apresentaram uma contribuição bem próxima de zero para o saldo final de produtividade, conclui-se que os locais citados acima estão se aproximando da fronteira de produção nacional.

O Rio de Janeiro apresenta, a exemplo de São Paulo, produtividade acumulada, abaixo daquela verificados no ano inicial da série. Tal Estado é o segundo com maior número de empresas instaladas contribuindo, desta forma, para o desempenho negativo dos índices nacionais. Já a Região Sul é aquela que mais sofre influência da ponderação no acumulado de produtividade. Os índices de média geométrica apontam para ganhos em relação à 1996 enquanto os índices de média ponderada apresentam uma redução de aproximadamente $10 \%$ para em relação ao ano base.

Vale ressaltar que para os locais onde o número de empresas é menor os índices ficam mais suscetíveis a empresas que possuam um desempenho muito superior (ou inferior) à media local. É possível visualizar a situações descritas anteriormente nos gráficos a seguir. Os valores para os índices de média móvel e média acumulada, para cada localidade, são apresentados no Apêndice IV. Explorados os resultados dos modelos estimados, apresenta-se a seguir as considerações finais deste trabalho. 


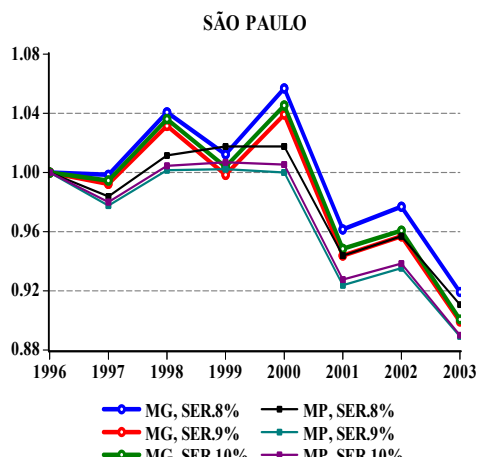

$\rightarrow$ MG, SER.8\% $\rightarrow$ MP, SER.8\%

$\multimap$ MG, SER.10\% $\rightarrow$ MP, SER.10\%

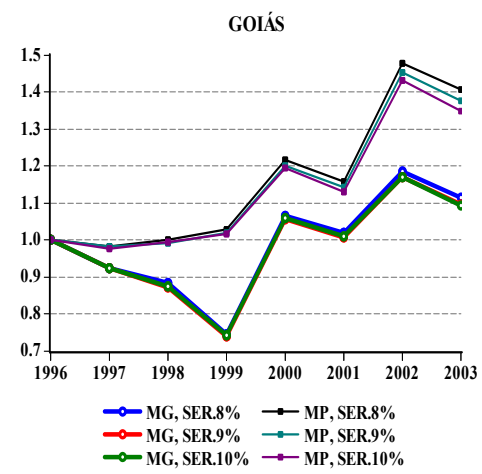

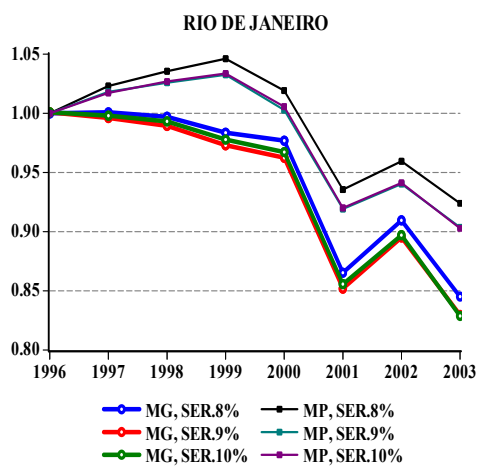

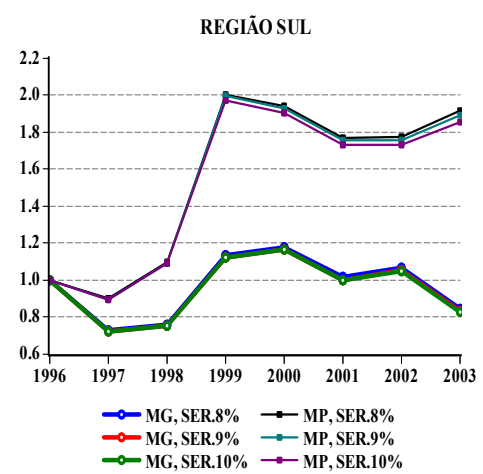

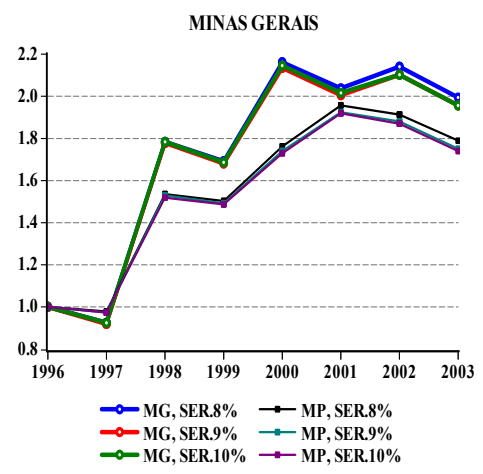

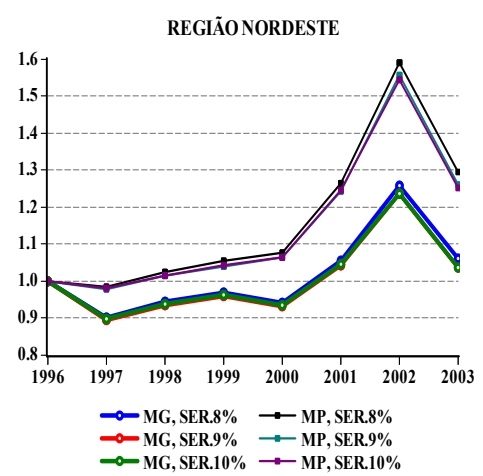




\section{6) Considerações Finais}

O presente estudo buscou avaliar, a partir de informações da Pesquisa Anual Industrial do IBGE, a evolução da Produtividade Total dos Fatores (PTF) para a indústria farmacêutica nacional, objetivando contribuir com o debate acerca dos reajustes de preços do setor no âmbito da resolução $\mathrm{N}^{\mathrm{o}}$ 1, de 27 de Fevereiro de 2004. Para tanto, foram estimadas as fronteiras de produção estocásticas segundo o modelo implementado em Battese e Coelli (1995) com o emprego da Forma Flexível de Fourrier. A partir da metodologia citada acima, calculou-se os índices PTF de Malmquist para o período compreendido entre 1996 e 2003.

A análise aqui conduzida sofre com a falta informações para o período mais recente o que impossibilita a comparação dos resultados obtidos com os dados oficiais ${ }^{37}$. Além disto, a metodologia empregada não permite fazer previsões. Entretanto, por ser fundamentada em hipóteses microeconômicas da teoria da firma, possui valor na avaliação do comportamento passado.

Dentre os resultados econométricos obtidos, vale destacar que, no período investigado, o setor não apresentou variações tecnológicas significativas. Os coeficientes são, numericamente próximos a zero e os índices de variação técnica variam positivamente até 1999 e, posteriormente, apresentam variações negativas que compensam o efeito positivo do período anterior. $\mathrm{O}$ mesmo não pode ser dito ineficiência técnica. De acordo com as equações estimadas, a ineficiência não apenas está presente, como predomina a variância do erro idiossincrático. Sua variação não apresenta um padrão decrescente nítido como a tecnologia. Entretanto, quando avaliada de maneira acumulada, os resultados mostram que, em todos os índices elaborados, houve uma perda de eficiência.

Foram construídos seis índices distintos de produtividade para avaliar o setor. Tal construção se deveu à necessidade de se atribuir exogenamente as taxas de depreciação para o cálculo do estoque de capital. Desta forma, três hipóteses distintas $(8 \%, 9 \%$ e $10 \%$, seguindo valores dentro do intervalo utilizado pela literatura de ciclos reais no Brasil) foram atribuídas com o objetivo de checar a robustez dos índices. A partir deste conjunto de três séries, foram calculados índices de média geométrica (seguindo a metodologia mais popular entre os

\footnotetext{
${ }^{37}$ Foram estabelecidos valores de $0,00 \%$ para 2004, 1,50\% para 2005, 1,87\% para 2006 e, conforme a resolução da Anvisa $\mathrm{n}^{\circ} 3$ de 28 de Setembro de 2006 foi estabelecido um fator de 2,02\% para 2007.
} 
autores da literatura de índices de Malmquist) e de média ponderada (cujo peso atribuído foi a participação do Valor da Transformação Industrial de cada empresa em relação ao total do mercado).

Os índices de média geométrica apresentaram uma volatilidade superior aos índices de média ponderada. Entretanto, no tocante à trajetória, os dois grupos de índices não parecem diferir sistematicatimente. Em relação as diferentes hipóteses de taxa de depreciação para as séries de capital, os valores obtidos intra-grupo não diferem de maneira abrupta o que leva a crer que os índices são robustos às três hipóteses.

Os resultados apontam para uma perda de produtividade acumulada nos dois grupos de índices, isto é, tomando como base o ano de 1996. Desta forma, o ano de 2003 apresentou uma perda média de $8 \%$ para a média ponderada e de aproximadamente $7 \%$ na média geométrica. Considerando as variações em relação ao período anterior, os índices de média geométrica apresentam perda de aproximadamente $8 \%$ enquanto a média ponderada apresenta perda média de 4,8\%. Uma vez os índices de média geométrica tratam todas as empresas de maneira idêntica, sem levar em consideração a relevância desta no mercado, acredita-se que tal medida seja menos apropriada.

Em relação aos determinantes da eficiência técnica, dado que informações que captam diferenças gerenciais entre as empresas (como, por exemplo, propriedade do capital) não estavam disponíveis, optou-se pela inclusão das variáveis "comportamentais" "Percentual de Compras Importadas" e "Vendas ao Mercado Externo" que, em certa medida, captam as diferenças de qualidade e estratégias de compra de insumos, no caso da primeira, e estratégias de venda no caso da segunda. Acredita-se que, em certa medida, estas variáveis estejam correlacionadas com diretrizes gerenciais. Os resultados apontam para uma maior eficiência das empresas que adquirem seus insumos no mercado externo ao passo que as empresas que optam pela venda de seus produtos no mercado externo perdem eficiência. Uma hipótese levantada para estes resultados é a de uma melhor qualidade dos insumos importados pois, como foi exposto no capítulo 2, o setor produtor de fármacos no Brasil é pequeno. Sendo assim as empresas estrangeiras possuem maior Knowhow na fabricação dos mesmos. Quanto á exportação, uma hipótese que se levanta é a existência de maiores custos de transação na atividade exportadora. 
Voltando as atenções para os índices de PTF, se mantida a trajetória encontrada neste estudo, os valores empregados para os anos subseqüentes estariam superestimando o fator de produtividade do setor. Entretanto, sem a posse das informações relevantes, qualquer sugestão aqui realizada teria caráter meramente especulativo.

Na desagregação por Estados da Federação e Grandes Regiões, verificou-se que o Estado de São Paulo é aquele que, por predominar na amostra, se comporta de maneira mais similar aos valores reportados para o país. Além disto, a partir dos coeficientes estimados pôde-se constatar que, em média, as empresas localizadas fora do Estado de São Paulo possuem ineficiência acima das empresas paulistas. Desta a forma a indústria paulista se caracteriza como a fronteira.

Uma série de ressalvas deve ser feita ao avaliar os resultados aqui reportados. Conforme colocado no capítulo 5, existem problemas inerentes à qualidade das informações disponíveis na PIA. A variável dependente Valor da Transformação Industrial, construída com base nas informações de receita operacional e custos da fabricação de medicamentos sofre influência das importações de produtos prontos comercialização. Desta forma, tal variável estaria elevando o verdadeiro valor agregado.

Já as variáveis de trabalho, que utilizaram informações acerca da quantidade de salários paga no ano, sofrem influência das elevações e reduções do salário real o que também leva a erros de medida. Por fim, o estoque de capital além de possuir um método de cálculo suscetível a erros, a variável investimento, utilizada para construir o mesmo, possui valores inerentes a compra de equipamentos de natureza não produtiva. Todos esses problemas citados certamente são transportados para os índices calculados. Vale lembrar que medidas de produtividade que desconsideram os gastos incorridos e a produção gerada na fase de $\mathrm{P} \& \mathrm{D}$ subestimam o verdadeiro potencial tecnológico e de escala deste setor. Pesquisas futuras que se encarreguem de esclarecer estas questões são complementares ao esforço aqui realizado.

Ainda assim, esses problemas não invalidam a iniciativa pioneira deste trabalho de tentar mensurar o desempenho da indústria farmacêutica uma vez que este setor carece estudos desta natureza. 


\section{Referências:}

Aigner, D., C. A. K. Lovell and P. Schmidt. (1977). "Formulation and Estimation of Stochastic Frontier Production Function Models.” Journal of Econometrics 6, 21-37.

ANVISA - Agência Nacional de Vigilância Sanitária, Resolução No 1 de 27 de Fevereiro de 2004, Câmara de Regulação do Mercado de Medicamentos (CMED), disponível em www.anvisa.gov.br.

Banker, R.D., A. Charnes e W.W. Cooper. (1984). "Some Models for Estimating Technical and Scale Inefficiencies in Data Envelopment Analysis." Management Science 30, 10781092.

Barbosa, S.M.K. (2003). “Análise da indústria farmacêutica e dos determinantes dos preços após a entrada dos medicamentos genéricos”. Dissertação (Mestrado) IPE-USP. São Paulo

Battese, G. and T.J. Coelli. (1988). "Prediction of Firm-Level Technical Efficiencies with a Generalized Frontier Production Function and Panel Data.” Journal of Econometrics 38, 38799.

Battese, G. and T.J. Coelli. (1992). "Frontier Production Functions, Technical Efficiency and Panel Data: With Application to Paddy Farmers in India.” Journal of Productivity Analysis 3, 153-69.

Battese, G. and T.J. Coelli. (1995). "A Model for Technical Inefficiency Effects in a Stochastic Frontier Production Function for Panel Data.” Empirical Economics 20(2), 325332.

Berger, A.N and L.J. Mester (1997) . "Inside the black box: What explains differences in the efficiencies of financial institutions?". Journal of Banking \& Finance 21, 895-947.

Bermudez, J.A.Z.; R. Epstejn; M. Oliveira and L. Hasenclever. (2000). The WTO Trips Agreement and patent protection in Brazil: recent changes and implications for local production and access to medicines. Rio de Janeiro: ENSP/FIOCRUZ. 
Bittencourt A. e E.L.L. Marinho. (2005a). "Produtividade, Crescimento Econômico e Dinâmica Distribucional: Um Estudo Comparado para Grupos de Países". Anais do VIII Encontro de Economia da Região Sul. ANPEC - Associação Nacional do Centros de Posgraduação em Economia.

Bittencourt, A. \& E.L.L. Marinho. (2005b). "Capital Humano, Progresso Técnico E Crescimento Econômico: Um Reexame Empírico Das Abordagens De Acumulação, Inovação E Difusão Tecnológica.” Anais do XXXIII Encontro Nacional de Economia 061, ANPEC Associação Nacional do Centros de Pos-graduação em Economia.

Bjurek, H., F. R. Førsund and L. Hjalmarsson. (1998). "Malmquist Productivity Indexes: An Empirical Comparison.” In R. Färe, S. Grosskopf and R. R. Russell (eds.), Index Numbers: Essays in Honour of Sten Malmquist. Kluwer Academic Publishers, Boston.

Bonelli, R. e R. Fonseca. (1998). “Ganhos de Produtividade e Eficiência: Novos Resultados para a Economia Brasileira.” Rio de Janeiro: IPEA. (Texto para discussão 12).

Bugarin, M.S., R. Ellery Jr., V. Gomes e A. Teixeira 2003. “The Brazilian Depression in the 1980s and 1990s", mimeo.

Carvalho R.M. e E.L.L. Marinho (2003). "Transformações Estruturais, Variações na Eficiência Técnica e Produtividade Total dos Fatores no Setor Agrícola dos Países SulAmericanos - 1970 a 2000.”

Caves, D. W., L. R. Christensen and W. E. Diewert. (1982), “The Economic Theory of Index Numbers and the Measurement of Input, Output, and Productivity." Econometrica 50(6) (November), 1393-1414.

Charnes A., W.W. Cooper and E. Rhodes. (1978). "Measuring the Efficiency of Decision Making Units.” European Journal of Operational Science 2, 429-444.

Coelli, T.J. (1995a). "Estimators and Hypothesis Tests for a Stochastic Frontier Function: A Monte Carlo Analysis.” Journal of Productivity Analysis, 6(4) (September), 247-248. 
Coelli, T.J. (1995b). "Measurement and Sources of Technical Inefficiency in Australian Eletricity Generation." New England Conference on Efficiency and Productivity. University of New England. Armidale (November), 23-24.

Coelli, T.J. (1996). “A Guide to FRONTIER Version 4.1: A Computer Program for Stochastic Frontier Production and Cost Function Estimation." Centre for Efficiency and Productivity $\begin{array}{lllll}\text { Analysis } & \text { Working } & \text { Paper } & \text { 96/07. } & \text { Disponível }\end{array}$ http://www.une.edu.au/econometrics/cepa.htm.

Coelli, T.J., D. S. P. Rao and G. Battese. (1998). An Introduction to Efficiency and Productivity Analysis. Kluwer Academic Publishers, Boston.

Coelli, T.J., S. Rahman and C. Thirltle. (2003). "A stochastic frontier approach to total factor productivity measurement in Bangladesh Crop Agriculture, 1961-92." Journal of International Development 15(3) (April), 321-333.

Cornwell, C., P. Schmidt, and R. Sickles. (1990). "Production Frontiers with Cross-Sectional and Time-Series Variation in Efficiency Levels.” Journal of Econometrics 46, 185-200.

Christensen, L.R., D.W. Jorgenson and L.J. Lau. (1973). “Transcendental Logarithmic Production Frontiers." Review of Economics and Statistics 55(1), 28-45.

Cuesta, R. (2000). “A Production Model With Firm-Specific Temporal Variation in Technical Inefficiency: With Application to Spanish Dairy Farms." Journal of Productivity Analysis 13, 139-158.

Debreu. G (1951). “The Coefficient of Resource Utilization.” Econometrica 19(3), 273-292.

Duarte, J. e P.B.R. Macedo. (2001). “Fronteira Tecnológica e Eficiência Técnica na Indústria Brasileira: Desempenho e Tendências no Período 1986-1995.” In: Anais do XXIX Encontro Nacional de Economia, 29. ANPEC - Associação Nacional do Centros de Pos-graduação em Economia.

Ellery Jr., R., V. Gomes e A. Sachsida (2002). "Business Cycle Fluctuations in Brazil," Revista Brasileira de Economia 56 (2): 269-308. 
Färe, R., S. Grosskopf, M. Norris and Z. Zhang. (1994). "Productivity Growth, Technical Progress, and Efficiency Change in Industrialized Countries.' American Economic Review 84(1) (March), 66-83.

Färe, R., S. Grosskopf and P. Roos. (1998). "Malmquist Productivity Indexes: A Survey of Theory and Practice.” In R. Färe, S. Grosskopf and R. R. Russell (eds.), Index Numbers: Essays in Honour of Sten Malmquist. Kluwer Academic Publishers, Boston.

Farrell, M. J. (1957). "The Measurement of Productive Efficiency." Journal of the Royal Statistical Society Series A, General, 120, 253-81.

Ferreira, P. C. e T.G. Malliagros (1998). "Impactos Produtivos de Infra-estrutura no Brasil, 1950-1995." Pesquisa e Planejamento Econômico, 2, 315-338.

Ferreira, Pedro C. e P.R.C. Val 2001. "Modelos de Ciclos Reais de Negócios Aplicados à Economia Brasileira,” Pesquisa e Planejamento Econômico 31 (2): 213-248.

Fiúza, E.P.S. e M.B. Lisboa. (2001). "Bens Credenciais e Poder de Mercado: Um Estudo Econométrico da Indústria Farmacêutica Brasileira". Rio de Janeiro: IPEA (Novembro). (Texto para discussão 846).

Fridman, S.V. e F.F. Rocha. (2004). "Análise Econometrica em Cross-Section da Demanda por Medicamentos no Brasil.” São Paulo: Febrafarma - Federação Brasileira da Indústria Farmacêutica

Frenkel, J. (2001). "O mercado farmacêutico brasileiro: a sua evolução recente, mercado e preços.” In Brasil: radiografia da saúde. Barjas Negri e Geraldo Di Giovanni. UNICAMP. $588 \mathrm{p}$.

Grifell-Tatjé, E. and K. Lovell. (1995). "A Note on Malmquist Productivity Index." Economics Letters 47(2), 169-175.

Greene, W. (1990). “A Gamma Distributed Stochastic Frontier Model.” Journal of Econometrics 46 (1), 141-164. 
Greene, W. (2000). Econometric Analysis, Prentice Hall.

Greene, W. (2005). "Fixed and Random Effects in Stochastic Frontier Models." Journal of Productivity Analysis 23, 7-32.

Gupta, S., and M. Verhoeven. (2001). "The Efficiency of Governement Expenditure Experiences from Africa." Journal of Policy Modeling 23, 433-467.

Hasenclever, L. (2002). Diagnóstico da indústria farmacêutica brasileira. UNESCO/FUJB/IRUFRJ. Rio de Janeiro.

Henderson, R. and L. Cockburn. (1996). "Scale, Scope and Spillovers: The Determinants of Reaserch Productivity in Drug Discovery." The Rand Journal of Economics 27(1), 32-59.

Kumbhakar, S. C. (1987). "Production Frontiers and Panel Data: An Application to U.S. Class 1 Railroads.” Journal of Business \& Economic Statistics 5, 249-255.

Koode, D. and F. Palm. (1986) "Wald Criteria for Jointly Testing Equality and Inequality Restrictions." Econometrica 54, 1243-1248.

Kumbhakar, S. C. (1990). "Production Frontiers, Panel Data and Time-Varying Technical Inefficiency." Journal of Econometrics 46, 201-211.

Kumbhakar, S.C. and K. Lovell. (2000). Stochastic Frontier Analysis. Cambridge University Press, Cambridge.

Magalhães, L. C. G. et al. (2003a) "Evolução e tendências da balança de comércio exterior da indústria farmacêutica brasileira: análise das importações e exportações de farmoquímicos e medicamentos., 1990-2000. Brasília: Ipea (Agosto). (Texto para Discussão, n. 973).

Magalhães, L. C. G. et al. (2003b). "Estratégias Empresariais de crescimento na Indústria Farmacêutica brasileira: Investimentos, Fusões e Aquisições, 1988-2002.” Brasília: Ipea (Novembro). (Texto para Discussão, n. 995). 
Malmquist, S. (1953). "Index Numbers and Indifference Surfaces." Trabajos de Estadistica 4, $209-42$.

Mas-Collell, A., M.D. Whinston and J.R. Green. (1995). Microeconomic Theory. Oxford University Press, New York.

Marinho, E.L.L. e F.A.F.D.Barreto (2000). “Análise da Produtividade e Progresso Tecnológico dos Estados do Nordeste." Centro de Estudos de Economia Regional - CAEN. Working paper $N^{\circ} 29$.

McKelvey, M. and Orsenigo, L. (2001). Paper prepared for the ESSY Project (European Sectoral Systems of Innovation) and within the Epris Project. Disponível em http://www.druid.dk/conferences/winter2002/gallery/orsenigo.pdf.

Meeusen, W. and J. van den Broeck. (1977). "Efficiency Estimation from Cobb-Douglas Production Functions with Composed Error." International Economic Review 18, 435-444.

Mello, E. P. G. Mello e P. B. R. Macedo (2003). “Total Factor Productivity, Technical Efficiency, Scale Change and Technical Change for 27 Brazilian Industries During the Period 1996-2000." Anais do XXXI Encontro Nacional de Economia d35, ANPEC Associação Nacional do Centros de Pos-graduação em Economia.

Moorsteen, R. H. (1961). “On Measuring Productive Potential and Relative Efficiency." Quarterly Journal of Economics 75(3) (August), 451-467.

Moreira M.M e P.G. Correia. (1996). “Abertura Comercial: O Que se Pode Esperar e o Que se Vem Obtendo.” Rio de Janeiro: BNDES/Departamento Econômico. (Texto para Discussão 49).

Moreira, M.M. (1999). A Indústria Brasileira nos Anos 90. O Que já se Pode Dizer?” In: Giambiagi, F e M.M. Moreira (org.): A Economia Brasileira nos Anos 90. Rio de Janeiro: BNDES, 293-332. 
Nightingale, P. (2000). "Economies of Scale in Experimentation: Knowledge and Technology in Pharmaceutical R\&D”. Industrial and Corporate Change 9 (2), 315-359.

Nishimizu, M. and J.M. Page. (1982). "Total Factor Productivity Growth, Technical Progress and Technical Efficiency Change: Dimension of Productivity Change in Yugoslavia, 196578.” Economic Journal 92, 920-936.

Nishijima, M. (2003). “Análise Econômica dos Medicamentos Genéricos no Brasil”. Tese de Doutorado IPE-USP, São Paulo.

Nishijima, M. e G. Biasoto Junior. (2003). “Os Preços dos Medicamentos de Referência Após a Entrada dos Medicamentos Genéricos no Mercado Brasileiro.” Anais do XXXI Encontro Nacional de Economia d29, ANPEC - Associação Nacional do Centros de Pos-graduação em Economia.

Okada, Y. and A. Kawara. (2004). "Research Productivity in the Japanese Pharmaceutical Industry: Economies of Scale, Economies of Scope and Spillovers." OPIR Research Paper Series No.15 (Fevereiro). Disponível em http://www.jpma.or.jp/opir/research/paper_15.pdf.

Olley, G.S and A. Pakes. (1996). "The Dynamics of Productivity in the Telecomunications Equipement Industry”, Econometrica 64, 1263-1297.

Pavcnik, N. (2000). “Trade Liberalization, Exit and Productivity Improvements: Evidence from Chilean Plants”. Working Paper 7852, NBER.

Queiroz, S. e A.J.V. Gonzáles. (2001). "Mudanças Recentes na Estrutura Produtiva da Indústria Farmacêutica". In Brasil: radiografia da saúde. Barjas Negri e Geraldo Di Giovanni. UNICAMP. 124-155.

Schor, A. (2003). "Productivity: Competition, Embodied Technology and Heterogeneous Response to Tariff Reduction. Evidence from Brazilian Manufacturing Industries.” NBER Working Paper NoW10544, http://papers.ssrn.com/sol3/papers.cfm?abstract id=556531, (June). 
Silverman, B. W. "Density estimation for statistics and data analysis". Monographs on Statistics and Applied Probability 26. New York: Chapman \& Hall/CRC, 175 p., 1986.

Sollow, R. (1957). "Technical Change and the Aggregate Production Function". Review of Economics and Statistics 39 (3), 312-320.

Stevenson, R. (1980). "Likelihood Functions for Generalized Stochastic Frontier Functions". Journal of Econometrics 13, 57-66.

Palmeira Filho, P.L. e S.S.K. Pam. (2003). "Cadeia Farmacêutica no Brasil: Avaliação Preliminar e Perspectivas.” BNDES Setorial 18 (Setembro) 3-22.

Pereira, M.F. et al. (2002). "Productivity Growth and Technological Progress in the Brazilian Agricultural Sector.” Pesquisa Operacional 22(2), 133-146.

Pitt, M. M. and L. F. Lee. (1981). "Measurement and Sources of Technical Inefficiency in the IndonesianWeaving Industry." Journal of Development Economics 9, 43-64.

Ritter, C. and L. Simar. (1997). "Pitfalls of Normal-Gamma Stochastic Frontier Models." Journal of Productivity Analysis 8, 167-182.

Romano, R. e P.J. Bernardo. (2001). "Padrões de regulação de preços do mercado de medicamentos: experiência brasileira doa anos 90 e novos arranjos institucionais." In Brasil: radiografia da saúde. Barjas Negri e Geraldo Di Giovanni. UNICAMP. 588p.

Rossi júnior, J.L.R. e P.C.Ferreira. (1999) "Evolução da Produtividade Industrial Brasileira e Abertura Comercial”. Rio de Janeiro: IPEA. (Texto para discussão 651).

Vicente, J.R. (2003). "Mudança Tecnológica, de Eficiência e Produtividade Total de Fatores na Agricultura Brasileira, 1970-95.” e30, ANPEC - Associação Nacional do Centros de Posgraduação em Economia. 


\section{APENDICES}

APÊNDICE I - Estimação das funções de produção por mínimos quadrados

APÊNDICE II - Densidade Kernel de Epanechnikov do termo de ineficiência $\left(u_{i}\right)$ e choque aleatório $\left(\mathrm{V}_{\mathrm{i}}\right)$

APÊNDICE III - Fronteiras sob hipóteses de retornos variáveis.

APÊNDICE IV - Índices de Produtividade Desagregados por Estado da Federação e Grande Região Contemplados na Amostra 


\begin{tabular}{lcccc}
\hline & MQO - SÉRIE A 8\% & & \\
\hline \hline Variável & Coef. & Std. Err. & t & P-valor \\
Ano & 0.0711 & 0.0466 & 1.5300 & 0.1270 \\
Ano & -0.0056 & 0.0078 & -0.7200 & 0.4710 \\
Ano*Trab.Prod. & 0.0197 & 0.0087 & 2.2800 & 0.0230 \\
Ano*Trab.Adm. & -0.0019 & 0.0080 & -0.2400 & 0.8140 \\
Trab.Prod. & -1.9149 & 1.4470 & -1.3200 & 0.1860 \\
Trab. Adm. & -2.0288 & 1.3990 & -1.4500 & 0.1470 \\
Trab. Prod.*Trab.Adm. & $-0.1550 *$ & 0.0373 & -4.1600 & 0.0000 \\
Trab. Prod. ${ }^{2}$ & -0.3543 & 0.3452 & -1.0300 & 0.3050 \\
Trab. Adm. ${ }^{2}$ & -0.3680 & 0.2473 & -1.4900 & 0.1370 \\
f_cos_bc & 1.8073 & 1.3886 & 1.3000 & 0.1930 \\
f_cos_wc & 4.1921 & 2.3059 & 1.8200 & 0.0690 \\
f_sen_bc & -0.2203 & 0.4426 & -0.5000 & 0.6190 \\
f_sen_wc & 1.9365 & 0.8754 & 2.2100 & 0.0270 \\
f_cos_2bc & 0.2152 & 0.1903 & 1.1300 & 0.2580 \\
f_cos_2wc & $0.4595 * *$ & 0.2513 & 1.8300 & 0.0680 \\
f_cos_bcwc & -0.1080 & 0.0673 & -1.6000 & 0.1090 \\
f_sen_2bc & -0.0234 & 0.1279 & -0.1800 & 0.8550 \\
f_sen_2wc & 0.7415 & 0.3252 & 2.2800 & 0.0230 \\
f_sen_bcwc & 0.0246 & 0.1009 & 0.2400 & 0.8080 \\
Constante & -4.0217 & 2.6097 & -1.5400 & 0.1240 \\
\hline Número de obs. & 885 & & F( 19, 865) & 107.580 \\
R-squared & 0.7026 & & Prob $>$ F & \\
R ${ }^{2}$ ajustado & & & & 0 \\
\hline
\end{tabular}




\begin{tabular}{|c|c|c|c|c|}
\hline \multicolumn{5}{|c|}{ MQO - SÉRIE A 9\% } \\
\hline Variável & Coef. & Std. Err. & 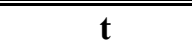 & P-valor \\
\hline Ano & 0.0684 & 0.0455 & 1.5000 & 0.1330 \\
\hline $\mathbf{A n o}^{2}$ & -0.0057 & 0.0078 & -0.7400 & 0.4600 \\
\hline Ano*Trab.Prod. & 0.0197 & 0.0087 & 2.2800 & 0.0230 \\
\hline Ano*Trab.Adm. & -0.0020 & 0.0080 & -0.2400 & 0.8070 \\
\hline Trab. Prod. & -1.8235 & 1.3858 & -1.3200 & 0.1890 \\
\hline Trab. Adm. & -1.9198 & 1.3490 & -1.4200 & 0.1550 \\
\hline \multicolumn{5}{|l|}{ Trab. } \\
\hline Prod.*Trab.Adm. & -0.1530 & 0.0373 & -4.1000 & 0.0000 \\
\hline Trab. Prod. $^{2}$ & -0.3547 & 0.3453 & -1.0300 & 0.3050 \\
\hline Trab. Adm. ${ }^{2}$ & -0.3652 & 0.2470 & -1.4800 & 0.1400 \\
\hline f_cos_bc & 1.8195 & 1.3889 & 1.3100 & 0.1910 \\
\hline f_cos_wc & 4.1727 & 2.3041 & 1.8100 & 0.0700 \\
\hline f_sen_bc & -0.2192 & 0.4418 & -0.5000 & 0.6200 \\
\hline f_sen_wc & 1.8900 & 0.8774 & 2.1500 & 0.0320 \\
\hline f_cos_2bc & 0.2171 & 0.1899 & 1.1400 & 0.2530 \\
\hline f_cos_2wc & 0.4715 & 0.2519 & 1.8700 & 0.0620 \\
\hline f_cos_bcwc & -0.1083 & 0.0672 & -1.6100 & 0.1070 \\
\hline f_sen_2bc & -0.0214 & 0.1283 & -0.1700 & 0.8680 \\
\hline f_sen_2wc & 0.7275 & 0.3249 & 2.2400 & 0.0250 \\
\hline f_sen_bcwc & 0.0295 & 0.1011 & 0.2900 & 0.7710 \\
\hline Constante & -3.1724 & 2.2555 & -1.4100 & 0.1600 \\
\hline Número de obs. & 885 & & $F(19,865)$ & 107.470 \\
\hline R-squared & 0.7024 & & Prob $>$ F & 0 \\
\hline$R^{2}$ ajustado & 0.6959 & & & \\
\hline
\end{tabular}




\begin{tabular}{lcccr}
\hline \multicolumn{5}{c}{ MQO - SÉRIE A 10\% } \\
\hline \hline Variável & Coef. & Std. Err. & t & P-valor \\
Ano & 0.0660 & 0.0446 & 1.4800 & 0.1390 \\
Ano & -0.0059 & 0.0078 & -0.7600 & 0.4490 \\
Ano*Trab.Prod. & 0.0197 & 0.0087 & 2.2800 & 0.0230 \\
Ano*Trab.Adm. & -0.0020 & 0.0080 & -0.2500 & 0.8000 \\
Trab.Prod. & -1.7491 & 1.3336 & -1.3100 & 0.1900 \\
Trab. Adm. & -1.8239 & 1.3054 & -1.4000 & 0.1630 \\
Trab.Prod.*Trab.Adm. & -0.1508 & 0.0373 & -4.0400 & 0.0000 \\
Trab.Prod.2 & -0.3560 & 0.3454 & -1.0300 & 0.3030 \\
Trab. Adm. & -0.3621 & 0.2465 & -1.4700 & 0.1420 \\
f_cos_bc & 1.8353 & 1.3889 & 1.3200 & 0.1870 \\
f_cos_wc & 4.1493 & 2.3009 & 1.8000 & 0.0720 \\
f_sen_bc & -0.2183 & 0.4408 & -0.5000 & 0.6210 \\
f_sen_wc & 1.8412 & 0.8790 & 2.0900 & 0.0360 \\
f_cos_2bc & 0.2195 & 0.1896 & 1.1600 & 0.2470 \\
f_cos_2wc & 0.4834 & 0.2523 & 1.9200 & 0.0560 \\
f_cos_bcwc & -0.1086 & 0.0671 & -1.6200 & 0.1060 \\
f_sen_2bc & -0.0194 & 0.1286 & -0.1500 & 0.8800 \\
f_sen_2wc & 0.7127 & 0.3244 & 2.2000 & 0.0280 \\
f_sen_bcwc & 0.0345 & 0.1013 & 0.3400 & 0.7330 \\
Constante & -2.4855 & 1.9685 & -1.2600 & 0.2070 \\
\hline Número de obs. & 885 & & F( 19, 865) & 107.370 \\
R-squared & 0.7022 & & Prob > F & 0 \\
R ${ }^{2}$ ajustado & 0.6957 & & & \\
\hline & & & & \\
\hline
\end{tabular}




\section{APÊNDICE II: Densidade Kernel de Epanechnikov do termo de ineficiência $\left(u_{i}\right)$ e choque aleatório $\left(v_{i}\right)$}

As funções Kernel têm por objetivo, identificar empiricamente o formato da distribuição de probabilidade de uma variável $x$ em pontos distintos do tempo. A opção pelo Kernel de se baseia no fato deste ser um procedimento que permite a identificação adequada do grau de assimetria e da presença de mais de uma moda como observa Silverman (1986). O Kernel de Epanechnikov para uma variável $x$ é dado pela seguinte função:

$K(x)=\frac{3}{4 \sqrt{5}}\left(1-\frac{1}{5} x^{2}\right), \forall|x| \leq \sqrt{5}$

$K(x)=0$, caso contrário

A literatura atribui ao Kernel de Epanechnikov a propriedade do cálculo da janela (bandwidth) ótima ( $h$ ) é determinado pelo seguinte critério de otimização:

$\phi=\min \left[(\text { variância de } \mathrm{x})^{1 / 2},(\right.$ intervalo interquartil de $\left.\mathrm{x} / 1,349)\right]$ e $h=\frac{0,9 \phi}{n^{1 / 5}}$, onde $x$ é variável para qual se deseja estimar o Kernel e $n$ o número de observações. 

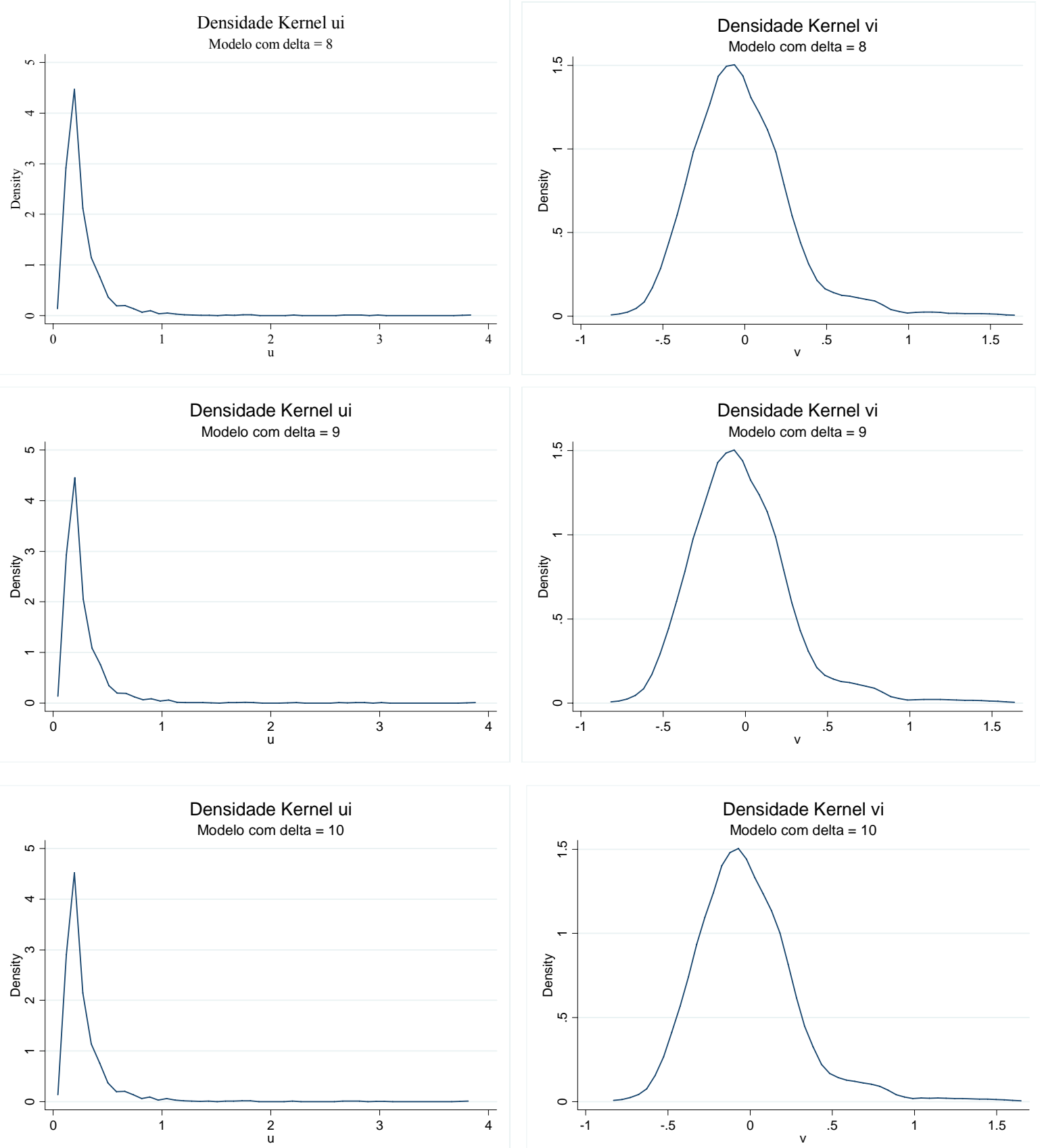


\section{APÊNDICE III: Fronteiras sob hipóteses de retornos variáveis.}

A seguir as Fronteiras Estocásticas de Produção sob a Hipótese de Retornos Variáveis, são apresentadas. Aqui se suprimiu os termos trigonométricos de Fourrier

\begin{tabular}{|c|c|c|c|c|}
\hline \multicolumn{5}{|c|}{ Fronteira Estocástica de Produção com Retornos Variáveis para $\delta=8 \%$} \\
\hline & Coeficiente & Desvio-Padrão & t-student & P-valor \\
\hline beta 0 & 485.5966 & 7.8841 & 61.5919 & 0.0000 \\
\hline Ano & 0.2095 & 0.0914 & 2.2931 & 0.0221 \\
\hline t_sq & -0.0056 & 0.0080 & -0.6998 & 0.4842 \\
\hline Tbc & 0.0140 & 0.0107 & 1.3127 & 0.1897 \\
\hline Twc & -0.0038 & 0.0078 & -0.4919 & 0.6229 \\
\hline Tk & -0.0190 & 0.0088 & -2.1625 & 0.0309 \\
\hline Lbc & -13.2426 & 4.7104 & -2.8114 & 0.0051 \\
\hline lwc & -10.8811 & 1.0194 & -10.6738 & 0.0000 \\
\hline $\mathbf{l k}$ & -40.6834 & 4.7376 & -8.5873 & 0.0000 \\
\hline lbc_lwc & -0.1104 & 0.0441 & -2.5022 & 0.0125 \\
\hline lbc_lk & 0.0723 & 0.0445 & 1.6253 & 0.1045 \\
\hline lwc_lk & 0.0077 & 0.0349 & 0.2198 & 0.8260 \\
\hline lbc_sq & 1.0769 & 0.3343 & 3.2208 & 0.0013 \\
\hline lwc_sq & 0.9307 & 0.0906 & 10.2778 & 0.0000 \\
\hline lk_sq & 2.3874 & 0.2897 & 8.2405 & 0.0000 \\
\hline delta 0 & -9.6566 & 1.1822 & -8.1685 & 0.0000 \\
\hline Per. Comp. Estrg. & -0.0344 & 0.0128 & -2.6981 & 0.0071 \\
\hline Vendas ao mercado externo & 0.0169 & 0.0148 & 1.1395 & 0.2548 \\
\hline 1997 & 2.4514 & 0.8546 & 2.8686 & 0.0042 \\
\hline 1998 & 1.4937 & 0.8570 & 1.7429 & 0.0817 \\
\hline 1999 & 1.8416 & 0.9200 & 2.0018 & 0.0456 \\
\hline 2000 & 0.4782 & 1.1059 & 0.4324 & 0.6655 \\
\hline 2001 & 2.4571 & 1.0310 & 2.3833 & 0.0174 \\
\hline 2002 & 0.4764 & 1.4458 & 0.3295 & 0.7418 \\
\hline 2003 & 2.1963 & 1.1096 & 1.9793 & 0.0481 \\
\hline MG & 3.7756 & 0.9256 & 4.0789 & 0.0000 \\
\hline RJ & 1.5558 & 0.3163 & 4.9182 & 0.0000 \\
\hline GO & 4.5365 & 0.7768 & 5.8400 & 0.0000 \\
\hline NE & 4.7317 & 0.8498 & 5.5681 & 0.0000 \\
\hline SUL & 5.0534 & 0.8056 & 6.2726 & 0.0000 \\
\hline sigma-squared & 2.6138 & 0.3552 & 7.3589 & 0.0000 \\
\hline gamma & 0.9554 & 0.0073 & 130.9847 & 0.0000 \\
\hline
\end{tabular}




\begin{tabular}{|c|c|c|c|c|}
\hline \multicolumn{5}{|c|}{ Fronteira Estocástica de Produção com Retornos Variáveis para $\delta=9 \%$} \\
\hline & Coeficiente & Desvio-Padrão & t-student & P-valor \\
\hline beta 0 & 476.6305 & 1.6122 & 295.6414 & 0.0000 \\
\hline ano & 0.2058 & 0.0911 & 2.2592 & 0.0241 \\
\hline t_sq & -0.0058 & 0.0079 & -0.7367 & 0.4615 \\
\hline tbc & 0.0129 & 0.0105 & 1.2312 & 0.2186 \\
\hline twe & -0.0039 & 0.0078 & -0.4921 & 0.6228 \\
\hline tk & -0.0181 & 0.0088 & -2.0493 & 0.0408 \\
\hline lbc & -9.9989 & 2.6291 & -3.8031 & 0.0002 \\
\hline lwc & -10.6356 & 0.8595 & -12.3746 & 0.0000 \\
\hline $\mathbf{l k}$ & -42.9427 & 2.0916 & -20.5313 & 0.0000 \\
\hline lbc_lwc & -0.1179 & 0.0433 & -2.7200 & 0.0067 \\
\hline lbc_lk & 0.0695 & 0.0443 & 1.5688 & 0.1171 \\
\hline lwc_lk & 0.0104 & 0.0350 & 0.2978 & 0.7659 \\
\hline lbc_sq & 0.8557 & 0.1896 & 4.5141 & 0.0000 \\
\hline lwc_sq & 0.9171 & 0.0833 & 11.0156 & 0.0000 \\
\hline lk_sq & 2.5498 & 0.1344 & 18.9787 & 0.0000 \\
\hline delta 0 & -10.3616 & 0.9452 & -10.9626 & 0.0000 \\
\hline Per. Comp. Estrg. & -0.0308 & 0.0069 & -4.4452 & 0.0000 \\
\hline Vendas ao mercado externo & 0.0091 & 0.0095 & 0.9647 & 0.3350 \\
\hline 1997 & 2.3386 & 0.4662 & 5.0166 & 0.0000 \\
\hline 1998 & 1.2679 & 0.7525 & 1.6850 & 0.0924 \\
\hline 1999 & 2.0202 & 0.7878 & 2.5644 & 0.0105 \\
\hline 2000 & 0.3532 & 1.1690 & 0.3021 & 0.7626 \\
\hline 2001 & 2.3702 & 0.7061 & 3.3568 & 0.0008 \\
\hline 2002 & 0.0046 & 1.2689 & 0.0036 & 0.9971 \\
\hline 2003 & 2.1315 & 0.8745 & 2.4375 & 0.0150 \\
\hline MG & 4.0734 & 0.9463 & 4.3048 & 0.0000 \\
\hline RJ & 1.5242 & 0.2950 & 5.1668 & 0.0000 \\
\hline GO & 4.8636 & 0.7672 & 6.3390 & 0.0000 \\
\hline NE & 5.1344 & 0.8312 & 6.1772 & 0.0000 \\
\hline SUL & 5.5568 & 0.8144 & 6.8229 & 0.0000 \\
\hline sigma-squared & 2.7488 & 0.4045 & 6.7947 & 0.0000 \\
\hline gamma & 0.9572 & 0.0088 & 108.4615 & 0.0000 \\
\hline
\end{tabular}




\begin{tabular}{|c|c|c|c|c|}
\hline \multicolumn{5}{|c|}{ Fronteira Estocástica de Produção com Retornos Variáveis para $\delta=10 \%$} \\
\hline & Coeficiente & Desvio-Padrão & t-student & P-valor \\
\hline beta 0 & 467.7300 & 1.0108 & 462.7295 & 0.0000 \\
\hline ano & 0.2749 & 0.0896 & 3.0695 & 0.0022 \\
\hline t_sq & -0.0112 & 0.0074 & -1.5119 & 0.1310 \\
\hline tbc & 0.0144 & 0.0107 & 1.3463 & 0.1786 \\
\hline twc & -0.0053 & 0.0078 & -0.6798 & 0.4968 \\
\hline tk & -0.0202 & 0.0089 & -2.2701 & 0.0235 \\
\hline lbc & -3.9649 & 0.9482 & -4.1816 & 0.0000 \\
\hline lwc & -10.6535 & 0.7800 & -13.6579 & 0.0000 \\
\hline $\mathbf{l k}$ & -47.1097 & 0.8736 & -53.9267 & 0.0000 \\
\hline lbc_lwc & -0.1127 & 0.0446 & -2.5286 & 0.0116 \\
\hline lbc_lk & 0.0878 & 0.0463 & 1.8942 & 0.0586 \\
\hline lwc_lk & 0.0050 & 0.0350 & 0.1431 & 0.8863 \\
\hline lbc_sq & 0.3782 & 0.0932 & 4.0582 & 0.0001 \\
\hline lwc_sq & 0.9210 & 0.0777 & 11.8567 & 0.0000 \\
\hline lk_sq & 2.8180 & 0.0701 & 40.2193 & 0.0000 \\
\hline delta 0 & -6.8510 & 1.7649 & -3.8818 & 0.0001 \\
\hline Per. Comp. Estrg. & -0.0287 & 0.0065 & -4.4177 & 0.0000 \\
\hline Vendas ao mercado externo & 0.0180 & 0.0069 & 2.5908 & 0.0098 \\
\hline 1997 & 3.1493 & 0.8623 & 3.6524 & 0.0003 \\
\hline 1998 & 2.6647 & 0.7972 & 3.3426 & 0.0009 \\
\hline 1999 & 3.1170 & 0.8906 & 3.5000 & 0.0005 \\
\hline 2000 & 2.5293 & 0.7680 & 3.2935 & 0.0010 \\
\hline 2001 & 3.7097 & 0.9146 & 4.0560 & 0.0001 \\
\hline 2002 & 2.7293 & 0.7699 & 3.5452 & 0.0004 \\
\hline 2003 & 3.6002 & 0.9176 & 3.9234 & 0.0001 \\
\hline MG & 2.2440 & 0.5718 & 3.9245 & 0.0001 \\
\hline RJ & 1.1196 & 0.3584 & 3.1238 & 0.0019 \\
\hline GO & 2.6957 & 0.6682 & 4.0344 & 0.0001 \\
\hline NE & 2.7478 & 0.6098 & 4.5064 & 0.0000 \\
\hline SUL & 2.8693 & 0.6688 & 4.2902 & 0.0000 \\
\hline sigma-squared & 1.4935 & 0.2651 & 5.6346 & 0.0000 \\
\hline gamma & 0.9209 & 0.0158 & 58.4487 & 0.0000 \\
\hline
\end{tabular}


Apêndice IV: Índices de Produtividade Desagregados por Estado da Federação e Grande Região Contemplados na Amostra

São Paulo

\begin{tabular}{|c|c|c|c|c|c|c|}
\hline \multicolumn{7}{|c|}{ Produtividade - Variação Relativa ao Ano Anterior } \\
\hline & \multicolumn{3}{|c|}{ Média Geométrica } & \multicolumn{3}{|c|}{ Média Ponderada } \\
\hline Ano & $\begin{array}{l}\text { Modelo } \delta \\
=\mathbf{8} \%\end{array}$ & $\begin{array}{l}\text { Modelo } \delta \\
\quad=9 \%\end{array}$ & $\begin{array}{c}\text { Modelo } \delta \\
=10 \%\end{array}$ & $\begin{array}{c}\text { Modelo } \delta \\
=\mathbf{8} \%\end{array}$ & $\begin{array}{l}\text { Modelo } \delta \\
=9 \%\end{array}$ & $\begin{array}{c}\text { Modelo } \delta \\
=10 \%\end{array}$ \\
\hline $1997 / 1996$ & 0.997798 & 0.992100 & 0.994462 & 0.983312 & 0.977176 & 0.979447 \\
\hline 1998/1997 & 1.042836 & 1.039466 & 1.041241 & 1.028237 & 1.024457 & 1.025321 \\
\hline $1999 / 1998$ & 0.972414 & 0.968160 & 0.969265 & 1.005806 & 1.00119 & 1.002631 \\
\hline 2000/1999 & 1.044071 & 1.040373 & 1.040956 & 1.000677 & 0.996973 & 0.997757 \\
\hline $2001 / 2000$ & 0.910057 & 0.908042 & 0.907526 & 0.927015 & 0.924012 & 0.923293 \\
\hline $2002 / 2001$ & 1.016061 & 1.014248 & 1.012576 & 1.013823 & 1.012625 & 1.011274 \\
\hline $2003 / 2002$ & 0.940969 & 0.939926 & 0.937523 & 0.952153 & 0.950725 & 0.948093 \\
\hline
\end{tabular}

Produtividade Acumulada - Base 1996

\begin{tabular}{|c|c|c|c|c|c|c|}
\hline \multirow[b]{2}{*}{ Ano } & \multicolumn{3}{|c|}{ Média Geométrica } & \multicolumn{3}{|c|}{ Média Ponderada } \\
\hline & $\begin{array}{c}\text { Modelo } \delta \\
\quad=8 \%\end{array}$ & $\begin{array}{c}\text { Modelo } \delta \\
=9 \%\end{array}$ & $\begin{array}{c}\text { Modelo } \delta \\
=10 \%\end{array}$ & $\begin{array}{c}\text { Modelo } \delta \\
=8 \%\end{array}$ & $\begin{array}{c}\text { Modelo } \delta \\
=9 \%\end{array}$ & $\begin{array}{c}\text { Modelo } \delta \\
=10 \%\end{array}$ \\
\hline 1996 & 1.000000 & 1.000000 & 1.000000 & 1.000000 & 1.000000 & 1.000000 \\
\hline 1997 & 0.997798 & 0.992100 & 0.994462 & 0.983312 & 0.977176 & 0.979447 \\
\hline 1998 & 1.040540 & 1.031254 & 1.035475 & 1.011077 & 1.001074 & 1.004247 \\
\hline 1999 & 1.011836 & 0.998419 & 1.003650 & 1.016948 & 1.002265 & 1.006889 \\
\hline 2000 & 1.056428 & 1.038728 & 1.044756 & 1.017637 & 0.999232 & 1.004631 \\
\hline 2001 & 0.961410 & 0.943209 & 0.948143 & 0.943364 & 0.923302 & 0.927569 \\
\hline 2002 & 0.976851 & 0.956648 & 0.960066 & 0.956404 & 0.934960 & 0.938026 \\
\hline 2003 & 0.919187 & 0.899178 & 0.900085 & 0.910643 & 0.888890 & 0.889336 \\
\hline
\end{tabular}


Rio de Janeiro

\begin{tabular}{cccc|ccc}
\hline \multicolumn{5}{c}{ Produtividade - Variação Relativa ao Ano Anterior } \\
\hline \multicolumn{3}{c}{ Média Geométrica } & \multicolumn{3}{c}{ Média Ponderada } \\
\hline Ano & Modelo $\delta$ & Modelo $\boldsymbol{\delta}$ & Modelo $\boldsymbol{\delta}$ & Modelo $\boldsymbol{\delta}$ & Modelo $\boldsymbol{\delta}$ & Modelo $\boldsymbol{\delta}$ \\
& $=\mathbf{8 \%}$ & $=\mathbf{9 \%}$ & $=\mathbf{1 0} \%$ & $=\mathbf{8 \%}$ & $=\mathbf{9 \%}$ & $=\mathbf{1 0 \%}$ \\
$\mathbf{1 9 9 7 / 1 9 9 6}$ & 1.000235 & 0.995481 & 0.998039 & 1.022224 & 1.017369 & 1.01698 \\
$\mathbf{1 9 9 8 / 1 9 9 7}$ & 0.99648 & 0.993592 & 0.995222 & 1.012328 & 1.008299 & 1.009222 \\
$\mathbf{1 9 9 9 / 1 9 9 8}$ & 0.986628 & 0.982898 & 0.983729 & 1.010672 & 1.006307 & 1.006922 \\
$\mathbf{2 0 0 0 / 1 9 9 9}$ & 0.992566 & 0.989687 & 0.989737 & 0.974052 & 0.971294 & 0.972527 \\
$\mathbf{2 0 0 1 / 2 0 0 0}$ & 0.886353 & 0.884928 & 0.884109 & 0.917684 & 0.916001 & 0.914642 \\
$\mathbf{2 0 0 2 / 2 0 0 1}$ & 1.050425 & 1.050309 & 1.048165 & 1.026204 & 1.023481 & 1.023881 \\
$\mathbf{2 0 0 3 / 2 0 0 2}$ & 0.92922 & 0.927375 & 0.924362 & 0.96234 & 0.961488 & 0.958283 \\
\hline
\end{tabular}

Produtividade Acumulada - Base 1996

\begin{tabular}{|c|c|c|c|c|c|c|}
\hline \multirow[b]{2}{*}{ Ano } & \multicolumn{3}{|c|}{ Média Geométrica } & \multicolumn{3}{|c|}{ Média Ponderada } \\
\hline & $\begin{array}{c}\text { Modelo } \delta \\
=8 \%\end{array}$ & $\begin{array}{c}\text { Modelo } \delta \\
=9 \%\end{array}$ & $\begin{array}{c}\text { Modelo } \delta \\
=10 \%\end{array}$ & $\begin{array}{c}\text { Modelo } \delta \\
=8 \%\end{array}$ & $\begin{array}{c}\text { Modelo } \delta \\
=9 \%\end{array}$ & $\begin{array}{c}\text { Modelo } \delta \\
=10 \%\end{array}$ \\
\hline 1996 & 1.00000 & 1.00000 & 1.00000 & 1.000000 & 1.000000 & 1.000000 \\
\hline 1997 & 1.00024 & 0.99548 & 0.99804 & 1.022224 & 1.017369 & 1.016980 \\
\hline 1998 & 0.99671 & 0.98910 & 0.99327 & 1.034826 & 1.025812 & 1.026358 \\
\hline 1999 & 0.98339 & 0.97219 & 0.97711 & 1.045870 & 1.032282 & 1.033462 \\
\hline 2000 & 0.97607 & 0.96216 & 0.96708 & 1.018731 & 1.002649 & 1.005070 \\
\hline 2001 & 0.86515 & 0.85144 & 0.85501 & 0.934873 & 0.918427 & 0.919280 \\
\hline 2002 & 0.90877 & 0.89428 & 0.89619 & 0.959371 & 0.939993 & 0.941233 \\
\hline 2003 & 0.84445 & 0.82933 & 0.82840 & 0.923241 & 0.903792 & 0.901968 \\
\hline
\end{tabular}


Minas Gerais

\begin{tabular}{|c|c|c|c|c|c|c|}
\hline \multicolumn{7}{|c|}{ Produtividade - Variação Relativa ao Ano Anterior } \\
\hline & \multicolumn{3}{|c|}{ Média Geométrica } & \multicolumn{3}{|c|}{ Média Ponderada } \\
\hline Ano & $\begin{array}{c}\text { Modelo } \delta \\
=8 \%\end{array}$ & $\begin{array}{c}\text { Modelo } \delta \\
=9 \%\end{array}$ & $\begin{array}{c}\text { Modelo } \delta \\
=10 \%\end{array}$ & $\begin{array}{c}\text { Modelo } \delta \\
=8 \%\end{array}$ & $\begin{array}{c}\text { Modelo } \delta \\
=9 \%\end{array}$ & $\begin{array}{c}\text { Modelo } \delta \\
=10 \%\end{array}$ \\
\hline 1997/1996 & 0.925996 & 0.921585 & 0.923894 & 0.980491 & 0.97646 & 0.974314 \\
\hline 1998/1997 & 1.924059 & 1.925869 & 1.928677 & 1.563497 & 1.565333 & 1.560822 \\
\hline 1999/1998 & 0.950509 & 0.94619 & 0.946857 & 0.981804 & 0.977829 & 0.977464 \\
\hline 2000/1999 & 1.276032 & 1.269049 & 1.269529 & 1.168479 & 1.163423 & 1.164662 \\
\hline 2001/2000 & 0.942092 & 0.940694 & 0.939685 & 1.110941 & 1.106059 & 1.105989 \\
\hline $2002 / 2001$ & 1.049384 & 1.046656 & 1.0443 & 0.979195 & 0.977287 & 0.976587 \\
\hline $2003 / 2002$ & 0.933275 & 0.932498 & 0.929826 & 0.934708 & 0.932141 & 0.930378 \\
\hline
\end{tabular}

Produtividade Acumulada - Base 1996

\section{Média Geométrica Média Ponderada}

\begin{tabular}{|c|c|c|c|c|c|c|}
\hline Ano & $\begin{array}{c}\text { Modelo } \delta \\
=8 \%\end{array}$ & $\begin{array}{c}\text { Modelo } \delta \\
=9 \%\end{array}$ & $\begin{array}{c}\text { Modelo } \delta \\
=10 \%\end{array}$ & $\begin{array}{c}\text { Modelo } \delta \\
=8 \%\end{array}$ & $\begin{array}{c}\text { Modelo } \delta \\
=9 \%\end{array}$ & $\begin{array}{c}\text { Modelo } \delta \\
=10 \%\end{array}$ \\
\hline 1996 & 1.00000 & 1.00000 & 1.00000 & 1.000000 & 1.000000 & 1.000000 \\
\hline 1997 & 0.92600 & 0.92159 & 0.92389 & 0.980491 & 0.976460 & 0.974314 \\
\hline 1998 & 1.78167 & 1.77485 & 1.78189 & 1.532994 & 1.528486 & 1.520731 \\
\hline 1999 & 1.69349 & 1.67935 & 1.68720 & 1.505099 & 1.494599 & 1.486460 \\
\hline 2000 & 2.16095 & 2.13118 & 2.14195 & 1.758676 & 1.738851 & 1.731224 \\
\hline 2001 & 2.03582 & 2.00478 & 2.01276 & 1.953785 & 1.923273 & 1.914714 \\
\hline 2002 & 2.13635 & 2.09832 & 2.10192 & 1.913137 & 1.879590 & 1.869885 \\
\hline 2003 & 1.99380 & 1.95668 & 1.95442 & 1.788225 & 1.752043 & 1.739700 \\
\hline
\end{tabular}


Goiás

\begin{tabular}{|c|c|c|c|c|c|c|}
\hline \multicolumn{7}{|c|}{ Produtividade - Variação Relativa ao Ano Anterior } \\
\hline & \multicolumn{3}{|c|}{ Média Geométrica } & \multicolumn{3}{|c|}{ Média Ponderada } \\
\hline Ano & $\begin{array}{c}\text { Modelo } \delta \\
=8 \%\end{array}$ & $\begin{array}{c}\text { Modelo } \delta \\
=9 \%\end{array}$ & $\begin{array}{c}\text { Modelo } \delta \\
=10 \%\end{array}$ & $\begin{array}{c}\text { Modelo } \delta \\
=\mathbf{8} \%\end{array}$ & $\begin{array}{c}\text { Modelo } \delta \\
=9 \%\end{array}$ & $\begin{array}{c}\text { Modelo } \delta \\
=10 \%\end{array}$ \\
\hline 1997/1996 & 0.924312 & 0.922918 & 0.924598 & 0.982684 & 0.981285 & 0.975406 \\
\hline $1998 / 1997$ & 0.955635 & 0.9451 & 0.946237 & 1.018557 & 1.010796 & 1.017816 \\
\hline $1999 / 1998$ & 0.843583 & 0.847039 & 0.847361 & 1.027036 & 1.027399 & 1.022364 \\
\hline $2000 / 1999$ & 1.428733 & 1.42897 & 1.427656 & 1.181157 & 1.178819 & 1.175854 \\
\hline $2001 / 2000$ & 0.955483 & 0.954119 & 0.952822 & 0.952842 & 0.949568 & 0.946944 \\
\hline $2002 / 2001$ & 1.163679 & 1.160679 & 1.158673 & 1.276419 & 1.272004 & 1.265611 \\
\hline 2003/2002 & 0.94165 & 0.937037 & 0.933739 & 0.952192 & 0.9481 & 0.943166 \\
\hline
\end{tabular}

Produtividade Acumulada - Base 1996

\begin{tabular}{|c|c|c|c|c|c|c|}
\hline \multirow[b]{2}{*}{ Ano } & \multicolumn{3}{|c|}{ Média Geométrica } & \multicolumn{3}{|c|}{ Média Ponderada } \\
\hline & $\begin{array}{c}\text { Modelo } \delta \\
=8 \%\end{array}$ & $\begin{array}{c}\text { Modelo } \delta \\
=9 \%\end{array}$ & $\begin{array}{c}\text { Modelo } \delta \\
=10 \%\end{array}$ & $\begin{array}{c}\text { Modelo } \delta \\
=8 \%\end{array}$ & $\begin{array}{c}\text { Modelo } \delta \\
=9 \%\end{array}$ & $\begin{array}{c}\text { Modelo } \delta \\
=10 \%\end{array}$ \\
\hline 1996 & 1.000000 & 1.000000 & 1.000000 & 1.000000 & 1.000000 & 1.000000 \\
\hline 1997 & 0.924312 & 0.922918 & 0.924598 & 0.982684 & 0.981285 & 0.975406 \\
\hline 1998 & 0.883305 & 0.872250 & 0.874889 & 1.000920 & 0.991879 & 0.992784 \\
\hline 1999 & 0.745141 & 0.738830 & 0.741347 & 1.027980 & 1.019056 & 1.014987 \\
\hline 2000 & 1.064608 & 1.055766 & 1.058389 & 1.214207 & 1.201282 & 1.193476 \\
\hline 2001 & 1.017214 & 1.007326 & 1.008456 & 1.156947 & 1.140699 & 1.130155 \\
\hline 2002 & 1.183711 & 1.169183 & 1.168470 & 1.476748 & 1.450974 & 1.430336 \\
\hline 2003 & 1.114641 & 1.095568 & 1.091045 & 1.406148 & 1.375668 & 1.349045 \\
\hline
\end{tabular}




\begin{tabular}{cccc|ccc}
\hline \multicolumn{7}{c}{ Produtividade - Variação Relativa ao Ano Anterior } \\
\hline \multicolumn{3}{c}{ Média Geométrica } & \multicolumn{3}{c}{ Média Ponderada } \\
\hline Ano & $\begin{array}{c}\text { Modelo } \boldsymbol{\delta} \\
=\mathbf{8} \%\end{array}$ & $\begin{array}{c}\text { Modelo } \boldsymbol{\delta} \\
=\mathbf{9 \%}\end{array}$ & $\begin{array}{c}\text { Modelo } \boldsymbol{\delta} \\
\mathbf{= 1 0} \%\end{array}$ & $\begin{array}{c}\text { Modelo } \boldsymbol{\delta} \\
=\mathbf{8 \%}\end{array}$ & $\begin{array}{c}\text { Modelo } \boldsymbol{\delta} \\
=\mathbf{9 \%}\end{array}$ & $\begin{array}{c}\text { Modelo } \boldsymbol{\delta} \\
=\mathbf{1 0} \%\end{array}$ \\
$\mathbf{1 9 9 7 / 1 9 9 6}$ & 0.724196 & 0.717084 & 0.717653 & 0.899952 & 0.893622 & 0.894809 \\
$\mathbf{1 9 9 8 / 1 9 9 7}$ & 1.042973 & 1.043355 & 1.043902 & 1.219969 & 1.221849 & 1.217673 \\
$\mathbf{1 9 9 9 / 1 9 9 8}$ & 1.495471 & 1.494285 & 1.494307 & 1.823029 & 1.827752 & 1.807385 \\
$\mathbf{2 0 0 0 / 1 9 9 9}$ & 1.043283 & 1.041337 & 1.040982 & 0.968767 & 0.96578 & 0.965731 \\
$\mathbf{2 0 0 1 / 2 0 0 0}$ & 0.860327 & 0.858459 & 0.857168 & 0.911885 & 0.908912 & 0.908778 \\
$\mathbf{2 0 0 2 / 2 0 0 1}$ & 1.05086 & 1.051006 & 1.048125 & 1.00128 & 1.001258 & 0.999586 \\
$\mathbf{2 0 0 3 / 2 0 0 2}$ & 0.793508 & 0.791788 & 0.789496 & 1.079866 & 1.078227 & 1.070779 \\
\hline
\end{tabular}

Produtividade Acumulada - Base 1996

\begin{tabular}{|c|c|c|c|c|c|c|}
\hline \multirow[b]{2}{*}{ Ano } & \multicolumn{3}{|c|}{ Média Geométrica } & \multicolumn{3}{|c|}{ Média Ponderada } \\
\hline & $\begin{array}{l}\text { Modelo } \delta \\
=8 \%\end{array}$ & $\begin{array}{c}\text { Modelo } \delta \\
=9 \%\end{array}$ & $\begin{array}{l}\text { Modelo } \delta \\
=10 \%\end{array}$ & $\begin{array}{c}\text { Modelo } \delta \\
=\mathbf{8} \%\end{array}$ & $\begin{array}{c}\text { Modelo } \delta \\
=9 \%\end{array}$ & $\begin{array}{c}\text { Modelo } \delta \\
=10 \%\end{array}$ \\
\hline 1996 & 1.000000 & 1.000000 & 1.000000 & 1.000000 & 1.000000 & 1.000000 \\
\hline 1997 & 0.724196 & 0.717084 & 0.717653 & 0.899952 & 0.893622 & 0.894809 \\
\hline 1998 & 0.755317 & 0.748173 & 0.749159 & 1.097913 & 1.091871 & 1.089585 \\
\hline 1999 & 1.129555 & 1.117984 & 1.119473 & 2.001527 & 1.995670 & 1.969299 \\
\hline 2000 & 1.178445 & 1.164199 & 1.165352 & 1.939014 & 1.927378 & 1.901814 \\
\hline 2001 & 1.013848 & 0.999417 & 0.998902 & 1.768158 & 1.751818 & 1.728327 \\
\hline 2002 & 1.065413 & 1.050393 & 1.046974 & 1.770421 & 1.754022 & 1.727613 \\
\hline 2003 & 0.845413 & 0.831689 & 0.826582 & 1.911817 & 1.891235 & 1.849892 \\
\hline
\end{tabular}




\begin{tabular}{cccc|ccc}
\hline \multicolumn{5}{c}{ Produtividade - Variação Relativa ao Ano Anterior } \\
\hline \multicolumn{3}{c}{ Média Geométrica } & \multicolumn{3}{c}{ Média Ponderada } \\
\hline Ano & Modelo $\delta$ & Modelo $\boldsymbol{\delta}$ & Modelo $\boldsymbol{\delta}$ & Modelo $\boldsymbol{\delta}$ & Modelo $\boldsymbol{\delta}$ & Modelo $\boldsymbol{\delta}$ \\
& $=\mathbf{8 \%}$ & $=\mathbf{9 \%}$ & $=\mathbf{1 0} \%$ & $=\mathbf{8 \%}$ & $=\mathbf{9 \%}$ & $=\mathbf{1 0} \%$ \\
$\mathbf{1 9 9 7 / 1 9 9 6}$ & 0.899967 & 0.894222 & 0.896363 & 0.984464 & 0.978292 & 0.979404 \\
$\mathbf{1 9 9 8 / 1 9 9 7}$ & 1.046332 & 1.046002 & 1.046865 & 1.03856 & 1.035549 & 1.035684 \\
$\mathbf{1 9 9 9 / 1 9 9 8}$ & 1.02632 & 1.024031 & 1.024252 & 1.029308 & 1.025498 & 1.025489 \\
$\mathbf{2 0 0 0 / 1 9 9 9}$ & 0.97166 & 0.970859 & 0.970706 & 1.022496 & 1.021917 & 1.021239 \\
$\mathbf{2 0 0 1 / 2 0 0 0}$ & 1.123499 & 1.118711 & 1.118096 & 1.174826 & 1.169915 & 1.171242 \\
$\mathbf{2 0 0 2 / 2 0 0 1}$ & 1.190892 & 1.186465 & 1.184493 & 1.257995 & 1.252262 & 1.241095 \\
$\mathbf{2 0 0 3 / 2 0 0 2}$ & 0.842629 & 0.839338 & 0.83768 & 0.814252 & 0.809535 & 0.809371 \\
\hline
\end{tabular}

Produtividade Acumulada - Base 1996

\begin{tabular}{|c|c|c|c|c|c|c|}
\hline \multirow[b]{2}{*}{ Ano } & \multicolumn{3}{|c|}{ Média Geométrica } & \multicolumn{3}{|c|}{ Média Ponderada } \\
\hline & $\begin{array}{l}\text { Modelo } \delta \\
\quad=8 \%\end{array}$ & $\begin{array}{c}\text { Modelo } \delta \\
=9 \%\end{array}$ & $\begin{array}{c}\text { Modelo } \delta \\
=10 \%\end{array}$ & $\begin{array}{c}\text { Modelo } \delta \\
=8 \%\end{array}$ & $\begin{array}{c}\text { Modelo } \delta \\
=9 \%\end{array}$ & $\begin{array}{c}\text { Modelo } \delta \\
=10 \%\end{array}$ \\
\hline 1996 & 1.000000 & 1.000000 & 1.000000 & 1.000000 & 1.000000 & 1.000000 \\
\hline 1997 & 0.899967 & 0.894222 & 0.896363 & 0.984464 & 0.978292 & 0.979404 \\
\hline 1998 & 0.941665 & 0.935359 & 0.938371 & 1.022425 & 1.013069 & 1.014354 \\
\hline 1999 & 0.966449 & 0.957837 & 0.961128 & 1.052391 & 1.038900 & 1.040208 \\
\hline 2000 & 0.939060 & 0.929924 & 0.932973 & 1.076065 & 1.061669 & 1.062301 \\
\hline 2001 & 1.055032 & 1.040317 & 1.043153 & 1.264189 & 1.242063 & 1.244211 \\
\hline 2002 & 1.256430 & 1.234300 & 1.235608 & 1.590344 & 1.555389 & 1.544184 \\
\hline 2003 & 1.058705 & 1.035995 & 1.035044 & 1.294941 & 1.259141 & 1.249818 \\
\hline
\end{tabular}

